Linköping Studies in Science and Technology

Dissertation No. 1541

\title{
Metal Oxide Nanoparticles for Contrast Enhancement in Magnetic Resonance Imaging Synthesis, Functionalization and Characterization
}

Maria Ahrén

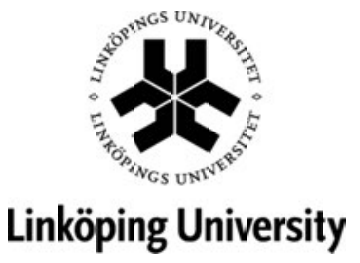

Division of Molecular Surface Physics and Nanoscience

Department of Physics, Chemistry and Biology

Linköping University, Sweden

Linköping 2013 
During the course of the research underlying this thesis Maria Ahrén has been enrolled in the multidisciplinary doctoral programme Forum Scientium at Linköping University, Sweden.

CC Copywright 2013 Maria Ahrén, unless otherwise noted

ISBN: 978-91-7519-522-3

ISSN: 0345-7524

Linköping Studies in Science and Technology

Dissertation No. 1541

Printed in Sweden by LiU-Tryck, Linköping 2013 
Vi vet inte om vingarna bär förrän vi prövat dem 

This thesis work focuses on the design and production of nanoparticle based contrast agents for signal enhancement in magnetic resonance imaging (MRI). Three different synthesis routes are explored, primarily to produce crystalline gadolinium oxide $\left(\mathrm{Gd}_{2} \mathrm{O}_{3}\right)$ nanoparticles, and surface modification is done to obtain stable, dispersible, biocompatible probes inducing high proton relaxivities.

In Paper I and II we utilized the polyol synthesis method and nanoparticle purification was performed with dialysis. Active surface functionalization was achieved by an innermost layer of 3-mercaptopropyl trimetoxy silanes (MPTS) and an outer layer of bifunctional PEG. Surface capping was shown to greatly affect the water proton relaxation to a degree which is strongly dependent on the purification time. PEGylation also induced stabilizing effects and the ability to provide the nanoparticles with luminescent properties was proven by linking the fluorescent dye Rhodamine to the bifunctional PEG.

In Paper III the magnetic behavior of yttrium (Y) alloyed $\mathrm{Gd}_{2} \mathrm{O}_{3}$ nanoparticles was investigated as a function of $\mathrm{Y}$ concentration. This was done by performing magnetic measurements and by studying the signal line width in electron paramagnetic resonance spectroscopy for $\mathrm{Gd}_{2} \mathrm{O}_{3}, \mathrm{Y}_{2} \mathrm{O}_{3}$ and a series of $\left(\mathrm{Gd}_{\mathrm{x}} \mathrm{Y}_{1-\mathrm{x}}\right)_{2} \mathrm{O}_{3}$ samples produced using the combustion synthesis. The results verified that the signal line width is dependent on the percent of yttrium dilution. This is considered as an indication of that yttrium dilution changes the electron spin relaxation time in $\mathrm{Gd}_{2} \mathrm{O}_{3}$.

Paper IV and V present a novel precipitation synthesis method for $\mathrm{Gd}_{2} \mathrm{O}_{3}$ nanoparticles. Acetate molecular groups were found to coordinate the nanoparticle surface increasing the water dispersability. The $\mathrm{Gd}_{2} \mathrm{O}_{3}$ nanoparticles induce a twice as high relaxivity per gadolinium atom, as compared to the commercially available contrast agent Magnevist. Incorporation of luminescent europium $\left(\mathrm{Eu}^{3+}\right)$ ions into the $\mathrm{Gd}_{2} \mathrm{O}_{3}$ nanoparticles in combination with surface modification with a fluorescent branched carboxyl terminated TEG, produced dual probes with tunable luminescence, maintained relaxivity and thus a bright contrast in MRI.

In Paper VI, a new approach to accomplish a dual probe was investigated. Luminescent $\mathrm{ZnO}$ nanoparticles decorated with Gd ions bound in an organic matrix were evaluated for MR signal enhancement and ability to function as fluorescent probes. Interestingly, these nanoprobes did show an enhanced capability to both strengthen the MR signal and increase the fluorescent quantum yield, as compared to the pure oxides. 
In Paper VII we investigate sub $5 \mathrm{~nm}$ crystalline manganese based nanoparticles produced by the precipitation synthesis used for $\mathrm{Gd}_{2} \mathrm{O}_{3}$ nanoparticles. Manganese oxide was chosen as another candidate for MRI contrast enhancement as it is expected to have a straight forward surface coupling chemistry. Characterization of the crystal structure and chemical composition indicated nanoparticles with a MnO core and presence of manganese species of higher valences at the nanoparticle surface. The MnO nanomaterial showed a superparamagnetic behavior and less capability to increase the MR signal as compared to $\mathrm{Gd}_{2} \mathrm{O}_{3}$.

Characterization of the nanoparticle crystal structure and size is, throughout the work, performed by means of transmission electron microscopy, X-ray diffraction and dynamic light scattering. The chemical composition is studied with $\mathrm{X}$-ray photoelectron spectroscopy, infrared spectroscopy and near edge X-ray absorption fine structure spectroscopy and the fluorescence characteristics are evaluated with fluorescence spectroscopy. In addition, theoretical models and calculated IR spectroscopy and near edge X-ray absorption fine structure spectroscopy data have been used for evaluation of experimental results.

To conclude, the aim of this work is the design, production and characterization of ultrasmall rare earth based nanoparticles for signal enhancement in biomedical imaging. Surface modification clearly increases the colloidal stability and biocompatibility of the nanoparticles. Compared to the agents in clinical use today, these nanoprobes have a higher capability to enhance the MR-signal, and they will in the near future be equipped with tags for specific targeting. 


\section{Populärvetenskaplig sammanfattning}

Den här avhandlingen handlar om design och utveckling av nanopartiklar med ändamålet att producera ett nytt lovande kontrastmedel för magnetresonanstomografi (MRT). En nanopartikel är per definition en mycket liten partikel med en diameter i storleksordningen mindre än $100 \mathrm{~nm}$. Den lilla storleken hos nanopartiklar får till följd att partikelns yta är mycket stor i förhållande till partikelns volym och det påverkar i högsta grad egenskaperna för materialet. Såväl de elektriska, magnetiska och optiska egenskaperna förändras och nanopartiklars unika karaktärer utnyttjas i en rad applikationer och i både medicinska och tekniska produkter.

Injicerbara kontrastmedel används idag vid magnetresonanstomografiska undersökningar av den mänskliga kroppen för att öka kontrasten mellan olika vävnader. Standardkontrastmedlen är uppbyggda av gadoliniumjoner som bundits hårt till organiska molekyler för att undvika toxiska reaktioner och biverkningar. Gadoliniumjonerna är magnetiska och har förmågan att katalytiskt påverka väteatomerna i kroppen, vilket i sin tur bidrar till en högre bildkontrast. I den här avhandlingen undersöks möjligheten att samla ett stort antal gadoliniumjoner i en nanopartikel för att på så sett öka påverkan på kontrasten i MRT-bilder. Produktion av nanopartiklar och ytmodifiering av dem med hjälp av inbindning av organiska molekyler på ytan är centralt. Ytmodifiering ökar stabiliteten hos nanopartikarna, vilken annars är relativt låg. En väldesignad ytmodifiering påverkar också graden av dispersion i vattenfas. En stor del av avhandlingsarbetet har fokuserats på karaktärisering av nanopartiklarnas storlek, struktur och molekylära sammansättning. De magnetiska egenskaperna hos partiklarna har studerats liksom deras stabilitet och förmåga att agera som ett kontrastmedel.

I flera av studierna som ingår i avhandlingen kombineras de magnetiska materialen med material som är fluorescenta, d.v.s. som när de blir belysta med ljus av en energi (färg) kan avge ljus av en annan energi (färg). Zinkoxid är ett exempel på ett fluorescent material som absorberar ljus inom UV området och emitterar ljus inom UV och det synliga området. Den synliga fluorescensen är känslig för ytmodifieringar, vilket också visas. Bland de tänkbara applikationerna finns möjligheten att märka in celler eller vävnader med zinkoxid för att sedan studera dessa med hjälp av mikroskopi. De zinkoxidnanopartiklar som studerades har en nanopartikelyta som är täckt med gadolinium, och de har därför också magnetiska egenskaper och förmågan att fungera även som kontrastmedel för MRT. Ytterligare fluoroscenta nanopartiklar som studerats består av gadoliniumoxid innehållande en liten andel (10 \%) fluorescenta europiumjoner. Europium avger främst rött ljus vid belysning och intensiteten beror till 
stor del av vilka molekyler som används vid ytmodifiering av partiklarna. Dessa ytmodifieringsmolekyler kan fungera likt antenner som absorberar energi som de sedan för över till europiumjonerna och därmed förstärker de fluorescensen. Liksom de gadoliniumdekorerade zinkoxidnanopartiklarna kan de gadolinium- och europiumbaserade nanopartiklarna fungera både som kontrastmedel för MRT och vid mikroskopiska studier.

I den här avhandlingen följs design, karakteristering och ytmodifiering av nanopartiklar upp av studier av interaktionen mellan nanopartiklar och flera olika typer av celler, däribland neutrofila granulocyter (vita blodkroppar) och THP-1 celler. Neutrofiler är celler som kan aktiveras i vårt försvar mot kroppsfrämmande objekt och kan därför användas som ett känsligt modellsystem för att utvärdera hur/om nanopartiklarna aktiverar immunförsvaret och vilken roll olika ytfunktionaliseringar spelar. Vidare undersöks viabiliteten, d.v.s. överlevnadsgraden, i samband med att celler utsätts för gadoliniumoxidnanopartiklar. Upptag av nanopartiklar i cellerna noteras liksom synliga förändringar på cellstrukturen med hjälp av infärgning av celler och mikroskopistudier. I avhandlingsarbetet har den kemiska karaktäriseringen genomförts med hjälp av en rad olika avancerade tekniker, främst inom spektroskopi. Genom dessa studier kan molekylära ytmodifieringar verifieras eftersom olika delar av molekylerna kan ge sig till känna i spektrumen i form av funktionella grupper. Teknikerna ger också information om hur en molekyl har bundit till partikelytan och vilka grupper som är fria och tillgängliga för fortsatt koppling av ytterligare molekyler som kan utrusta nanoproben med fler egenskaper.

Det långsiktiga målet med arbetet som utförts inom ramen för den här avhandlingen är att skapa nanopartikelprober med goda kontrastegenskaper som är specifika och möjliga att selektivt binda till speciella celler eller vävnader. Med det målet i siktet ökar möjligheten att använda låga doser av nanoprober och att i framtiden lättare kunna diagnosticera olika sjukdomstillstånd, till exempel tumörvävnad, i ett tidigare skede än vad som idag är möjligt. 
I. Positive MRI contrast enhancement in THP-1 cells with $\mathrm{Gd}_{2} \mathrm{O}_{3}$ nanoparticles

Anna Klasson, Maria Ahrén, Eva Hellqvist, Fredrik Söderlind, Anders Rosén, Per-Olov Käll, Kajsa Uvdal and Maria Engström

Contrast Media \& Molecular Imaging 20083 106-111

II. Synthesis and Characterization of PEGylated $\mathrm{Gd}_{2} \mathrm{O}_{3}$ Nanoparticles for MRI Contrast Enhancement

Maria Ahrén, Linnéa Selegård, Anna Klasson, Fredrik Söderlind, Natalia Abrikossova, Caroline Skoglund, Torbjörn Bengtsson, Maria Engström, PerOlov Käll and Kajsa Uvdal

Langmuir 201026 5753-5762

III. Magnetic and Electron Spin Relaxation Properties of $\left(G d_{x} Y_{1-x}\right)_{2} O_{3}$ $(0 \leq x \leq 1)$ Nanoparticles Synthesized by the Combustion Method. Increased Electron Spin Relaxation Times with Increasing Yttrium Content

Håkan Gustafsson, Maria Ahrén, Fredrik Söderlind, José M. Córdoba Gallego, Per-Olov Käll, Per Nordblad, Per-Olof Westlund, Kajsa Uvdal and Maria Engström

The Journal of Physical Chemistry C 2011115 5469-5477

IV. A simple polyol-free synthesis route to $\mathrm{Gd}_{2} \mathrm{O}_{3}$ nanoparticles for MRI applications: an experimental and theoretical study

Maria Ahrén, Linnéa Selegård, Fredrik Söderlind, Mathieu Linares, Joanna Kauczor, Patrick Norman, Per-Olov Käll, Kajsa Uvdal Journal of Nanoparticle Research 2012 14:1006

V. Highly Water-Dispersible Surface-Modified $\mathrm{Gd}_{2} \mathrm{O}_{3}$ Nanoparticles for Potential Dual-Modal Bio-Imaging

Zhangjun Hu, Maria Ahrén, Linnéa Selegård, Caroline Skoglund, Fredrik Söderlind, Xuanjun Zhang, Kajsa Uvdal

Chemistry A European Journal 2013 12658-12667 
VI. Bifunctional gadolinium decorated ZnO nanocrystals integrating both enhanced MR signal and bright fluorescence

Linnéa Selegård, Maria Ahrén, Caroline Brommesson, Fredrik Söderlind, Per O. Å. Persson and Kajsa Uvdal

In manuscript

VII. One-step synthesis of sub $5 \mathrm{~nm}$ sized manganese oxide based nanoparticles

Maria Ahrén, Fredrik Söderlind, Mathieu Linares, Patrick Norman, Kajsa Uvdal

In manuscript 


\section{Author's Contribution}

\section{Paper I}

I synthesized and dialyzed the nanoparticles and was responsible for the planning, performing, evaluating and writing of the XPS part. I also prepared grids for TEM measurements and evaluated TEM images.

\section{Paper II}

I was involved in most parts of the work. I synthesized, functionalized and dialyzed the nanoparticles. XRD and TEM measurements were performed together with a co-author, whereas I evaluated the data. I performed DLS and IR spectroscopy measurements and analyzed the results. I was responsible for the planning and performing of the relaxation time measurements and the writing of the manuscript.

\section{Paper III}

I was responsible for the XPS part of the manuscript. I also prepared TEM grids and evaluated the TEM results of the measurements. I took part in the scientific discussion and in the revision of the manuscript.

\section{Paper IV}

I was the main responsible for the paper and performed the work in close collaboration with the second author. My specific responsibilities were the XRD, TEM, DLS and IR spectroscopy measurements and the relaxation time study. I also incorporated the results from the theoretical calculations in the IR spectroscopy and NEXAFS part of the paper but did not take part in the calculations. I wrote the major parts of the manuscript.

\section{Paper V}

I transferred knowledge about the synthesis route and the washing steps, which were explored in Paper IV. I performed DLS measurements and took part in the collecting of MR images at the Center for Medical Image Science and Visualization. I also performed XPS measurements and interpreted XPS results. I was strongly engaged in the scientific discussion and helped out in the revision of the manuscript. 


\section{Paper VI}

This paper was done in close collaboration with the first author. I took part in the synthesis and washing of the nanoparticles and performed IR Spectroscopy, XRD and DLS measurements. Relaxation time measurements were done in collaboration with the first author. I was engaged in the scientific discussion and wrote several sections of the paper.

\section{Paper VII}

I wrote the manuscript and I was responsible for all measurements. Magnetic measurements were done externally and the TEM measurement was performed by the second author but I took part in the interpretation of all data. 


\section{Related publications (not included in this thesis)}

Biotinylation of ZnO Nanoparticles and Thin Films: A Two-Step Surface Functionalization Study

Linnéa Selegård, Volodymyr Khranovskyy, Fredrik Söderlind, Cecilia Vahlberg, Maria Ahrén, Per-Olov Käll, Rositsa Yakimova and Kajsa Uvdal

ACS Applied Materials and Interfaces 20102 (7) 2128-2135

Nanoscale Ln(III)-carboxylate coordination polymers $(\mathrm{Ln}=\mathrm{Gd}, \mathrm{Eu}, \mathrm{Yb})$ : temperature-controlled guest encapsulation and light harvesting

Xuanjun Zhang, Mohamed Ali Ballem, Maria Ahrén, Anke Suska, Peder Bergman and Kajsa Uvdal

Journal of the American Chemical Society 2010, 132 (30) 10391-10397.

$\mathrm{Gd}_{2} \mathrm{O}_{3}$ nanoparticles in hematopoietic cells for MRI contrast enhancement

Anna Hedlund, Maria Ahrén, Håkan Gustafsson, Natalia Abrikossova, Marcel Warntjes, Jan-Ivar Jönsson, Kajsa Uvdal and Maria Engström

International Journal of Nanomedicine 20116 3233-3240.

Effects of gadolinium oxide nanoparticles on the oxidative burst from human neutrophil granulocytes

Natalia Abrikossova, Caroline Skoglund, Maria Ahrén, Torbjörn Bengtsson and Kajsa Uvdal

Nanotechnology 201223 (27) 275101.

Book Chapter

Two-dimensional Gel Electrophoresis and Mass Spectrometry in Studies of Nanoparticle-Protein Interactions

Helen Karlsson, Stefan Ljunggren, Maria Ahrén, Bijar Ghafouri, Kajsa Uvdal, Mats Lindahl and Anders Ljungman

Gel electrophoresis-Advanced Techniques, In Tech 2012 1-32. 


\begin{tabular}{|c|c|}
\hline APTES & 3-aminopropyl triethoxy silane \\
\hline BM & Bohr magneton \\
\hline DEG & Diethylene glycol \\
\hline DLS & Dynamic light scattering \\
\hline DMSO & Dimethyl sulfoxide \\
\hline DTPA & Diethyltriamine pentaacetic acid \\
\hline EDC & 1-ethyl-3-(3-dimethylaminopropyl) carbodiimide \\
\hline EPR & Electron paramagnetic resonance \\
\hline FWHM & Full-width height at half maximum \\
\hline IMFP & Inelastic mean free path \\
\hline IR & Infrared or Inversion recovery \\
\hline MRI & Magnetic resonance imaging \\
\hline MOFs & Metal organic frameworks \\
\hline MPTS & 3-mercaptopropyl trimethoxy silane \\
\hline NEXAFS & Near-edge X-ray absorption fine structure spectroscopy \\
\hline PEG & Polyethylene glycol \\
\hline PEY & Partial electron yield \\
\hline $\mathrm{RE}$ & Rare earth (metals) \\
\hline RES & Reticuloendothelial system \\
\hline $\mathrm{RF}$ & Radio frequency \\
\hline ROS & Reactive oxygen species \\
\hline SAED & Selected area electron diffraction \\
\hline SE & Spin echo \\
\hline SPIO & Superparamagnetic iron oxide \\
\hline TE & Echo time \\
\hline TEOS & Tetraethylortho silicate \\
\hline TEY & Total electron yield \\
\hline TR & Repetition time \\
\hline TEM & Transmission electron microscopy \\
\hline TMAH & Tetramethylammonium hydroxide \\
\hline XRD & X-ray diffraction \\
\hline
\end{tabular}




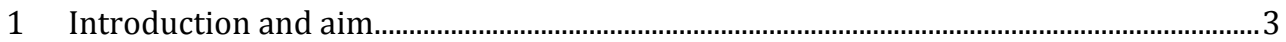

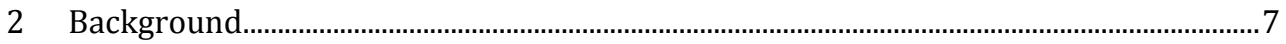

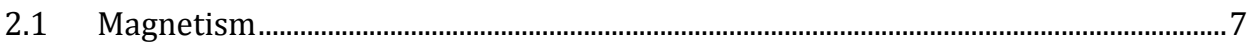

2.2 Nanoscience, nanotechnology and nanoparticles.................................................... 10

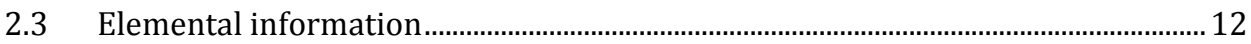

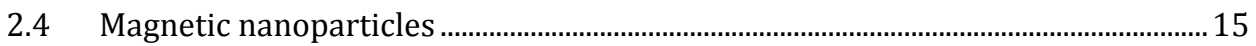

2.5 Magnetic and fluorescent nanoparticles ...................................................................... 17

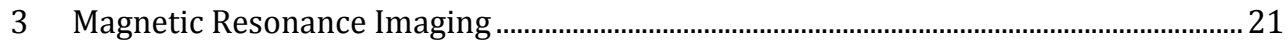

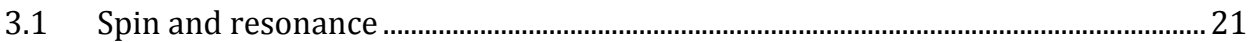

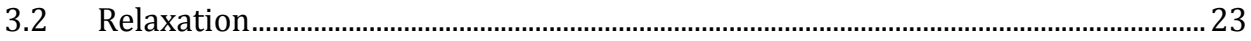

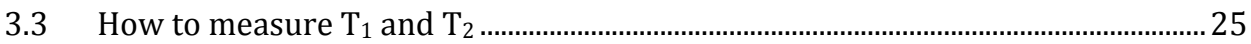

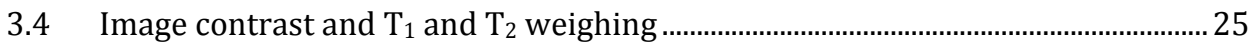

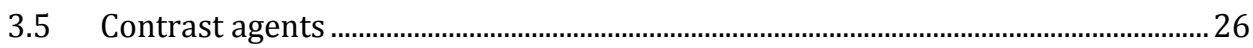

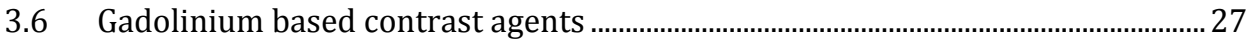

3.7 Requirements for gadolinium based contrast agents .............................................. 29

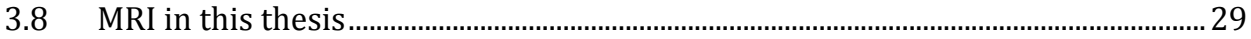

$4 \quad$ Nanoparticle synthesis and characterization ..................................................................... 31

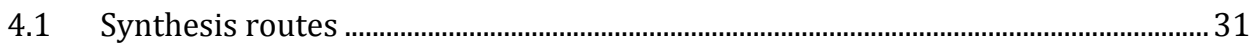

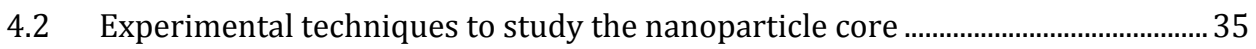

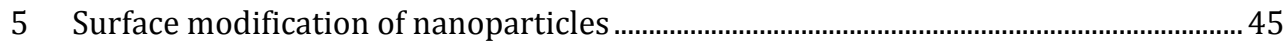

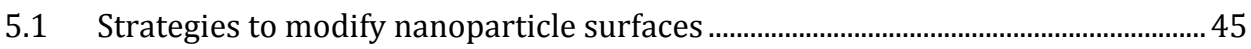




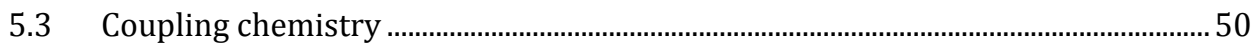

5.4 Instrumentation to study surface capping of nanoparticles ................................... 51

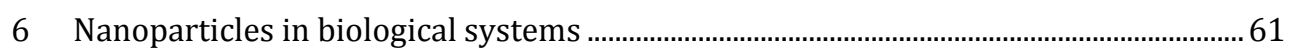

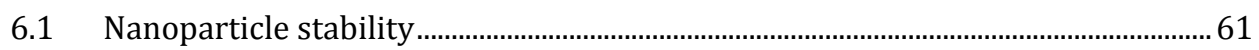

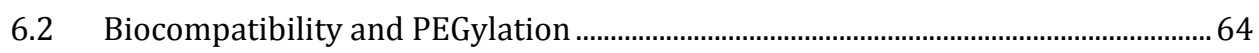

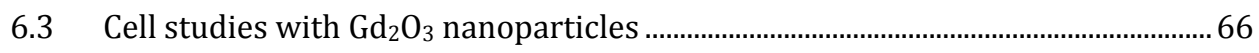

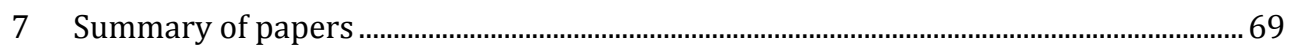

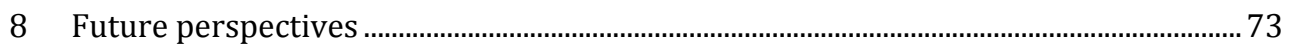

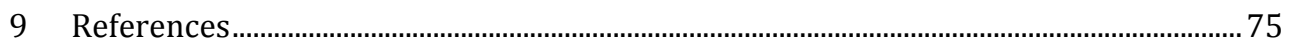


I'm close to the end now. To the end of this long personal and scientific journey that started more than seven years ago, when I performed my diploma work at IFM with Kajsa Uvdal as supervisor. I didn't know then how much time we would spend together the next coming years but when she eventually offered me a PhD student position I accepted. This journey has occasionally felt unfeasible, as expected with three parental leaves splitting up and prolonging the time. At other times it has felt exciting, stimulating and fun, mainly due to the inspiring working environment with many helpful and nice colleagues at work. Without these people, who have read and commented, suggested and criticized, experimented, measured and evaluated, shared a coffee break, listened to me and talked with me, all these years would not have had the same impression on my life as they have today. I would therefore like to humbly acknowledge some of the persons who have been close to me during the production of this thesis.

First of all I would like to acknowledge Kajsa, my supervisor, for all wonderful times, talks and adventures. Thanks also for your ever present support and your ability to immediately tackle difficulties when they appear. I will above all remember your energy and your joy in working with research, but also your engagement in others well-being. Next, I would like to acknowledge all past and present members of my group; Molecular surface physics and nanoscience Rodrigo, Luminita, Cecilia, Linnéa S, Caroline, Linnéa A, Natalia, Andreas, Xuanjun, Zhangjun, Guannan, Peter, Cui and Emanuel. Thanks for nice times and interesting discussions in which you have shared your knowledge. I really enjoyed canoeing with you as well... Among these persons special thanks are devoted to Caroline, my co supervisor, for all times that you have made my day happier with your presence. Thank you for encouraging me but also for valuable comments and suggestions in the revision of my works. Zhangjun, thanks for being a considerate roommate and for listening to my talk about my everyday life as well as the past, present and future gadolinium oxide nanoparticle related work. Another thought is dedicated to Cecilia for being a very supportive and good friend. Your experience has helped you to help me!

Many are those hours which I have spent together with Linnéa $S$ to collect and evaluate data for our papers in common. We have combined the work with social activities in many positive ways and I really have appreciated the close collaboration that we have had. Thanks for listening to me in all situations and for taking care of my projects during times of parental leaves. I miss you now when you are not here anymore! 


\section{Papers Included in this thesis}

The articles associated with this thesis have been removed for copyright reasons. For more details about these see:

http://urn.kb.se/resolve?urn=urn:nbn:se:liu:diva-98693 
Yet another important person for my thesis is Fredrik, who in fact is a cowriter of all my papers. I'm deeply thankful for all measurements you have done, for transferring knowledge about gadolinium oxide, XRD and TEM and for always letting me disturb you instantly without having booked a meeting time before. In addition I have always appreciated our talks in the darkness during the TEM measurements.

Per-Olov Käll, thanks a lot for always leaving the door open for me to come to you and discuss research related issues. Thanks also for organizing suitable $\mathrm{PhD}$ courses and for telling me so many amusing stories. Maria E, Anna and Håkan from CMIV. Thank you all for very fruitful collaboration and for help with measurements. Thanks also for kindly sharing your knowledge about MRI and EPR. Mathieu and Patrick, thanks for introducing me to the field of theoretical calculations of spectroscopy and for helping me see the value of incorporating such data in the papers. Our discussions have always been rewarding! Thanks also to all administrative and technical personnel including Pia, Anna-Maria, Therese, Malin, Anette, Susanne, Thomas L, Jörgen and Bo T. Your presence simplifies the daily life at the university in many aspects! Stefan $K$ is another valuable person leading the research school Forum Scientium. I have taken part in some of the activities organized through Stefan and I really feel that Forum Scientium is appreciated by many PhD students. If I wouldn't have felt that my time was running to fast during all my part-time working days, I would definitely have been more engaged in these activities. Thanks to both you and Charlotte for doing a good job and especially for being very supportive. Another thought is devoted to all former and present members of the Molecular Physics group. Thanks to all of you for advice, interesting discussions and presentations on the weekly meetings and nice talks in the lunchroom and during fika times. Paula, thanks for nice times as roommates in the early PhD student life. I really enjoyed our discussions which mostly not concerned about work related topics but about our children, life in general and future plans.

I would also like to take the opportunity to thank my close friends and relatives for support, encouragements and help during the time at IFM. The sole presence of you helps a lot for widening my perspective in moments of tunnel vision. A special thought is devoted to my mother Kerstin for having taught me to persist and fight even in hard times. Last but not least I would like to genuinely express my gratitude to my love Claes who is always handling me patiently and tenderly and again and again has reminded me of what is most important in life. For me, it is not successful lab results or splendid scientific papers but my closest family including our beloved children Alma, Anton and Nora.

October $2013 \quad$ Maria Ahrén 


\section{CHAPTER 1}

\section{Introduction and aim}

Magnetic resonance imaging (MRI) is a widely used non-invasive tool to visualize soft tissues in the body ${ }^{1}$. Among the benefits of the technique are both the high resolution yielding anatomical information useful for instance in cancer diagnostics and the absence of X-ray radiation. The signal in MRI is originating from the hydrogen protons in water and fat in the body. Image contrast is dependent on variations in intrinsic parameters, such as proton density or relaxation times, in between different tissues. In many cases contrast can be increased by the use of contrast agents. These are usually based on $\mathrm{Gd}^{3+}$ ions coordinated to a multidentate chelating molecule, as for instance the Gd-DTPA, see Figure 1.1. In this contrast agent, the magnetic Gd ion is the element affecting the contrast by catalytically shortening the relaxation times of the hydrogen protons.

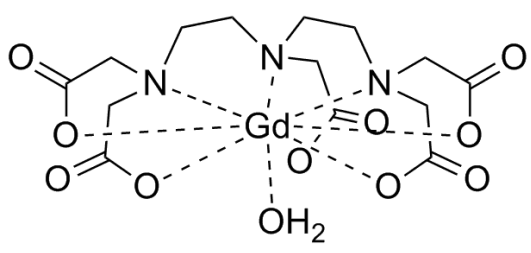

Figure $1.1 \mathrm{Gd}(\mathrm{DTPA})\left(\mathrm{H}_{2} \mathrm{O}\right)^{2-}$

In this thesis the main aim has been to produce alternative gadolinium containing contrast agents for magnetic resonance imaging based on nanoparticles. These 
nanoparticles in particular are composed of small $\mathrm{Gd}_{2} \mathrm{O}_{3}$ nanocrystals comprising about a thousand of gadolinium atoms. The idea has been to collect a large number of wellordered atoms in a small volume with a large surface area to increase the effect on the protons in the surrounding water. The central thesis work has been focused on the synthesis, surface modification and characterization of nanoparticle cores while the long term goal has been to specifically guide the nanoparticles to a certain tissue or cell type by adding targeting properties. A number of different synthesis strategies and purification methods have been explored, all with their own advantages and disadvantages. The task of encapsulating the metal oxide nanoparticle core in a more biocompatible and hydrophilic capping layer has been crucial for the aim of producing a probe for medical imaging. Organic capping also affects the stability of the nanoparticles which is also very important. Throughout the work the physical characters of the nanoparticles have been studied by means of transmission electron microscopy (TEM), X-ray diffraction (XRD) and dynamic light scattering (DLS) whereas the chemical modification has been evaluated with spectroscopic methods such as X-ray photoelectron spectroscopy (XPS), infrared spectroscopy (IR) and near edge X-ray absorption fine structure spectroscopy (NEXAFS).

The six first chapters of this thesis introduction are written with the aim to put the papers into their research field context and to discuss the main issues concerning the work performed. The outline of the thesis is schematically presented in Figure 1.2. In short, Chapter 2 is an introduction to the nanoparticle materials, and covers general facts about magnetism and nanoparticles as well as background information related to the metal oxide nanoparticles used in Paper I-VII. The theory of magnetic resonance imaging is briefly discussed in Chapter 3. In Chapter 4, the synthesis of nanoparticles and the characterization of the nanoparticle core are described. Chapter 5 covers main aspects of the nanoparticle surface modification and the experimental techniques used for chemical characterization. Finally, Chapter 6 is devoted to a few comments about biocompatibility and PEGylation and two examples are given of in vitro cell studies with $\mathrm{Gd}_{2} \mathrm{O}_{3}$ nanoparticles produced within the frame of this thesis. A summary of the papers is found in Chapter 7 and Chapter 8 deals with the future perspectives of gadolinium based nanoparticle probes for contrast enhancement. 

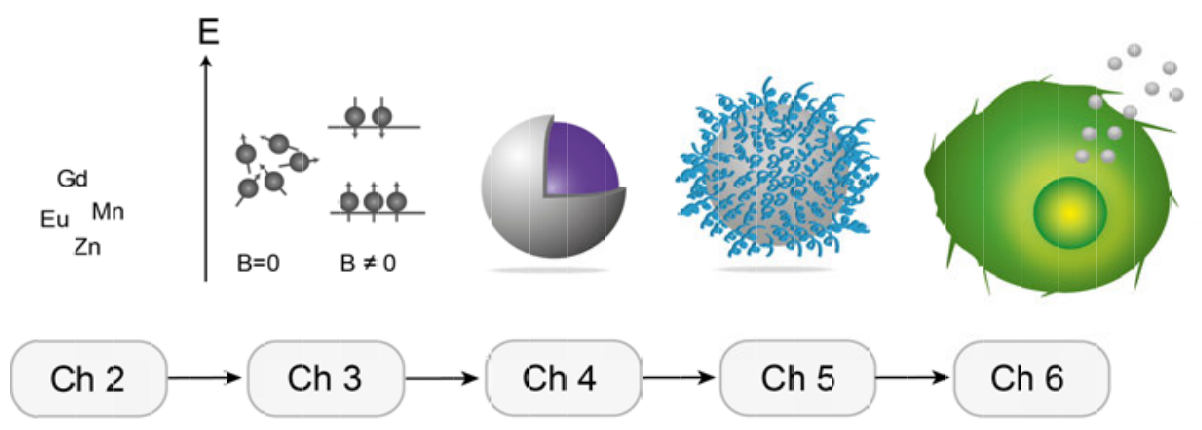

$\begin{array}{lllll}\text { Nanoparticles in } & \text { Magnetic } & \text { Nanoparticle ccre } & \text { Nanoparticle surface } & \text { Nanoparticles in } \\ \text { general } & \text { Resonance } & \text { Synthesis and } & \text { functionalization } & \text { biclog cal systems } \\ \text { Material facts } & \text { Imaging } & \text { characterization } & \text { and characterization } & \end{array}$

Figure 1.2 Schematic illustration presenting the outline of the thesis 


\section{CHAPTER 2}

\section{Background}

The aim of the work performed within the frame of this thesis has been focused on the production of nanoparticles to be used as a contrast agent for magnetic resonance imaging. This implies that the material itself has to be magnetic. This chapter introduces concepts and fundamental theory of magnetic properties in solid state. The general properties of nanoparticles are thereafter covered as well as information related to the elements and nanoparticles studied in this thesis.

\subsection{Magnetism}

The magnetic behavior of a material is strongly dependent on the electronic structure of the elements building up the material. Diamagnetism originates from electron circulation in atoms or molecules and is present as a negative contribution to an external magnetic field. This is generally a weak type of magnetism which is furthermost valid for elements having full electron shells. Presence of unpaired electrons on the other hand, gives rise to paramagnetic behavior, as described by the Curie law2:

$$
\chi=\frac{C}{T}
$$

where $\chi$ is the magnetic susceptibility (ability to be magnetized in an external magnetic field), $C$ is the Curie constant and $T$ is the temperature in Kelvin. If a paramagnetic material is placed in an external magnetic field, independent magnetic moments tend to 
align with the field and increase the total magnetic flux density. This alignment is temporary and when the external field is removed the moments immediately become randomly oriented. In ferromagnetic materials, with a high density of states near the Fermi level, a cooperative influence is producing magnetic domains. These domains consist of aligned magnetic moments which are strongly coupled to each other. Ferromagnetic materials usually have a very small net magnetic moment as the individual domains tend to magnetically compensate each other. When exposed to an external field, the internal magnetic moments align parallel to the field and the total magnetic field is enhanced. Ferromagnetic behavior is quite rare but it is shown for example by metals such as iron, nickel, cobalt and gadolinium in their metallic states. Above the so called Curie temperature $\left(T_{c}\right)$, the thermal energy is randomizing the magnetic spins and at high temperatures ferromagnetic materials thus show a paramagnetic behavior. The magnetic susceptibility of ferromagnetic materials above the Curie temperature is described by the Curie-Weiss law ${ }^{3}$ :

$$
\chi=\frac{C}{T-\theta}
$$

where $\theta$ is the paramagnetic Curie temperature or the Weiss constant, which usually is slightly greater than $T_{C}$. Gadolinium is unusual having a $T_{C}$ of $293 \mathrm{~K}$, i.e. approximately room temp, whereas iron, nickel and cobalt have $T_{C}$ of about 1043,630 and $1395 \mathrm{~K}$ respectively ${ }^{4}$. The temperature dependency of the magnetic susceptibility is illustrated in Figure 2.1 for a paramagnetic and a ferromagnetic material.
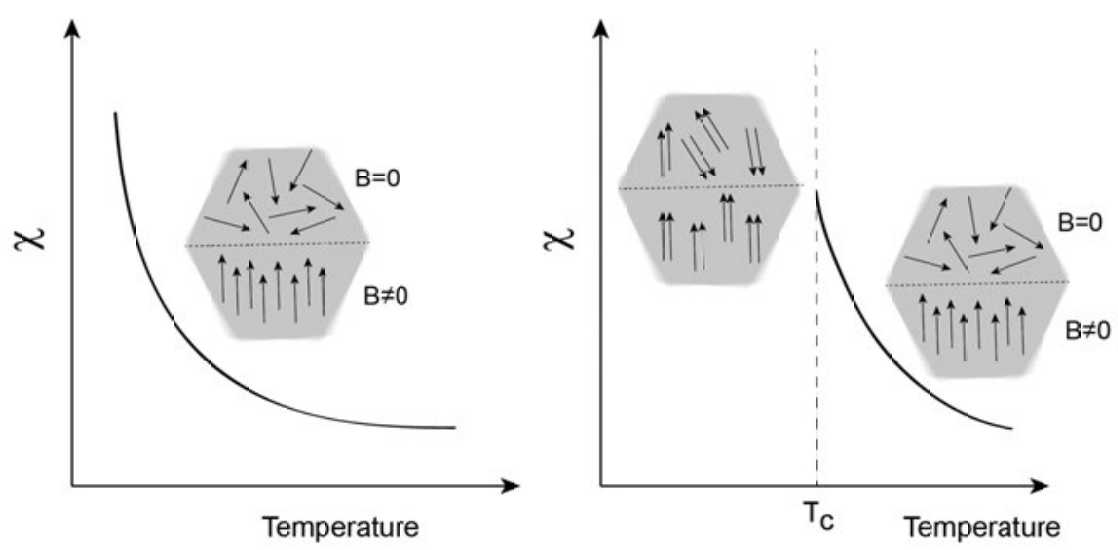

Figure 2.1 Schematic illustration showing the magnetic susceptibility of paramagnetic (left) and ferromagnetic (right) materials at different temperaures. 
Another kind of magnetic behavior is observed in antiferromagnetic materials. In these spins are coupled in an anti-parallel manner up to a certain temperature called the Neél temperature $\left(T_{N}\right)$. Antiferromagnetic materials obey the Curie-Weiss law but in contrast to the ferromagnetic materials they have a negative Weiss constant.

In the case of nanoparticles, the magnetic properties are truly influenced by the chemical composition as well as the size of the nanoparticles. Superparamagnetism is an example of a size effect present in small iron oxide nanoparticles with a size smaller than the ferromagnetic domains building up the corresponding bulk material. The strong cooperative force aligning the spins in a specific direction is diminished in the small nanoparticle, and the spins can hence flip to the opposite direction in the absence of an applied field. As the flip time reversing the nanoparticle magnetic field is very short, the net magnetization appears to be zero. This behavior is very similar to paramagnetic ones with the main difference that it occurs below the Curie temperature. Superparamagnetic iron oxide (SPIO) nanoparticles have previously been used as contrast agents for MRI giving negative (dark) contrast and in Paper VII superparamagnetism is verified for manganese oxide nanoparticles.

The magnetic moment $(\mu)$ of an element is a consequence of the orbital and spin angular momentum of the unpaired electrons in the material. The number of unpaired electrons has a considerable effect on the magnetic moment which can be calculated using ${ }^{2}$ :

$$
\begin{aligned}
& \mu=g \sqrt{J(J+1)} \mu_{B} \\
& \text { where } g=1+\frac{J(J+1)+S(S+1)-L(L+1)}{2 J(J+1)}
\end{aligned}
$$

and $S$ is the spin angular momentum quantum number, $L$ is the orbital angular momentum quantum number, $J$ the total angular momentum quantum number, i.e. the sum of $S$ and $L$, and $\mu_{B}$ is a constant called the Bohr magneton (BM; $9.274 \cdot 10^{-24} \mathrm{~J} / \mathrm{T}$ ) . In some cases, when $\mathrm{L}=0$ or the contribution from the orbital momentum is greatly quenched, such as for the first-row transition elements, the formula can be simplified to:

$$
\mu_{s}=g \sqrt{S(S+1)} \mu_{B}
$$

with a constant $\mathrm{g}$ with a value of 2 . Owing to the half-filled $4 \mathrm{f}$ shell in gadolinium ions $\left(\mathrm{Gd}^{3+}\right) \mathrm{L}=0$ and this simplified formula was used to calculate the theoretical magnetic moment of these ions to $7.94 \mathrm{BM}$ in paper I and paper III $^{5}$. 


\subsection{Nanoscience, nanotechnology and nanoparticles}

The last thirty years the field of nanoscience and nanotechnology has expanded enormously from being a vision to an interdisciplinary well established sector attracting huge amounts of funding every year. The ideas behind nanotechnology were discussed already in 1959 in a famous talk by Richard Feyman', but the term nanotechnology was not introduced until more than 15 years later 7 . In 2004 the Royal Society carried out and presented a study about these growing research fields in which they defined the term nanoscience as "the study of phenomena and manipulation of materials at atomic, molecular and macromolecular scales, where properties differ significantly from those at a larger scale". Nanotechnology was similarly defined as "the design, characterization, production and application of structures, devices and systems by controlling shape and size at nanometre scale". The Royal Society broadly categorize nanomaterials as materials having structured components with at least one dimension less than $100 \mathrm{~nm}^{8}$. This definition thus cover materials ranging from thin films $(<100$ $\mathrm{nm}$ in one dimension) and nanowires (<100 nm in two dimensions) to nanoparticles ( $<100 \mathrm{~nm}$ in three dimensions) and by definition all of these materials are expected to show properties different from their corresponding bulk material. Nanoparticles are today found in a wide range of applications as for instance medicine and material and product technology. The specific application requires nanoparticles of a certain chemical or physical character and there are several categories of nanoparticle types. Organic nanoparticles are often built up by organic polymers while gold nanoparticles are purely metallic as are bimetallic nanoparticles composed of a combination of two metals 9 . Mixtures in between these categories as for example metallofullerenes or core shell structures are furthermore studied extensively. Examples of inorganic nanoparticles are the metal oxide nanoparticles $\mathrm{Gd}_{2} \mathrm{O}_{3}$ and $\mathrm{ZnO}$ investigated within this thesis. These nanoparticles are crystalline, i.e. they are built up by atoms in a well ordered pattern.

\subsubsection{Properties of nanoparticles}

Nanoparticles have unique properties due to their small size which imply a large surface to volume ratio and a considerably amount of surface atoms. The fraction of surface atoms, as a function of the nanoparticle size, can be approximately calculated. By assuming a face centered cubic close packed structure comprising four atoms in the unit cell and an atomic radius of $0.144 \mathrm{~nm}$ (gold), the function describing the fraction of surface atoms in a spherical nanoparticle is

$$
f \approx 1-\left(1-\frac{2 r}{R}\right)^{3}
$$


where $r$ is the atomic radius and $R$ the nanoparticle radius. A plot of this function for $0.5 \mathrm{~nm} \leq r \leq 20 \mathrm{~nm}$ can be observed in Figure 2.2. From Table 2.1 it can be noticed that the fraction of surface atoms is less than one percent for a particle of $100 \mathrm{~nm}$ radius. The fraction increases enormously for smaller sized nanoparticles and a particle with a radius of $1 \mathrm{~nm}$ has a larger proportion of surface atoms than bulk atoms. The high surface to volume ratio makes nanoparticles more reactive as compared to the corresponding bulk material and surface defects such as dislocations are playing a further significant role.

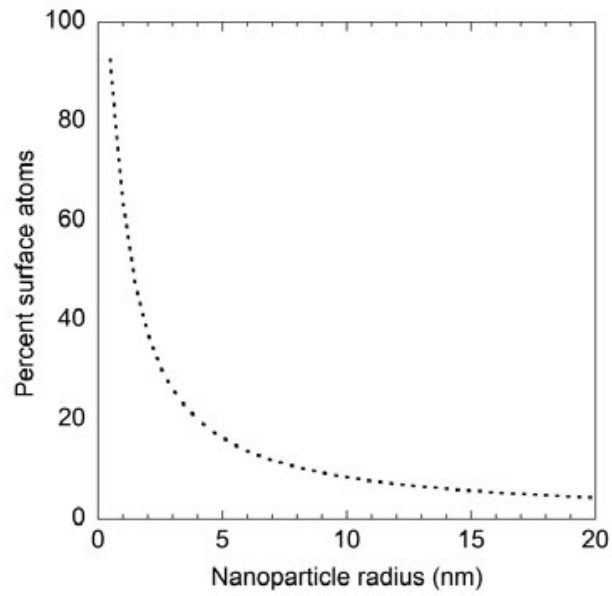

Figure 2.2 Plot showing the fraction of surface atoms as a function of nanoparticle radius.
Table 2.1 Table displaying the fraction of surface atoms for fcc gold nanoparticles with radii in the range $0.5-100 \mathrm{~nm}$.

\begin{tabular}{cc}
\hline $\begin{array}{c}\text { Nanoparticle } \\
\text { radius (nm) }\end{array}$ & $\begin{array}{c}\text { Fraction of } \\
\text { surface } \\
\text { atoms (\%) }\end{array}$ \\
\hline 0.5 & 92 \\
\hline 1 & 64 \\
\hline 2 & 37 \\
\hline 5 & 16 \\
\hline 10 & 8 \\
\hline 25 & 3 \\
\hline 50 & 1.7 \\
\hline 100 & 0.9 \\
\hline
\end{tabular}

The small size of nanoparticles furthermore has a great impact on the electronic structure of the material. This so called quantum size effect can be illustrated by discussing the semiconductor energy levels. A bulk semiconductor crystal has energetically very close energy levels building up more or less continuum states in the valence- and conduction band which are separated by a bandgap. For very small crystals, on the other hand, these continuum electronic levels are quantized and the band gap increases as compared to the bulk. This is noted for instance in CdSe crystals; the bandgap increases with more than $1 \mathrm{eV}$ for crystals of $1.2 \mathrm{~nm}$ as compared to the 1.8 $\mathrm{eV}$ bandgap in $11.5 \mathrm{~nm}$ sized crystals $^{2}$. In fluorescent materials, as for instance the $\mathrm{ZnO}$ nanoparticles studied in Paper VI, this electronic quantum effect has an impact also on the wavelength of the emitted light. Smaller particles hence emit light of higher energy (blue shifted) as compared to larger sized particles, as also presented by Lin et $\mathrm{al}^{10}$. 
Besides the electronic and optical effects in nanoparticulate systems size also has a major effect on the magnetic properties and the phenomenon of superparamagnetism is only observed for particles which size is less than that of a single ferromagnetic domain of the materials.

Altogether, the unique electronic, optical and magnetic properties of nanoparticles are not only affected by the size of the nanoparticles but also by their shape and composition. The molecular surface coating positioned in the interface of the particles and the surrounding medium also plays a major role. This is noted for instance in Paper $\mathbf{V}$, in which energy transfer from surface coating ligands to the nanoparticle core material efficiently can affect the light emission properties of $\mathrm{Eu}^{3+}$ ions incorporated into $\mathrm{Gd}_{2} \mathrm{O}_{3}$ nanoparticles. The field of nanoparticle synthesis and design is in many aspects still in its infancy and one of the driving forces to explore the field is the chance to find nanomaterials with further novel or enhanced physical properties obtained when scaling down to the nano size.

\subsection{Elemental information}

An overview, in which the fundamental facts about the elements building up the nanoparticles within this thesis are collected, is presented in this section.

\subsubsection{Gadolinium}

The lanthanide series elements ranging from cerium (atomic number 58) to lutetium (atomic number 71) are called the rare-earth (RE) elements. Lanthanum (atomic number 57) is also often associated with the RE elements as are likewise scandium and yttrium. One of the elements in this RE series is gadolinium (Gd), with atomic number 64 and an electron configuration of $[\mathrm{Xe}] 4 \mathrm{f}^{7} 5 \mathrm{~d}^{1} 6 \mathrm{~s}^{2}{ }^{11}$. The trivalent ionic state of Gd is stable in most chemical compounds such as the synthesis precursors used in this thesis; $\mathrm{Gd}\left(\mathrm{NO}_{3}\right)_{3}, \mathrm{GdCl}_{3}$, and $\mathrm{Gd}(\mathrm{OAc})_{3}$. In contrast to many of the other lanthanides, Gd has no visible fluorescence but emit light in the UV region upon high energy excitation (Figure 2.3). The seven unpaired f-electrons provide $\mathrm{Gd}$ with a high magnetic moment and this fact together with the high symmetry of the electronic state, which slows down the electronic spin relaxation, makes Gd outstanding when it comes to the design of positive contrast agents for magnetic resonance imaging (MRI) ${ }^{12}$. Because of the toxicity of free Gd ions, commercially available contrast agents are composed of Gd ions strongly chelated to organic molecules such as for example diethylentriamine pentaacetic acids 
(DTPA). The development of Gd based contrast agents for clinical MRI use has opened up for an interest also in other medical fields. Among these is the idea of making use of the very high thermal neutron cross-section (255000 barns for ${ }^{157} \mathrm{Gd}$ ) and $\mathrm{Gd}$ has therefore been suggested for neutron capture therapy (NCT), i.e. the selective treatment of cancer cells with neutron beams ${ }^{13}$.

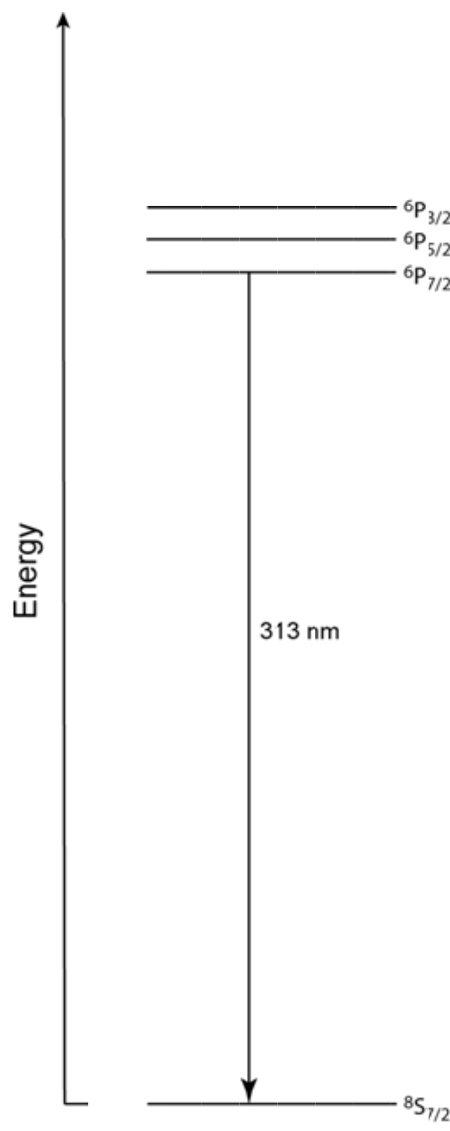

Gd

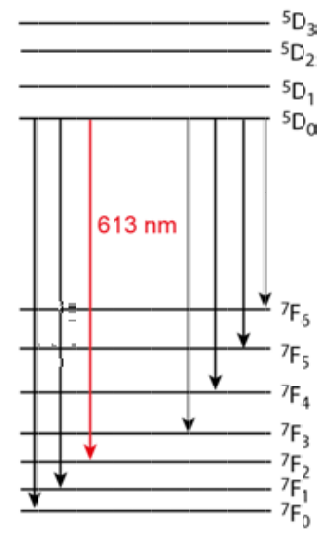

$\mathrm{Eu}$

Figure 2.3 Schematic diagram illustrating some energy levels involved in the emission process in $\mathrm{Gd}^{3+}$ and $\mathrm{Eu}^{3+}$. The $\mathrm{Gd}$ ion emits light in the UV range whereas the $\mathrm{Eu}$ ion mainly emits red light originating from ${ }^{5} \mathrm{D}_{0} \rightarrow{ }^{7} \mathrm{~F}_{2}$ transitions ${ }^{14}$. This simplified diagram is constructed based on a Dieke diagram ${ }^{15}$. 


\subsubsection{Europium}

Europium $(\mathrm{Eu})$ has an electron configuration of $[\mathrm{Xe}] 4 \mathrm{f}^{7} 6 \mathrm{~s}^{2}$ and is thus the element located next to Gd in the periodical table. Similar to some other lanthanide ions as for instance $\mathrm{Tb}^{3+}$ and $\mathrm{Dy}^{3+}$, europium ions have interesting luminescent properties with absorption in the UV range and emission in the visible region. A number of emission bands exist of which the ones originating from electron de-excitations from the D-level to the F-level mainly are considered ${ }^{16}$. The most intense emission line is red and originates from the ${ }^{5} \mathrm{D}_{0} \rightarrow{ }^{7} \mathrm{~F}_{2}$ transition of $\mathrm{Eu}^{3+}$ ions as shown in the schematic emission energy level diagram in Figure 2.3. Free ions only have weak fluorescence but the process can be greatly enhanced by chelation of suitable chromophores as energy then is absorbed by the ligands and transferred to the lanthanide ions ${ }^{17}$. The intensity of the luminescence is thought to be highly dependent on the degree of asymmetry in the close environment of the europium ion, and the choice of ligands and bonding groups therefore has a major impact on the system ${ }^{16}$.

\subsubsection{Yttrium}

The diamagnetic transition metal yttrium has atom number 39 in the periodic table. In contrast to most of the transition metals yttrium ions have only one stable oxidation state (+III) in molecular compounds. The ionic form of the element is characterized by absence of unpaired electrons. Yttrium is frequently found in the lanthanide minerals and has very similar chemical properties as the lanthanides ${ }^{18}$. This fact together with the very similar ionic size of Y ( ionic radii of $104 \mathrm{pm}$ ) and some lanthanides (ionic radii of 108 pm for Gd) make Y invariably associated with rare earth elements ${ }^{19}$.

\subsubsection{Zinc}

Zinc (Zn) is a biologically very important metal which is part of the d-block elements in the periodic table. The electron configuration of $[\mathrm{Ar}] 3 \mathrm{~d}^{10} 4 \mathrm{~s}^{2}$ implies full electron shells and a diamagnetic behavior. The bivalent ionic state has no luminescent properties in contrast to the oxidized form of the element which is a wide band gap (3.3-3.4 eV) semiconductor emitting light in the UV region ${ }^{20}$. One advantage of using $\mathrm{Zn}$ in nanomaterials for bioimaging is the relatively low toxicity as $\mathrm{Zn}$ is naturally present in the body. Drugs containing Zn are used to treat various medical problems but excessive intake is still associated with toxicological concerns ${ }^{21}$. 


\subsubsection{Manganese}

Manganese (Mn) is a transition metal and present as an important trace element in living organisms. Mn can adopt a wide range of oxidation states from zero up to +VII. The 5 unpaired d-electrons in manganese having an electron configuration of [Ar] $3 d^{5} 4 s^{2}$ provides manganese compounds with a high magnetic moment. The magnitude of the magnetic moment for the free ion depends on the oxidation state, as presented in Table 2.2. Manganese is paramagnetic at room temperature.

Table 2.2 Magnetic moments of different manganese ions as calculated from formula 2.4.

\begin{tabular}{cccc} 
Mn ion & $\begin{array}{c}\text { Number of unpaired } \\
\text { electrons }\end{array}$ & $\begin{array}{c}\text { Spin quantum } \\
\text { number }(S)\end{array}$ & $\begin{array}{c}\text { Nanoparticle } \\
\mu_{\mathrm{s}} / \mu_{\mathrm{B}}(\mathrm{BM})\end{array}$ \\
\hline $\mathrm{Mn}(\mathrm{II})$ & 5 & $5 / 2$ & 5.92 \\
$\mathrm{Mn}(\mathrm{III})$ & 4 & 2 & 4.90 \\
$\mathrm{Mn}(\mathrm{IV})$ & 3 & $3 / 2$ & 3.87 \\
$\mathrm{Mn}(\mathrm{V})$ & 2 & 1 & 2.83 \\
$\mathrm{Mn}(\mathrm{VI})$ & 1 & $1 / 2$ & 1.73 \\
$\mathrm{Mn}(\mathrm{VII})$ & 0 & 0 & 0 \\
\hline
\end{tabular}

\subsection{Magnetic nanoparticles}

All nanoparticles studied within the frame of this thesis are composed of a magnetic material, either in the core or on the nanoparticle surface. In this short section nanoparticles comprising a magnetic nanoparticle core are described.

\subsubsection{Gadolinium oxide}

Trivalent rare earth elements form oxides called sesquioxides with molecular formula $\mathrm{RE}_{2} \mathrm{O}_{3}$. These oxides are basic oxides which are insoluble in water but decompose in aqueous acids. Several polymorphs of the sesquioxides exist of which at least three, called the A-, B- and C-type polymorphs, are well studied ${ }^{11}$. The $\mathrm{Gd}_{2} \mathrm{O}_{3}$ sesquioxide nanoparticles examined within the scope of this thesis are all of the C-type polymorph having a cubic crystal structure (space group $I a \overline{3}$ ) with 32 gadolinium atoms and 48 oxygen atoms per unit cell and a metal coordination number of 6 . Each unit cell is thus comprised of 16 formula units of $\mathrm{Gd}_{2} \mathrm{O}_{3}$ and the cell parameter is given by $a=b=c=10.809$ 
$\AA^{22}$. Similar to chelates containing Gd ions nanoparticles of $\mathrm{Gd}_{2} \mathrm{O}_{3}$ are paramagnetic at room temperature.

The main focus within this thesis is the design and characterization of nanoparticles to be used as contrast agents for magnetic resonance imaging. The choice of using Gd containing nanoparticles is based on its optimal magnetic properties which highly affects the water proton relaxation and produces a strong signal enhancement. In Paper I, Paper II and Paper IV pure $\mathrm{Gd}_{2} \mathrm{O}_{3}$ nanocrystals were studied primarily for the purpose to increase the sensitivity of the MRI by increasing the number of Gd ions per contrast agent unit. This was done to enhance the local contrast and to increase the molecular weight and size of the contrast agent, and thereby increase the rotational correlation time ${ }^{23} . \mathrm{Gd}_{2} \mathrm{O}_{3}$ nanoparticles have in themselves no visible fluorescence but they are often used as hosts for luminescent Eu or Tb ions, as in Paper V.

\subsubsection{Manganese oxide}

In Paper VII nanoparticles composed of $\mathrm{MnO}_{\mathrm{x}}(1 \leq \mathrm{x} \leq 2)$ are studied. Manganese has generally a lower impact on the water proton relaxation as compared to gadolinium but is still judged as a valuable alternative, especially because of a more straight forward nanochemistry and a somewhat lower toxicity. The magnetic moment of the Mn ion is dependent on the oxidation state and states of lower valency are expected to be more efficient in affecting the water proton relaxation in MRI as compared to those of higher valency. A major challenge when working with manganese is the numerous oxidation states and the polymorphs of manganese oxide crystals. Manganese containing nanoparticle samples exhibiting a mixture of different oxidation states are frequently reported in the literature ${ }^{24}$. The crystal state is usually determined by X-ray diffraction, but with very small particles considerable peak broadening and low intensities (as a consequence of very few planes) complicates the interpretation.

\subsubsection{Gadolinium yttrium oxide}

The chemical properties of yttrium and the rare earth elements are similar, as previously mentioned in section 2.3.3. The size of $Y$ is in the same size range as Gd and isostructural cubic $\mathrm{Gd}_{2} \mathrm{O}_{3}$ and $\mathrm{Y}_{2} \mathrm{O}_{3}$ oxides (space group $\mathrm{I} a \overline{3}$ ) can be synthesized via the same synthesis route ${ }^{25}$. The cubic cell parameter (a) is slightly smaller for $\mathrm{Y}_{2} \mathrm{O}_{3}(10.604$ $\AA)^{25}$ as compared to the corresponding value for $\mathrm{Gd}_{2} \mathrm{O}_{3}(10.809 \AA)^{22}$, as a consequence of the marginally smaller size of the yttrium atom. The similarities between these two elements make it possible to synthesize solid solution nanoparticles composed of 
$\left(\operatorname{Gd}_{x} \mathrm{Y}_{1-\mathrm{x}}\right)_{2} \mathrm{O}_{3}(0 \leq \mathrm{x} \leq 1)$. In such a case the magnetic behavior can be tuned by altering the $\mathrm{x}$-value in the synthesis, as gadolinium is paramagnetic and yttrium diamagnetic. Nanoparticles composed of $\left(\mathrm{Gd}_{\mathrm{x}} \mathrm{Y}_{1-\mathrm{x}}\right)_{2} \mathrm{O}_{3}(0 \leq \mathrm{x} \leq 1)$ are studied in Paper III.

\subsection{Magnetic and fluorescent nanoparticles}

In one part of the work performed within this thesis (Paper VI), the elements gadolinium and zinc have been combined in the very same nanoparticle to achieve both fluorescent and magnetic properties and a bimodal imaging probe. The surface bound Gd provides this probe with MRI contrast agent properties whereas the sub $5 \mathrm{~nm}$ fluorescent $\mathrm{ZnO}$ core makes it useful for in-vitro cell and tissue bioimaging. Another strategy to achieve a combined probe is also studied in Paper $\mathbf{V}$, namely the europium doped gadolinium oxide. Below the most important facts are summarized about the nanoparticles exhibiting fluorescent properties.

\subsubsection{Gd decorated zinc oxide}

A study of hexagonal $\mathrm{ZnO}$ nanoparticles decorated with Gd ions is done and the work is presented in Paper VI. The aim was to make use of the luminescent properties of the semiconducting $\mathrm{ZnO}$, which are of interest in the design of fluorescent nanoprobes. The process behind the fluorescence emission is briefly discussed in the following. When irradiated with light of a high enough energy electrons in $\mathrm{ZnO}$ are excited from the valence band to the conduction band creating an electron-hole pair, i.e. an exciton. The relaxation of the excited electron to the ground state is associated with light emission or more precisely fluorescence. For $\mathrm{ZnO}$ particles, the emission involves two bands, of which one is broad and in the visible range and one is sharp and in the UV range. The UV emission is directly related to the band gap of $\mathrm{ZnO}$ and micrometer sized particles emit light of $380 \mathrm{~nm}^{26}$. Nanoparticulate $\mathrm{ZnO}$ emit UV light of a shorter wavelength as a consequence of the previously mentioned quantum size effect, i.e. the increased bandgap for nanoparticulate systems. Van Dijken et al for example report values of 320-350 nm for 1-6 $\mathrm{nm}$ sized $\mathrm{ZnO}$ nanoparticles ${ }^{26}$. The visible emission is usually in the range of 540 to $590 \mathrm{~nm}$ but emission maxima of even shorter wavelengths are also reported. The origin of the UV emission is quite clearly understood but a full explanation of the visible emission is not yet fully established. In sub $10 \mathrm{~nm}$ nanoparticulate systems, the UV emission is very weak and hence the visible emission is of most interest. As the $\mathrm{ZnO}$ nanoparticle size decreases the intensity of the visible emission increases, and the mechanism is thus thought to be surface related. Whereas the UV emission is 
characterized by very short life times, the visible emission is associated with long life times, likely as a consequence of electron and hole trapping in the relaxation process. Among the various proposals of the visible emission origin are oxygen vacancies, which are considered to play a major role as recombination points between holes and electrons ${ }^{26-27}$. Surface defects and the number of oxygen vacancies influence the fluorescence intensity and chemical surface modification is hence very interesting in purpose to tune the major relaxation pathway and thereby optimize the efficiency of the fluorescence process. In Paper VI in this thesis it was investigated how the amount of surface bound $\mathrm{Gd}$ acetates on the nanoparticles correlates to the efficiency of the fluorescence process. This was done by studying the quantum yield of the visible green fluorescence as a function of gadolinium concentration.

\subsubsection{Europium doped gadolinium oxide}

The distinct luminescent properties of several of the lanthanides have made them highly interesting as dopants in other host nanoparticles. Especially the optical and structural properties of europium doped $\mathrm{Gd}_{2} \mathrm{O}_{3}$ has been studied by Goldys et al, Nichkova et al, Dosev et al and others ${ }^{28}$. In contrast to semiconducting $\mathrm{ZnO}$ nanoparticles, the emission wavelength of lanthanide oxide nanoparticles are independent of the nanoparticle size $^{28 c}$. The emission spectra are characterized by sharp narrow peaks with the most intense band positioned at about 610-615 $\mathrm{nm}$ corresponding to the characteristic "europium red" luminescence. Similar to the europium ions the luminescence of europium doped nanoparticles can be greatly enhanced by binding organic chromophores to the nanoparticle surface transferring energy to europium. Among the peaks in the europium emission spectra most of them are very sensitive to the structure of the ligand and the ligand field symmetry as a consequence of the dipole character of the luminescence ${ }^{29}$. The choice of molecule in the surface capping of these nanoparticles hence has a considerable impact on the fluorescence and is most effective with molecules maximizing the absorption and transferring of energy to the europium ions.

In Paper $\mathbf{V}$ gadolinium oxide nanoparticles doped with $10 \%$ europium were studied. The close similarity of Gd and Eu in the sense of for instance oxidation state (+III mainly) and size together with the fact that europium and gadolinium forms isostructural cubic metal oxide lattices enable a smooth incorporation of $\mathrm{Eu}$ into the $\mathrm{Gd}_{2} \mathrm{O}_{3}$ lattice and the production of a nanomaterial exhibiting both magnetic and fluorescent properties ${ }^{22}$. The results showed that capping of the doped nanoparticles with organic ligands efficiently 
enhanced the emission intensity of the ${ }^{5} \mathrm{D}_{0} \rightarrow{ }^{7} \mathrm{~F}_{1}$ and ${ }^{5} \mathrm{D}_{0} \rightarrow{ }^{7} \mathrm{~F}_{2}$-transitions of europium at about 590 and $615 \mathrm{~nm}$ respectively, as a consequence of the increased light harvesting capacity of the europium using excitation energy of $365 \mathrm{~nm}^{16}$. 


\section{CHAPTER 3}

\section{Magnetic Resonance Imaging}

Magnetic Resonance Imaging (MRI) is a non-invasive technique that generates images of the soft tissue of the body using the principles of nuclear magnetic resonance (NMR). In addition to an excellent image resolution, one of the benefits of MRI is the absence of hazardous ionization radiation, i.e. X-ray. Magnetic resonance is the phenomenon of the nuclei of atoms such as ${ }^{1} \mathrm{H},{ }^{13} \mathrm{C}$ and ${ }^{31} \mathrm{P}$ absorbing or emitting a specific amount of energy when placed in a magnetic field. These specific nuclei have a net magnetic moment which makes them MR active. The most commonly used nuclei for imaging in biological systems is the hydrogen nuclei $\left({ }^{1} \mathrm{H}\right)$ as a considerable part of the human body consists of water and fat containing hydrogen atoms.

\subsection{Spin and resonance}

A hydrogen nucleus possesses an intrinsic property called spin and can be regarded as a magnetic dipole behaving like a tiny magnet ${ }^{30}$. In general, the nuclear spin quantum number (I) is dependent on the nuclear constitution and is zero only if the number of protons and neutrons are even. A ${ }^{1} \mathrm{H}$ nuclei has $\mathrm{I}=1 / 2$ and since the number of possible spin directions is $2 \mathrm{I}+1$ it can adopt two spin states when placed in an external field. ${ }^{31} \mathrm{In}$ the absence of an external field, the spin vectors are randomly oriented in space. Upon applying an external field the spins align either parallel or anti-parallel with the external field and an energy split appears between the two spin states. Since the narrow majority of the spins align parallel with the external field, a net magnetization $\left(\mathrm{M}_{\mathrm{z} 0}\right)$ is created in the direction of the external field, often called the z-direction (Figure 3.1) ${ }^{32}$. 
When a specific amount of energy, that fulfills the resonance condition, is introduced to the system, spin states can be excited. The frequency of this specific amount of energy is proportional to the strength of the applied field according to:

$$
\omega=\gamma \times \mathrm{B}_{0}
$$

where $\omega$ is called the Larmor frequency (MHz), $\gamma$ is the gyromagnetic ratio of the specific nucleus and $B_{0}$ is the strength of the magnetic field in Tesla (T). Protons have a gyromagnetic ratio of $\gamma=42.58 \mathrm{MHz} / \mathrm{T}$ which with $\mathrm{B}_{0}=1.5 \mathrm{~T}$ results in a Larmor frequency of $63.9 \mathrm{MHz}$, i.e. the Larmor frequency is in the radio frequency (RF) range. ${ }^{30}$

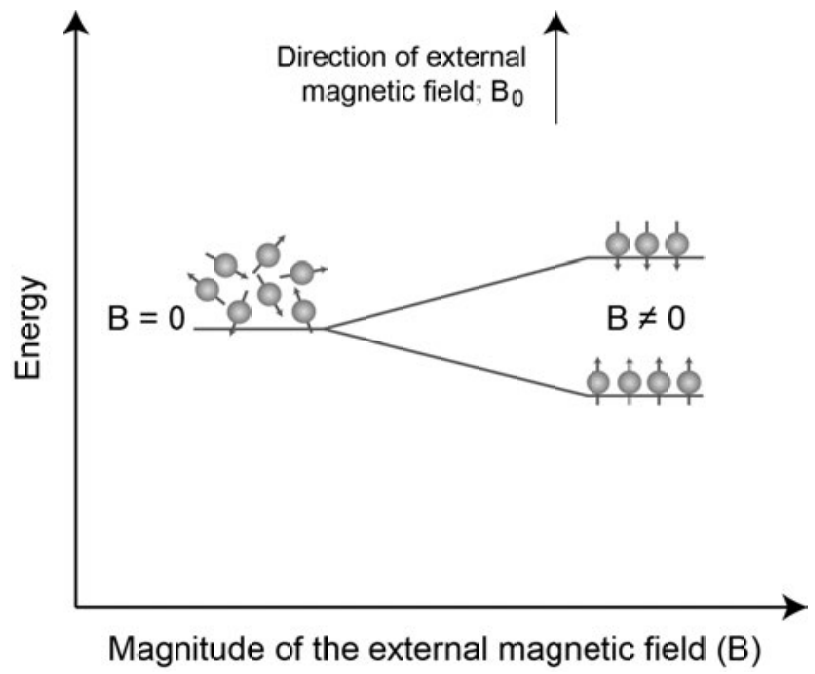

Figure 3.1 Illustration of the energy of the spin states at no magnetic field and at applied magnetic field.

Excitation of spin states by applying a RF pulse induces a change in the distribution of spin states and this is detected as a changed net magnetization. When for example a $90^{\circ}$ $\mathrm{RF}$ pulse is applied, the $\mathrm{M}_{\mathrm{z}}$ magnetization disappears after excitation, a $\mathrm{M}_{\mathrm{xy}}$ magnetization is created and the spins will rotate (precess) about the z-axis. A short delay after excitation, the $\mathrm{M}_{\mathrm{z} 0}$ magnetization will be regained and the equilibrium state recovered. The process of returning to the ground state from the excited state is called relaxation ${ }^{30}$. 


\subsection{Relaxation}

The main relaxation processes that influence the magnetic resonance signal are those described by $\mathrm{T}_{1}$ and $\mathrm{T}_{2}$ relaxation. $\mathrm{T}_{1}$ is a time constant describing the process of $\mathrm{M}_{\mathrm{z}}$ returning to its equilibrium value $\left(\mathrm{M}_{\mathrm{z} 0}\right)$ and $\mathrm{T}_{1}$ is usually called the longitudinal time constant or the spin lattice relaxation time constant. This type of relaxation depends on the interaction between the hydrogen atom and fluctuating dipoles in its close environment. The longitudinal relaxation is expressed as a function of $\mathrm{T}_{1} \mathrm{by}^{32}$ :

$$
M_{\mathrm{z}}=M_{\mathrm{z} 0}\left(1-e^{-\mathrm{t} / \mathrm{T}} 1\right)
$$

where $t$ is the time. A schematic illustration of the recovery of the $M_{z}$ magnetization after an applied $90^{\circ}$ pulse is shown in Figure 3.2.
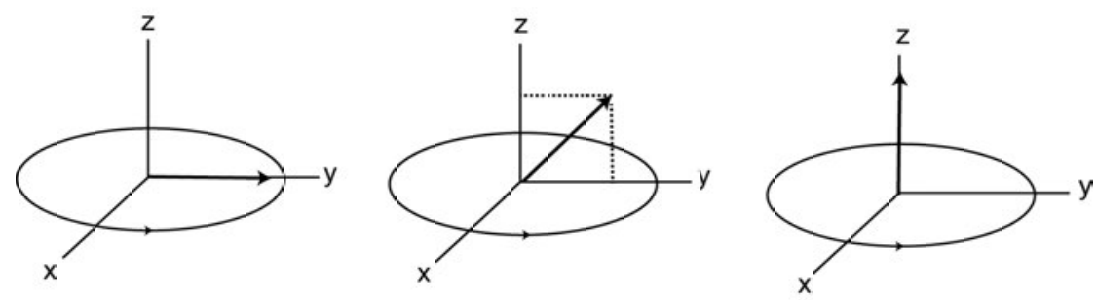

time

Figure 3.2 The longitudinal relaxation process characterized by $\mathrm{T}_{1}$.

$\mathrm{T}_{2}$ on the other hand is a time constant describing the process of $\mathrm{M}_{\mathrm{xy}}$ decay after excitation. $\mathrm{T}_{2}$, which is usually called the transverse relaxation time constant or the spinspin relaxation time constant, depends on the dephasing of precessing protons after excitation. Dephasing occurs as the spins experience small differences in the magnetic field and thus precess at slightly different frequencies. The $\mathrm{T}_{2}$ relaxation process is expressed by ${ }^{32}$ :

$$
M_{\mathrm{xy}}=M_{\mathrm{xy} 0} \mathrm{e}^{-\mathrm{t} / \mathrm{T}} 2
$$

where $t$ is time. A schematic illustration of the loss of phase coherence in the $x-y$ plane after an applied $90^{\circ}$ pulse is shown in Figure 3.3. 

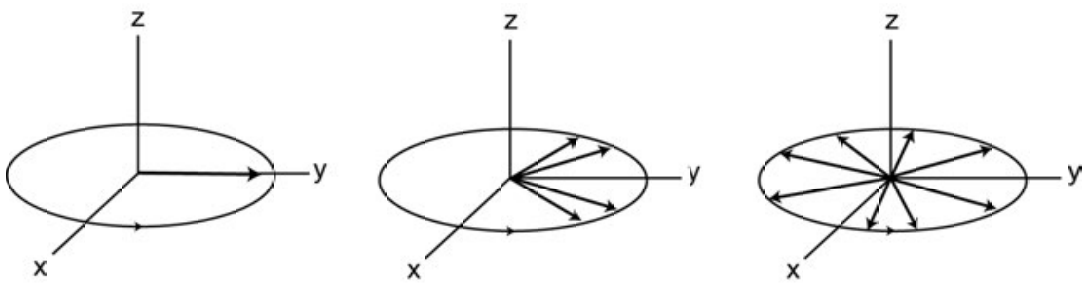

time

Figure 3.3 The transverse relaxation process characterized by $\mathrm{T}_{2}$.

It is clear from formula 3.2 and 3.3 that $\mathrm{M}_{\mathrm{z}}$ is a function increasing by time, which approaches $M_{z 0}$ for large $t$, whereas $M_{x y}$ is a function declining by time. If $t=T_{1}$ then $\mathrm{M}_{\mathrm{z}} \approx 0.63 \mathrm{M}_{\mathrm{z} 0}$ whereas if $\mathrm{t}=\mathrm{T}_{2}$ the transverse magnetization is decreased by a factor of $\mathrm{e}$ as can be observed in Figure 3.4. In this figure it is also obvious that the absolute shapes of these two functions are dependent on the specific $\mathrm{T}_{1}$ and $\mathrm{T}_{2}$ values.

$\mathrm{T}_{1}$ and $\mathrm{T}_{2}$ relaxation occur simultaneously but are still entirely independent of each other. Decay of transverse magnetization $\left(\mathrm{M}_{\mathrm{xy}}\right)$ is always faster as compared to the longitudinal magnetization $\mathrm{M}_{\mathrm{z}}$. This means that $\mathrm{T}_{2}$ is always less than or equal to the corresponding $\mathrm{T}_{1}$ time $^{32}$.
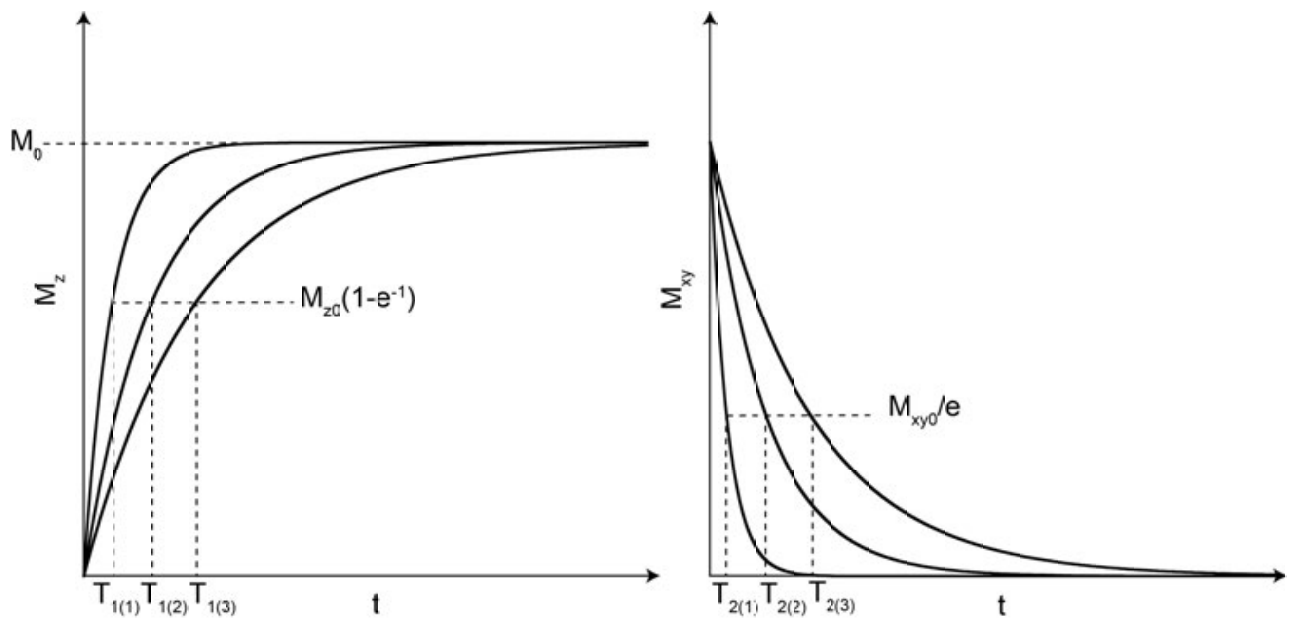

Figure 3.4 Graphs showing the recovering of the $\mathrm{M}_{\mathrm{z}}$ magnetization and the decay of the $\mathrm{M}_{\mathrm{xy}}$ magnetization. Graphs were plotted by using $\mathrm{T}_{1(1,2,3)}=500,1200$ and $2000 \mathrm{~ms}$ and $\mathrm{T}_{2(1,2,3)}=300$, 1000 and $1800 \mathrm{~ms}$. 


\subsection{How to measure $T_{1}$ and $T_{2}$}

A vast number of different pulse sequences are used in the excitation of spin states in MRI. In this thesis the $\mathrm{T}_{1}$ and $\mathrm{T}_{2}$ relaxation times have been monitored using an inversion recovery (IR) pulse sequence and a spin echo (SE) pulse sequence respectively. In the inversion recovery sequence, a $180^{\circ}$ pulse rotates the magnetization to the negative z-direction where after the recovery is monitored by studying the longitudinal magnetization at a number of different time delays (inversion times; TI) after excitation. A curve is mathematically fitted to the measured points and from this curve $\mathrm{T}_{1}$ is yielded.

In the spin echo sequence, the magnetization is flipped into the $\mathrm{x}-\mathrm{y}$ plane by a $90^{\circ}$ pulse. The spins start to dephase and the $x-y$ magnetization is decreases gradually. The spins are refocused by applying a $180^{\circ}$ pulse at a certain time point and a signal (echo) can be recorded at a time equal to the echo time (TE). $\mathrm{T}_{2}$ is calculated from a curve fitted to the magnitude of the transverse magnetization for different echo times.

\subsection{Image contrast and $T_{1}$ and $T_{2}$ weighing}

Contrast in magnetic resonance imaging is affected by several intrinsic and extrinsic factors. $\mathrm{T}_{1}, \mathrm{~T}_{2}$ and proton density are intrinsic factors whereas extrinsic ones are factors that can be changed in the measurement, as for example the already mentioned echo time (TE) and the repetition time (TR), which is the time in between the repeated units of pulses. The choice of repetition time and the echo time largely affect the signal intensity when using SE sequences, as illustrated by the following formula which is valid when TR $>\mathrm{TE}^{32}$ :

$$
S=\mathrm{k} \rho\left(1-e^{\frac{-T R}{T_{1}}}\right) e^{\frac{-T E}{T_{2}}}
$$

In this formula, $\mathrm{k}$ is proportionality constant and $\rho$ is the spin density in the sample. When choosing very long TR the $\mathrm{M}_{\mathrm{z}}$ magnetization recover entirely before the next excitation pulse is delivered, which implies that tissues with different $\mathrm{T}_{1}$ cannot be distinguished. When on the other hand choosing short $\mathrm{TR}$, a strong $\mathrm{T}_{1}$ effect can be achieved separating structures with different $\mathrm{T}_{1}$ in the image. The repetition time can thus be used to control the degree of $\mathrm{T}_{1}$-weighting. The degree of $\mathrm{T}_{2}$-weighting can similarly be controlled by the choice of TE. In general the usage of pulse sequences with long $\mathrm{TE}$ increases the ability to distinguish in between tissues having different $\mathrm{T}_{2}$ 
relaxation times. The optimal choice of TR and TE is though very much dependent on the specific tissue ${ }^{30}$.

\subsection{Contrast agents}

Image contrast can be enhanced by the use of contrast agents that shorten the relaxation times of protons. Contrast agents affect both $\mathrm{T}_{1}$ and $\mathrm{T}_{2}$, but often not to the same extent. Agents that primarily affect the $\mathrm{T}_{1}$ relaxation time (positive contrast agents) enhance the MRI signal, whereas agents that affect the $\mathrm{T}_{2}$ relaxation time (negative contrast agents) reduce the signal.

The relaxation rate is defined as the inverse of the relaxation time, i.e. $1 / \mathrm{T}_{1}$ and $1 / \mathrm{T}_{2}$ respectively. The ability of a contrast agent to affect the relaxation rate is represented by its relaxivity, $r_{1}$ or $r_{2}$ depending on if $T_{1}$ or $T_{2}$ is in focus. The relaxivity of a contrast agent can be calculated by plotting the inverted relaxation time as a function of the concentration of the contrast agent. A linear function is achieved with the slope of the line being the relaxivity $\left(\mathrm{mM}^{-1} \mathrm{~s}^{-1}\right)$ according to the formula ${ }^{33}$ :

$$
\frac{1}{T_{i}}=\left(\frac{1}{T_{i}}\right)_{d}+r_{i}[C A] \quad i=1,2
$$

where $[C A]$ represents the contrast agent concentration and $d$ stands for diamagnetic contribution (i.e. the solvent relaxation rate in absence of a contrast agent). Values of $r_{2} / r_{1}$ are often reported. Positive contrast agents usually have $r_{2} / r_{1}$ ratios in the range 12 whereas negative contrast agents can have ratios of 10 or more ${ }^{12}$.

The $r_{1}$ relaxivity is influenced by various parameters, among these the strength of the external field (B) and the electronic properties of the contrast agent metal ion. The electronic properties of the contrast agent are comprised of the magnitude of the magnetic dipole, which is characterized by the spin (S), and the correlation time concerning the electron spin relaxation $\left(\mathrm{T}_{1 \mathrm{e}, 2 \mathrm{e}}\right)$. Other chemically important parameters are the number of water molecules coordinated to the metal (q), their residence lifetime at the site $\left(\tau_{M}\right)$ and the rotating motion of the contrast agent complex $\left(\tau_{R}\right)$ as summarized in Figure 3.5. At 1.5 T field strengths, the rotational dynamics correlation time $\left(\tau_{R}\right)$ typically is more important than the electron spin relaxation and the shape, size and rigidity of the contrast agent thus greatly affect its efficiency.1,33 


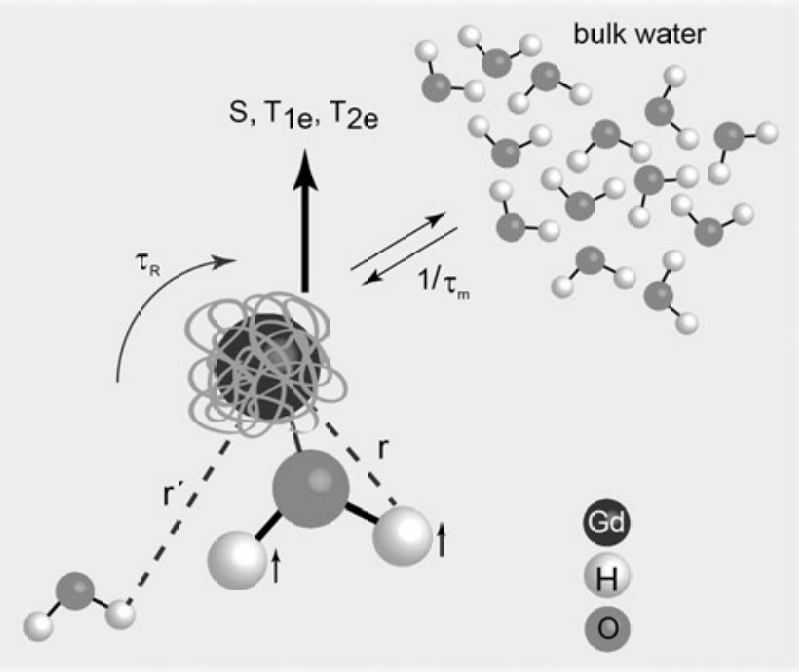

Figure 3.5 Molecular parameters influencing the $r_{1}$ relaxivity induced by a Gd contrast agent.

Contrast agents preferentially have a high q, a slow rotational dynamics and a short water residence life time to ensure an efficient water exchange and a high relaxivity 1 .

\subsection{Gadolinium based contrast agents}

Gadolinium complexes producing positive contrast represent the major part of clinically used contrast agents in MRI today. The main reason to the usage of gadolinium is, as mentioned earlier, the high magnetic moment as a consequence of 7 unpaired felectrons together with the symmetry of the electronic state efficiently affecting the water proton relaxation. Clinically available Gd based contrast agents are commonly built up by Gd ions chelated to an organic molecule hindering the free toxic ion to leak out into the body. One of the most well-known trademark is Magnevist $\mathbf{t}^{\circledR}$, in which the Gd ion is strongly coupled to diethylene triamine pentaacetic acid (DTPA), but several other chelates also exist. The specificity of the commercial Gd agents is low and the distribution of Gd-DTPA and its counterparts is more or less evenly throughout the extracellular space after intravenous injection. 
A lot of effort has been made to increase the sensitivity of MRI by optimizing the molecular parameters of contrast agents. This can for example be done by linking several Gd complexes together to increase the rotational dynamics and increase the number of Gd atoms per contrast agent molecule ${ }^{1}$. An alternative approach is to accumulate numerous Gd atoms in or on a dense nanoparticle. The main reasons to design nanoparticle contrast agents are i) the number of Gd per particle is very high, especially for crystalline Gd nanoparticles, and ii) the high molecular weight slows down the rotational motion and thereby increases the rotational correlation time ${ }^{23}$. The large surface area is furthermore beneficial in the controlled addition of capping, i.e. the surface modification for fluorescent and targeting purposes.

Numerous examples of nanoparticle carriers of gadolinium chelates have been reported in the literature. They are usually composed of silica ${ }^{34}$, quantum $\operatorname{dots}^{35}$ or gold nanoparticles ${ }^{36}$ often in purpose to combine the contrast agent properties with fluorescent properties or, as in the case of gold particles, therapy of cancer cells by means of X-ray. Most of the clinically approved Gd chelates contains one or several carboxylic acid units and can thus easily provide amine functionalized particles with paramagnetic properties ${ }^{23}$. Considerable effort has also been made in the studies of organic carriers of gadolinium, as in the case of metal organic frameworks ${ }^{37}$ (MOFs), micelles ${ }^{38}$, dendrimers ${ }^{39}$ etc, all of which are characterized by an increased contrast agent molecular weight as well as several Gd ions per contrast agent. In comparison though, inorganic nanoparticles have even higher Gd payload per particle. Intense research on Gd containing inorganic nanoparticles has been in progress over the last decade and among the systems studied gadolinium fluoride ${ }^{40}$, gadolinium phosphate ${ }^{41}$, gadolinium carbonate ${ }^{42}$ and sodium gadolinium fluoride ${ }^{43}$ can be mentioned. The major part of organic Gd based carriers as well as the mentioned inorganic systems suffer from the drawback of having a rather considerable size well above the limit for renal clearance which is about 6-10 $\mathrm{nm}^{44}$. Sub $10 \mathrm{~nm}$ nanoparticles studied for contrast agents for MRI has therefore mainly been focused on gadolinium oxide $\left(\mathrm{Gd}_{2} \mathrm{O}_{3}\right)$. The core size of crystalline $\mathrm{Gd}_{2} \mathrm{O}_{3}$ nanoparticles, often synthesized within the polyol route, are usually around 3-5 $\mathrm{nm}$. The small size optimizes the number of surface atoms and makes it possible to avoid uptake by the reticuloendothelial system (RES) ${ }^{44}$. Chemical modification is commonly performed using for instance poly ethylene glycols ${ }^{45}$, carboxylic acids ${ }^{46}$ or silanes ${ }^{47}$ in purpose to produce water soluble nanoparticle based contrast agents. 


\subsection{Requirements for gadolinium based contrast agents}

The requirements on a Gd based contrast agent for MRI is dependent on the final purpose but ultimately for human in vivo usage, a number of safety prerequisites must be fulfilled. Among these is the stability, including lack of gadolinium ion loss and aggregation, of the contrast agent in environments having different $\mathrm{pH}$ values and temperatures. High solubility and biocompatibility are moreover very important. It is essential to avoid high doses to reduce the risk of biological side effects. The contrast enhancement should therefore be considerable, even at low concentrations of the contrast agent, to certify low doses. For optimized MR signals, the rotational dynamics should be slow, the water exchange fast and the hydration number high ${ }^{1}$.

\subsection{MRI in this thesis}

The magnetic resonance images presented in Paper I, Paper II, Paper V and Paper VI and the relaxivity data presented in Paper I and Paper II were achieved using a Philips $1.5 \mathrm{~T}$ whole body scanner (room temperature) at the Center for Medical Image Science and Visualization (CMIV) at Linköping University. The remaining relaxivity data presented in paper Paper IV to Paper VII were collected using a bench-top NMR analyzer $\left(1.41 \mathrm{~T}, 40{ }^{\circ} \mathrm{C}\right)$. 


\section{CHAPTER 4}

\section{Nanoparticle synthesis and characterization}

This chapter is devoted to a description of the synthesis methods used in the production and analysis of nanoparticles within the frame of this thesis. In addition, the main experimental techniques for characterization of the size, shape and crystal structure of the nanoparticle cores are presented.

\subsection{Synthesis routes}

A wide range of strategies for the synthesis of nanoparticles to control the growth, size and stability of the achieved product have been reported in the literature ${ }^{48}$. In this thesis, the main work is built on three synthesis routes, as described below and schematically illustrated in Figure 4.1.

\subsubsection{Polyol method}

The so called polyol method was utilized in the production of nanoparticles in Paper I and Paper II. This method was firstly studied by Fievet et al for synthesis of submicrometer transition metal particles ${ }^{49}$. Later, in 2003, a similar method was introduced by Bazzi et al in the synthesis of lanthanide oxides ${ }^{50}$. The polyol process is based on the direct precipitation of metal salts in a high boiling point solvent, such as for instance diethylene glycol (DEG). $\mathrm{NaOH}$ is added to induce particle formation in the synthesis which usually is performed at a temperature of $180-220{ }^{\circ} \mathrm{C}$ for at least 4 hours. 
In most cases the polyol solvent DEG acts as a capping agent stabilizing the nanoparticle core, but also other capping agents can be added during the synthesis. Söderlind et al for example studied the functionalization of $\mathrm{Gd}_{2} \mathrm{O}_{3}$ with a number of organic acids, among them citric acid and oleic acid ${ }^{46 b}$. The main reasons to introduce long-chained hydrophobic carboxylic acids on the nanoparticle surface are to further stabilize the particle core and to increase the solubility in non-polar solvents. Such nanoparticles are though, without further treatment, unsuitable for MRI as a consequence of the very low water solubility. Substitution reactions can be performed to exchange a capping molecule for another, as shown by Zhou et al on gadolinium iron oxide nanoparticles and Hou et al on $\mathrm{NaGdF}_{4}$ nanoparticles 43,51 .

Purification of as-synthesized colloidal $\mathrm{Gd}_{2} \mathrm{O}_{3}$ suspensions involves in most cases dialysis. Gd ions and precursor residues are removed by means of dialysis against DEG. Removal of DEG is usually performed through dialysis against water. The high viscosity of the DEG solvent and the low stability of bare $\mathrm{Gd}_{2} \mathrm{O}_{3}$ nanoparticles however complicate a total solvent exchange and a small amount of DEG molecules remain in the nanoparticle sample after dialysis. Presence of DEG molecules makes it difficult to modify the nanoparticle surface. DEG might also induce negative results in cell studies as toxic effects on for example neutrophil granulocytes have been verified ${ }^{52}$.

\subsubsection{Combustion method}

In Paper III in this thesis work $\left(\mathrm{Gd}_{\mathrm{x}} \mathrm{Y}_{1-\mathrm{x}}\right)_{2} \mathrm{O}_{3} \quad(0 \leq \mathrm{x} \leq 1)$ nanoparticles were synthesized via the combustion method. This method has previously been utilized in the production of $\mathrm{Y}_{2} \mathrm{O}_{3}$ :Eu nanoparticles, as described by Zhang et al ${ }^{53}$. In short, rare earth nitrates and the amino acid glycine are dissolved in water and heated on a hot plate. The water evaporates and upon further heating the mixture self-ignites and a dry fine nanopowder is produced. In the case of $\mathrm{Gd}$ the reaction pathway is suggested to be $\mathrm{b}^{53}$

$$
6 \mathrm{Gd}\left(\mathrm{NO}_{3}\right)_{3}+10 \mathrm{NH}_{2} \mathrm{CH}_{2} \mathrm{COOH}+18 \mathrm{O}_{2} \rightarrow 3 \mathrm{Gd}_{2} \mathrm{O}_{3}+20 \mathrm{CO}_{2}+5 \mathrm{~N}_{2}+25 \mathrm{H}_{2} \mathrm{O}+18 \mathrm{NO}_{2}
$$

Centrifuge washing is commonly performed to remove precursor residues. Nanoparticles synthesized via the combustion method are highly crystalline, but the absence of molecular capping induces highly aggregated particles. The nanoparticles are not water soluble and as uncapped thus not suitable for MRI studies. 


\subsubsection{Precipitation method}

In Paper IV-Paper VII, a short time low temperature synthesis route for production of $\mathrm{Gd}_{2} \mathrm{O}_{3}$, Gd decorated $\mathrm{ZnO}$ and $\mathrm{MnO}_{\mathrm{x}}(1 \leq \mathrm{x} \leq 2)$ nanoparticles is reported. This synthesis route has previously been reported to produce fine $\mathrm{ZnO}$ and $\mathrm{ZnO}: \mathrm{MgO}$ nanoparticles but it has not earlier been used for rare earth gadolinium oxides ${ }^{54}$. Metal acetate salts are dissolved in dimethylsulfoxide (DMSO) and particle formation is induced upon dropwise adding of tetramethylammonium hydroxide (TMAH). TMAH is a strong base and the $\mathrm{pH}$ in newly synthesized nanoparticle solutions is approximately 14 . Purification, which is done by centrifuge washing to remove free ion precursors, TMAH and DMSO, neutralizes the $\mathrm{pH}$ to at about seven in water based solutions. In contrast to nanoparticles obtained from combustion synthesis, the particles obtained via this route are well dispersed with a low degree of aggregation. Acetate groups are covering the particle surface increasing the hydrophilicity and the solubility in water. The main benefits with the method are the short reaction time and the low temperature in the synthesis.

COMBUSTION SYNTHESIS

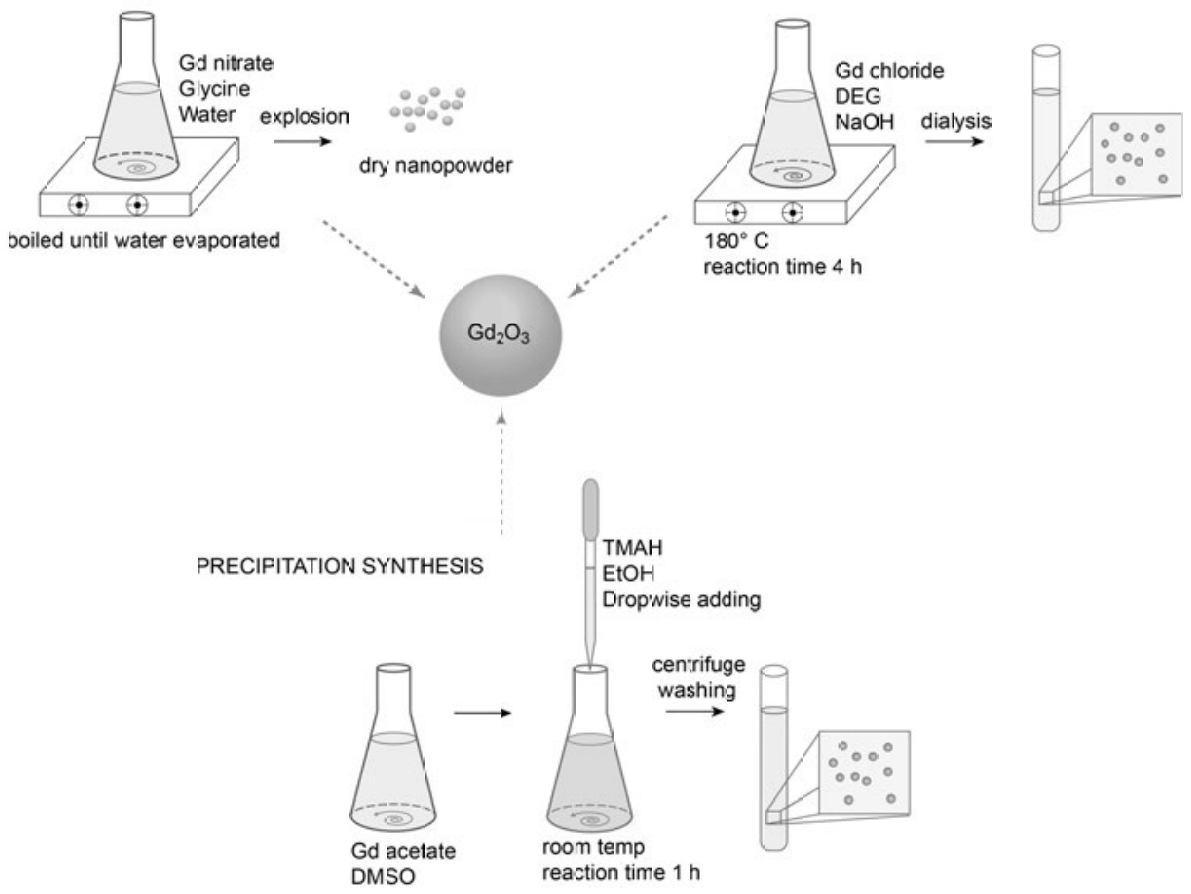

Figure 4.1 Overview of the main synthesis routes explored in this thesis 


\subsubsection{Other methods}

In addition to the three main synthesis routes presented above, $\mathrm{Gd}_{2} \mathrm{O}_{3}$ nanoparticles can be synthesized by several other methods ${ }^{48}$. Two of these methods are hereby shortly discussed.

\section{Infiltration method}

Mesopourous silica (SBA-15) has been used as solid templates in the synthesis of $\mathrm{Gd}_{2} \mathrm{O}_{3}$ nanoparticles, as presented by Ballem et $\mathrm{al}^{55}$. Infiltration of $\mathrm{Gd}\left(\mathrm{NO}_{3}\right)_{3}$ into the pores of SBA-15 is followed by thermal treatment to form the desired product. The silica framework is dissolved by $\mathrm{NaOH}$ treatment and the nanoparticles are collected and washed by centrifugation. The idea is to let the pores in the silica framework function as a solid template to restrict the growth and size of the nanoparticles. Monodisperse samples are expected. Using SBA-15 templates to produce $\mathrm{Gd}_{2} \mathrm{O}_{3}$ nanoparticles was performed also within the scope of this thesis, with the conclusion that infiltration degree is very low and that less than $5 \%$ yield is achieved after synthesis and washing. The method is still quite interesting if the infiltration efficiency can be increased.

\section{Microwave method}

Rare earth sesquioxides have furthermore been produced using microwave assisted techniques. Oleyl amine and oleic acid were used as capping agent when Panda et al produced a range of different shapes of nano sized rare earth sesquioxides ${ }^{56}$. The relative ratio of the oleyl amine and oleic acid and the reaction time was shown to have a great impact on the size and shape of the nanostructures and rod-sphere- and plate shaped structures were synthesized. As sub $10 \mathrm{~nm}$ sized spherical $\mathrm{Gd}_{2} \mathrm{O}_{3}$ nanoparticles were formed with a molar ratio of 1:17:17 of metal precursor/oleic acid/ oleyl amine a similar method was briefly explored also within the frame of this thesis work. In spite of the hydrophobic character of the end product and the challenge of resolving the very small particles in TEM measurements, for all reaction times and relative ratios studied, further investigations would be valuable, as microwave syntheses are characterized by short reaction times and facile operation. A transmission electron microscopy image of nanoparticles synthesized by the microwave method is presented in Figure 4.2. The electron microscopy image confirms the presence of well separated nanoparticles sized $\sim 2 \mathrm{~nm}$. 


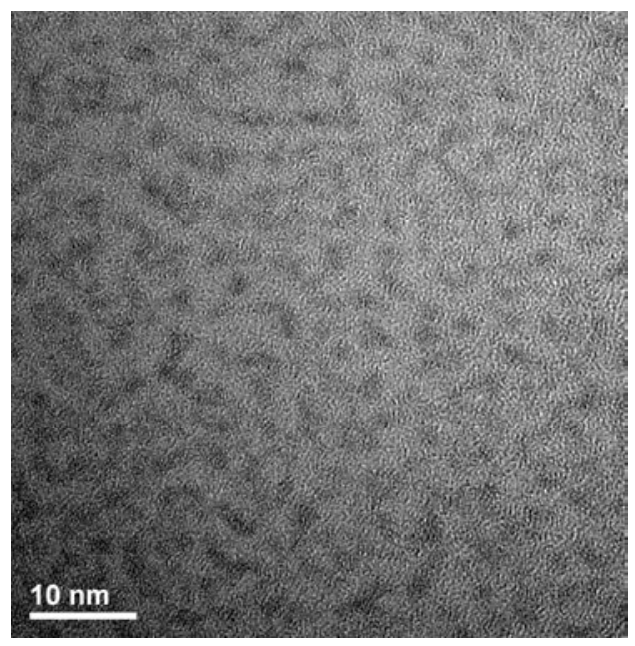

Figure 4.2 TEM image of oleyl- and oleic acid capped Gd based nanoparticles synthesized using a microwave route.

\subsection{Experimental techniques to study the nanoparticle core}

The size, shape, and crystal structure of nanoparticles are commonly studied by means of transmission electron microscopy (TEM) and X-ray diffraction (XRD). The hydrodynamic radius, which is calculated from the diffusional properties of the nanoparticles in a solvent, is often studied by means of dynamic light scattering (DLS). Basic theory about these techniques as well as fluorescence spectroscopy and electron paramagnetic resonance (EPR) is found below.

\subsubsection{X-Ray Diffraction}

In X-ray diffraction electromagnetic radiation with a wavelength in the order of $1 \AA$ is elastically scattered by matter. When X-rays interact in this way with solid systems with periodic arrangement of the atoms, a diffraction pattern is achieved as a consequence of interference between light reflected from different crystal planes. The diffraction pattern holds information regarding the crystal structure in the material. The fundamental equation in X-ray diffraction is Bragg's law ${ }^{57}$ :

$$
2 d_{h k l} \sin \theta=n \lambda
$$

where $d_{h k l}$ is the distance between two atomic planes (indexed $h, k, l$ ), $\theta$ is the angle of incidence between a plane wave of wavelength $\lambda$ and the atomic planes and $n$ is the 
order of the diffraction. Bragg's law can easily be derived from Figure 4.3 by using geometrical aspects and considering the path length difference between the two X-ray beams.

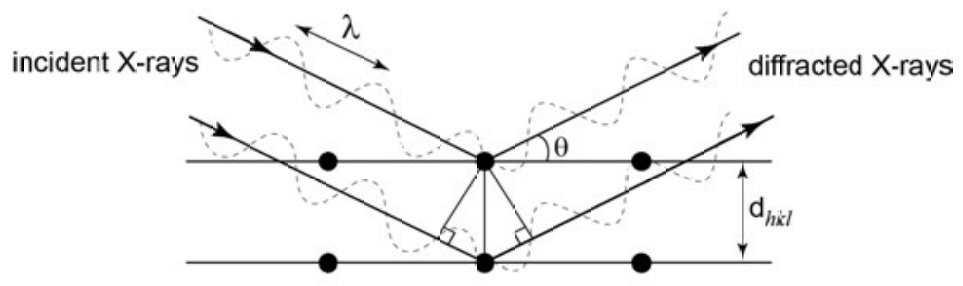

Figure 4.3 Schematic illustration of X-ray diffraction. Constructive interference between the two diffracted beams is achieved when Bragg's law is fulfilled.

Material characterization by means of X-ray diffraction enables identification of unknown material. Furthermore, sample purity can be studied and lattice parameters determined. In materials consisting of very small crystallites and few planes, peak broadening occurs as a consequence of non-destructive interference for angles that differ only slightly from the Bragg angle. This broadening of the XRD peaks can be used to determine the crystallite size by using the Scherrer formula ${ }^{58}$ :

$$
t=\frac{0.9 \lambda}{\sqrt{B_{M}^{2}-B_{S}^{2}} \cos \theta}
$$

in which $t$ is the estimated crystal size, $\lambda$ is the $\mathrm{X}$-ray wavelength, $\theta$ is the Bragg angle and $B_{M}$ and $B_{S}$ is the full width half maxima in radians of corresponding diffraction peaks in the sample and a large crystalline grain standard respectively.

\subsubsection{Transmission Electron Microscopy}

The setup of a transmission electron microscope (TEM) is similar to the setup of a general light microscope with the glass lenses exchanged to magnetic lenses and the light source exchanged to an electron source. The main benefit historically of using ionization radiation with electrons instead of light is higher resolution but also the presence of numerous secondary processes in progress when electrons interact with the 
sample. In TEM a parallel beam of high energy electrons (100 keV-400 keV) in vacuum is sent towards a thin sample. Electrons are inelastically or elastically scattered or transmitted through the sample. Secondary processes give rise to X-rays or Auger electrons being emitted from the sample, as shown in Figure 4.459.

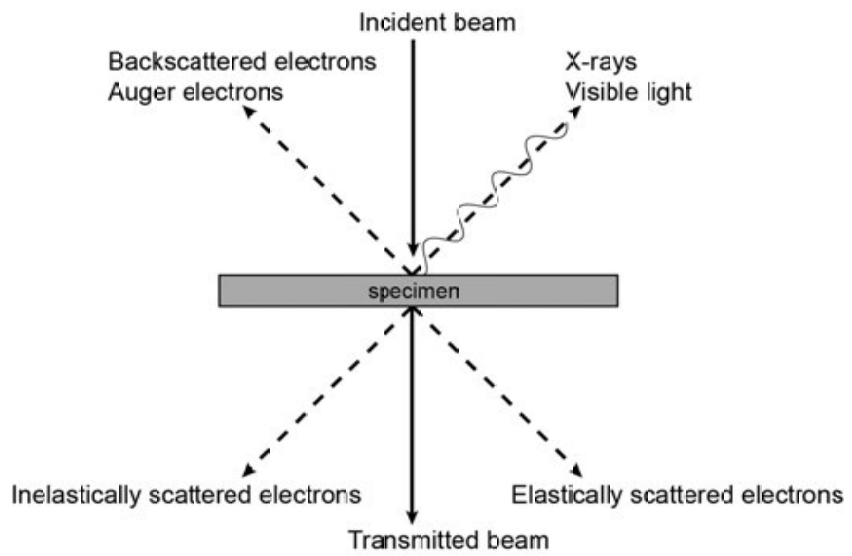

Figure 4.4 Schematic illustrating some signals that are generated from the interaction of an electron beam with a thin specimen.

The main applications of TEM are diffraction studies and imaging. Beam path diagrams for imaging and diffraction modes are illustrated in Figure 4.5. In electron diffraction, a selected area electron diffraction aperture (SAED) is used to get the diffraction pattern of a small part of the sample. The diffraction pattern can be observed as a regular array of spots or rings comprising information regarding the crystal structure of the sample. 


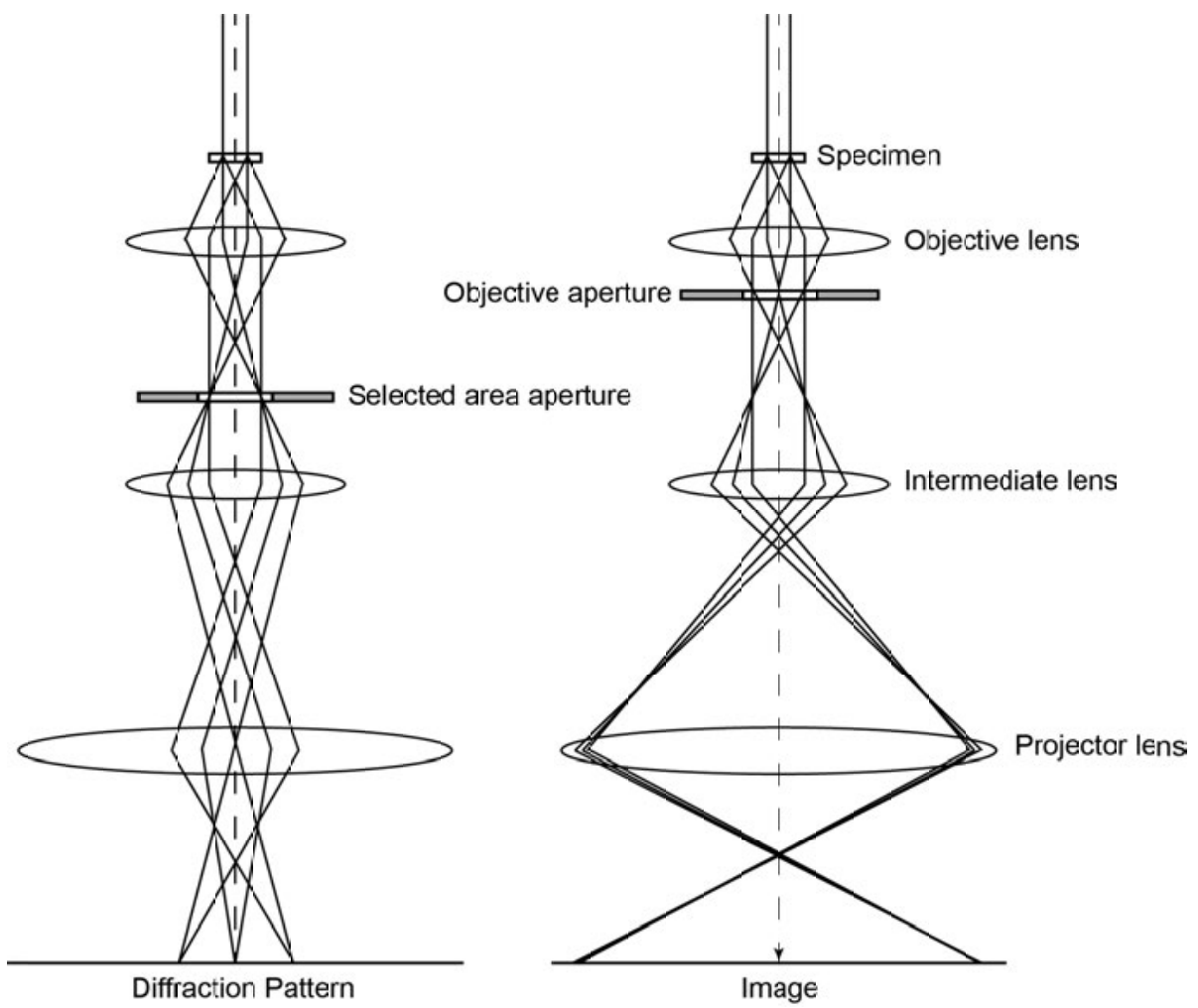

Figure 4.5 Beam path diagrams for diffraction and imaging modes in TEM. Adopted from Williams and Carter ${ }^{59}$.

Bragg's law applies to both X-ray diffraction and electron diffraction. This law states that the scattering angle is dependent of the wavelength according to $\sin \theta=\lambda / 2 \mathrm{~d}$. The electron wavelength in TEM is very short $(0.025 \AA$ for $200 \mathrm{kV}$ accelerating voltage) and consequently the scattering angle in electron microscopy typically is very small $\left(<2^{0}\right)^{60}$.

The distances between atomic planes in a crystal specimen can be calculated from an electron diffraction pattern using the fundamental formula

$$
d_{h k l}=\frac{L \lambda}{r_{h k l}}
$$

where $L$ is the length of the camera, $\lambda$ is the wavelength of the electrons, $r_{h k l}$ is the spacing between the diffraction spots due to the direct and the diffracted beam 
respectively and $\mathrm{d}$ is the distance between the atomic planes with indices $h k^{59-60}$. This relationship can be understood by studying the geometries illustrated in Figure 4.6. For a defined setup, the $L \lambda$ value is constant; which implies that $d_{h k l} r_{h k l}$ is a constant value for all $h k l$. The ratio of two $r$ values hence agrees with the inverted ratio of the corresponding d values, a fact that has been used to verify the crystal structure of the nanocrystals in this thesis.

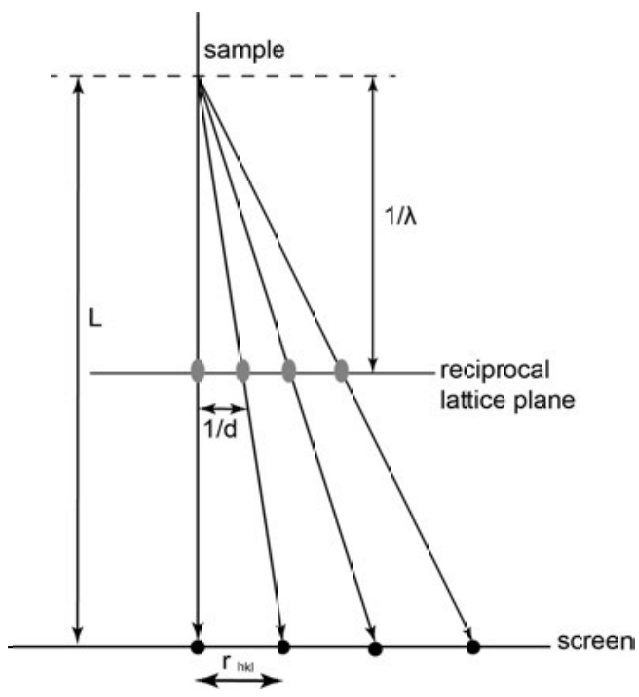

Figure 4.6 Illustration of the geometry of electron diffraction. Adopted from Zou et al ${ }^{60}$.

Image contrast in TEM is for instance dependent on density variations in the sample. High density areas scatter more electrons as compared to low density areas and intensity differences are thus given producing image contrast.

\subsubsection{Dynamic Light Scattering}

Dynamic light scattering (DLS) ${ }^{61}$, also known as photon correlation spectroscopy, is used in the determination of the average size and size distribution of sub-micrometer particles in a suspension. The technique is based upon the Rayleigh scattering of light for particles in diffusive random motion. By using a coherent and monochromatic light source, it is possible to monitor this Brownian motion with a very sensitive detector, as schematically described in Figure 4.7. Temporal variations of the intensity, $I(t)$, of the 
scattered light are studied by means of autocorrelation. The autocorrelation function $(G(\tau))$ is the average value of the product of the scattered intensity $(I)$ at time $t$ and at time $(t+\tau)$, that is at a time delay $\tau$ later. $G(\tau)$ is a decaying function of time with a maximum value of unity or close to unity for $\tau$ approaching zero. The decay rate $(\Gamma)$ of $G(\tau)$ is coupled to the translational diffusion coefficient $(D)$ by

$$
\Gamma=\mathrm{D} \boldsymbol{q}^{2}
$$

where $\boldsymbol{q}$ is defined as the scattering vector, i.e. the difference between the incident and the scattered wave vectors. $D$, which holds information about the average displacement for a Brownian motion, is the quantity determined in DLS. As small rapidly diffusing particles produce fast fluctuations in opposite to larger particles and aggregates which yield slow fluctuations, diffusion is coupled to the nanoparticle size. The time at which the significant decay of $G(\tau)$ starts hence carries information about the mean size of the particles and the slope of the function carries information about size distribution. To relate the diffusion quantity to the nanoparticle size, the Stokes Einstein relation is commonly used:

$$
D=\frac{k_{B} T}{3 \pi \eta d}
$$

where $D$ is the translational diffusion coefficient, $k_{B}$ is the Boltzmann constant, $T$ is the absolute temperature, $\eta$ is the viscosity of the solvent and $d$ is the hydrodynamic diameter $61 \mathrm{~b}$. Formula 4.5 is valid only in cases of non-interacting spherically shaped particles and using the model of having spherical particles having non-spherical particles affects the hydrodynamic size. Particle interaction increases with concentration, as do multiple scattering, and DLS measurements should therefore be performed with very dilute suspensions. In addition to the usage of the above mentioned Stokes-Einstein relation, data weighting is commonly performed in DLS. This is due to the fact that the intensity $(I)$ of the scattered light is highly dependent on the particle diameter $(d)$ according to ${ }^{62}$ :

$$
I \propto d^{6}
$$

For polydisperse nanoparticle suspensions, data weighting thus enable the user to compensate for the high scattering of even very few large particles and to get a distribution in which the intensity is proportional to the number of particles of a certain size. The major benefit of the DLS technique is that it is fast as the size and size distribution of a nanoparticle suspension can be determined in a few minutes. The hydrodynamic diameter can furthermore be studied as a function of solvent; hence nanoparticle stability in various chemical environments can be evaluated. As observed 
in formula 4.5, temperature control and knowledge about the precise solvent viscosity are of major importance to correctly interpret the data.

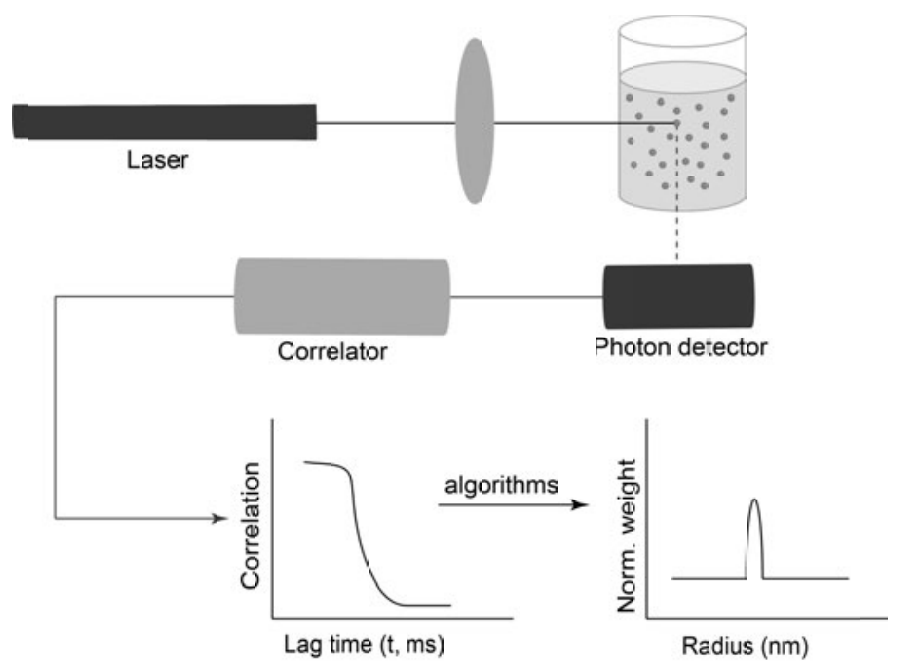

Figure 4.7 Schematic illustrating the set up in dynamic light scattering.

\subsubsection{Fluorescence Spectroscopy}

In fluorescence spectroscopy the light emission of a fluorescent nanoparticle or fluorophore is studied. Fluorescence emission is initiated by photon absorption and excitation of electrons from ground state $\left(\mathrm{S}_{0}\right)$ to an excited state $\left(\mathrm{S}_{1}\right)$ as illustrated in Figure 4.8. The deexcitation is comprised of several parallel pathways including nonradiative energy loss as vibration and thermal energy transfer and radiative energy loss, i.e. fluorescence. In contrast to the more long-lived phosphorescence emission, fluorescence emission life times are usually within the range picoseconds to nanoseconds and the short time span makes continuously excitation necessary to observe emission63. Emission wavelengths are always longer than the excitation wavelength, as a consequence of the non-radiative processes progressing after excitation. The difference between the excitation and emission wavelengths is characterized by the so called Stokes shift (Figure 4.8). Photoluminescent materials are often characterized by a property called quantum yield having a value in between zero and one. The quantum yield is a measure of the efficiency of the fluorescent process and 
is based on the ratio between the number of photons emitted and absorbed. A reference molecule with known quantum yield is needed for comparison in the calculation. In Paper VI quinine sulphate was used in the calculation having a quantum yield of $0.55^{63}$. Rhodamine 123 used in Paper II is a highly efficient fluorophore having a quantum yield of about $0.9^{64}$.
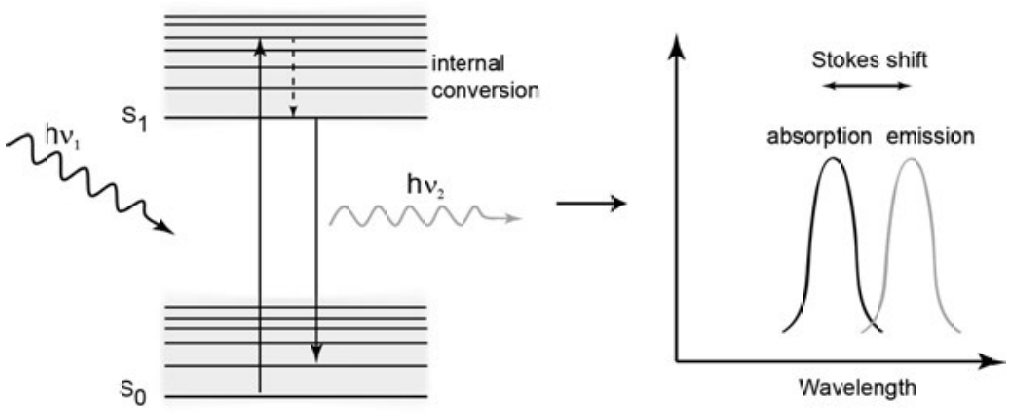

Figure 4.8 Schematic illustrating the exitation and emission events in a flourescence process and the corresponding absorption and emission spectra.

\subsubsection{Electron Paramagnetic Resonance}

In electron paramagnetic resonance spectroscopy (EPR) materials with unpaired electrons are studied ${ }^{65}$. Similar to hydrogen nuclei in MRI, electrons behave as small bar magnets and align parallel or anti-parallel with an applied external magnetic field. The energy difference between these two states increases linearly with the strength of the applied field and the energy needed to excite a state from the lower to the higher level (resonance condition) hence is dependent on the field strength. By sweeping the magnetic field strength and simultaneously recording the energy absorption of electromagnetic radiation sent towards the sample, it can be found at what condition the resonance condition is fulfilled (field for resonance). The electromagnetic radiation used in EPR is in the microwave range, and the result is presented in an EPR spectrum commonly displaying the first derivative of the EPR signal intensity (Absorbance) as a function of the magnetic field. The line width and line shape in an EPR spectrum is affected by e.g. hyperfine interactions, i.e. interactions between the electrons and nearby 
nuclei having a magnetic moment, and electron-electron interactions. These interactions affect the resonance condition and the broadening of the EPR line width and line shape as additional energy states are introduced. EPR is used in various applications when studying radicals or paramagnetic materials. In Paper III EPR was used to evaluate if dilution of paramagnetic $\mathrm{Gd}_{2} \mathrm{O}_{3}$ nanoparticles with diamagnetic yttrium atoms affected the line width of the EPR spectra. The reason to do this is that changes in line broadening can be interpreted as changes in the electronic relaxation time of the gadolinium electrons. 


\section{CHAPTER 5}

\section{Surface modification of nanoparticles}

Non-coated metal oxide nanoparticles are prone to aggregate into large nanoparticle clusters and most often they are inherently insoluble in water. Transferring them to water phase is mainly done by introducing hydrophilic molecular groups on the nanoparticle surface. By doing so the small nanoparticles are stabilized and kept separated from each other. Through further coupling steps the nanoparticle abilities can be expanded to include even fluorescent or targeting properties.

\subsection{Strategies to modify nanoparticle surfaces}

The directed capping of nanoparticle surfaces can be reached through a wide range of strategies. Capping molecules can be introduced in the nanoparticle synthesis or to synthesized and washed nanoparticle samples. The choice and amount of capping molecules have a major impact on the physical and chemical nanoparticle properties. The defect related fluorescence of $\mathrm{ZnO}$ nanoparticles is for example affected by the amount of surface oriented Gd acetate, as shown in Paper VI. The hydrophilicity, as well as the biocompatibility, is furthermore mainly determined by the outermost layer of the particles. Surface modification is hence of major importance in the development of a nanoparticle based contrast agent.

\subsubsection{In situ organic capping}

Nanoparticle surface capping can, as mentioned, be introduced already in the synthesis step. In Paper I and Paper II the $\mathrm{Gd}_{2} \mathrm{O}_{3}$ nanoparticles are covered with diethylene glycol 
molecules being part of the synthesis solvent. In Paper IV, Paper V and Paper VI precursor acetate groups similarly stabilize the $\mathrm{Gd}_{2} \mathrm{O}_{3}$ and $\mathrm{ZnO}: \mathrm{Gd}_{\mathrm{x}}$ nanoparticles. In general, long hydrophobic chains as for instance oleic acid and/or oleyl amine frequently are used in synthesis routes to stabilize metal oxide nanoparticles ${ }^{46 \mathrm{~b},} 66$. These particles are very hydrophobic and with no further treatment they are not suitable as contrast agents for MRI. The amount of surfactant molecules added in the synthesis step has been shown to have a major impact on the nanoparticle size and shape $56,66 \mathrm{~b}, 67$. The optimization of in situ surface modification is hence highly dependent on the wanted end product. It is moreover a multifactor related issue including parameters as choice of molecule, reaction time, solvent, $\mathrm{pH}$, temperature etc.

\subsubsection{Exchange reactions}

In cases when surface capping is passively or actively introduced within the synthesis, ligand exchange reactions are sometimes in question to introduce new properties to the nanoparticles. Ligand exchange can be performed already in the end of synthesis, as in the case of citric acid capped $\mathrm{Gd}_{2} \mathrm{O}_{3}$ described by Söderlind et al, or with as-synthesized nanoparticles ${ }^{46 \mathrm{~b}}$. The displacement of the original capping layer is achieved by introducing an excess of ligands. In most cases these ligands bind stronger than the exchanged molecules ${ }^{68}$. Post synthesis ligand exchange of noble metal nanoparticles has, as reviewed by $\mathrm{Wu}$ et al, shown to be very successful, especially the self-assembly of thiols on gold nanoparticles. Ligand exchange reactions on metal oxide nanoparticles are on the other hand less common but similar pathways to increase the hydrophilicity of iron oxide nanoparticles have quite recently been reported by several groups ${ }^{69}$. Zhou et al furthermore present a study in which hybrid gadolinium iron nanoparticles covered with oleic acid and oleyl amine are transferred to water phase through exchange reaction with zwitterionic dopamine sulphate molecules ${ }^{51}$. They claim that successful exchange relied on the stronger binding of the dopamine moiety as compared to the amine or carboxyl groups of oleic acid and oleyl amine. Similar reports on pure gadolinium oxide are very rare, most likely as a consequence of very few groups working within this field.

\subsubsection{Silanes for nanoparticle stabilization}

In many cases organosilanes are used as stabilizers in the surface modification of nanoparticles. Among the most common used molecules are the 3-mercaptopropyl trimetoxy silane (MPTS), 3-aminopropyl triethoxy silane (APTES) and tetraethylortho 
silicate (TEOS), which all are presented in Figure 5.1. Silanization of nanoparticles is dependent on the presence of $-\mathrm{OH}$ groups of the nanoparticle surface as these are central in the formation of the silicon-oxygen-metal bonds through condensation reaction ${ }^{70}$. Presence of water induces polymerization between the silane molecules and the formation of Si-O-Si bonds which might introduce further stabilizing effects ${ }^{71}$. Due to this process, the capping procedure must be optimized to avoid too severe aggregation among the nanoparticles. The covalent character of the silane-oxygen bond ensures a stable attachment to the nanoparticle ${ }^{72}$. Other benefits of using silanes are the low price and the readily availability of silanes with different functional groups facilitating further nanoparticle modification.

In Paper II MPTS was used in the surface modification of $\mathrm{Gd}_{2} \mathrm{O}_{3}$ nanoparticles. Silanization of $\mathrm{Gd}_{2} \mathrm{O}_{3}$ nanoparticles is also reported by a few other groups ${ }^{45}$ a, 73 . The main work within the field is performed by the group of Tillement, and has been focused on the functionalization of $\mathrm{Gd}_{2} \mathrm{O}_{3}$ nanoparticles with a polysiloxane layer composed of TEOS and APTES and PEG ${ }^{47}$. In contrast to MPTS and APTES, the molecular structure of the TEOS makes it prone to polymerize in all directions. The amino group of APTES enriches the nanosystem with further coupling capabilities and the degree of the polymerization is strictly controlled by the amount of silane precursors. The contrast agent water accessibility in MRI is likely decreased as a consequence of the relatively thick polysiloxane layer and the relaxivites reported for their GadoSiPEG are lower than the extensively dialyzed PEGylated $\mathrm{Gd}_{2} \mathrm{O}_{3}$ in Paper II ${ }^{23,45 a}$.

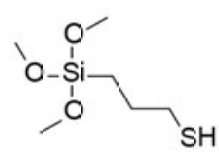

MPTS

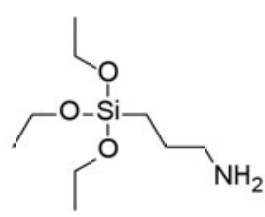

APTES

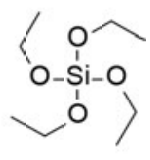

TEOS

Figure 5.1 The molecular structure of the 3-mercaptopropyl trimetoxy silane (MPTS), 3-aminopropyl triethoxy silane (APTES) and the tetraethylortho silicate (TEOS).

\subsubsection{Carboxylic acids for nanoparticle stabilization}

Carboxylic acids (R-COOH) are frequently used in surface modification of metal oxide nanoparticles. In particular oleic acids and citric acid etc. are used within the synthesis 
route, to ensure stable colloidal suspensions and high solubility in organic solvents. PEGacids are used to increase the biocompatibility and water solubility of the particles. Faucher et al have for example modified $\mathrm{Gd}_{2} \mathrm{O}_{3}$ nanoparticles with a PEG di-acid within the synthesis step ${ }^{74}$. Post synthesis modification with PEGs is more common, due to the high price of PEGs. In Paper V, a novel self-designed conjugated carboxylate molecule containing multi(ethylene glycol) groups was used in the modification of $\mathrm{Gd}_{2} \mathrm{O}_{3}$. Nanoparticle surface capping using this molecule was shown to increase the water solubility as well as the stability of the colloidal suspension.

The carboxylic acids are present as negatively charged carboxylate ions (R-COO-), at $\mathrm{pH}$ lower than the pKa. The negative charge facilitates the chemisorption to the nanoparticle metal ions. The strength of the binding is affected by the choice of metal ion and the way of coordination. Bidentate, bridging and unidentate coordination forms are possible as well as a more ionic character as further discussed in the section about infrared spectroscopy (5.4.1).

\subsubsection{Phosphonates for nanoparticle stabilization}

Among the benefits of using phosphonates $\left(\mathrm{R}-\mathrm{PO}(\mathrm{OH})_{2}\right)$ in the nanoparticle surface modification is the multidentate character of the ligand to particle interaction. The possibility of bi- or tridentate binding of phosphonates in particular is a stabilizing factor feasibly ensuring a more rigid nanoparticle modification based on stable metal oxygen phosphorous bonds, as reviewed by Neouze and Schubert70. Phosphonate groups have been used in the modification of several different metal oxide nanoparticles such as $\mathrm{CrO}_{2}, \mathrm{Y}_{2} \mathrm{O}_{3}, \mathrm{Al}_{2} \mathrm{O}_{3}, \mathrm{ZrO}_{2}$ etc ${ }^{75}$. For MRI applications, ultrasmall superparamagnetic iron oxides similarly have been encapsulated with $\mathrm{N}$-phosphonomethyl iminodiacetaic acid (PMIDA) via phosphonate groups attached to the oxide surface ${ }^{76}$. $\mathrm{TiO}_{2}$ nanoparticles have moreover been provided with a gadolinium ion complex carrying a phosphonate group for attachment ${ }^{77}$. In cases when more than one phosphonate group per anchoring molecule have been utilized an increase in the nanoparticle stability, as compared to when using molecules carrying only one phosphonate group, is expected. That thesis was also verified for instance by Cao et al who exchanged oleic acid on $\mathrm{NaGdF}_{4}$ to mono-, di- and tetraphosphonate terminated PEGs and observed a higher stability in phosphate buffers at different $\mathrm{pH}$ for multi phosphonate group binding ${ }^{78}$. Phosphonate anchoring of $\mathrm{Gd}_{2} \mathrm{O}_{3}$ nanoparticles is very rare but Guay-Bégin et al recently capped $\mathrm{Gd}_{2} \mathrm{O}_{3}$ nanoparticles and $\mathrm{Gd}_{2} \mathrm{O}_{3}$ thin films with PEG-phosphonates. The $\mathrm{Gd}_{2} \mathrm{O}_{3}$ 
nanoparticles were synthesized via the polyol route and the authors claim that the phosphonate attachment was strong and the as-modified particles stable ${ }^{79}$. Surface modification of nanoparticles using phosphonate anchoring groups hence seem to be promising and a growing number of studies using this kind of surface chemistry is likely.

\subsection{Parameters defining capping efficiency}

Strong anchoring of the chemical molecules to the nanoparticle surface increases the likelihood for capped nanoparticles to persist in changed conditions such as washing steps or further functionalization. Additionally, intermolecular interaction between long chained ligands or polymerization in some cases increases the colloidal stability and reduces the risk of core metal ion leakage and agglomeration. Besides these ligand oriented issues, successful surface modification of nanoparticles relies on the optimization of reaction parameters such as temperature, time, concentration of particles and ligands, solvent, choice of nanoparticles etc. Electrostatic interaction is highly dependent on molecular charges and hence $\mathrm{pH}$ and isoelectric points are yet other important parameters. Ideal conditions rely on the interaction between negatively and positively charged structures, as shown in Figure 5.2. Hemmer et al, who studied the $\mathrm{pH}$ dependency of PEG-carboxylate modification of $\mathrm{Gd}_{2} \mathrm{O}_{3}$ nanoparticles, noted that functionalization of $\mathrm{Gd}_{2} \mathrm{O}_{3}$ was clearly more pronounced at lower $\mathrm{pH}$ (3.7) as compared to functionalization at higher $\mathrm{pH}(8.0)^{80}$. The main reason to this is thought to be the positive surface charge of the nanoparticle at $\mathrm{pH}=3.7$. The formation of free Gd ions on the surface at low $\mathrm{pH}$ is believed to be another key factor. The impact of the nanoparticle isoelectric point and the pKa of ligands is further discussed by Basly et al, who similarly deduce that optimal capping conditions are achieved at about $\mathrm{pH} 5$ for PEG dendron phosphonante capping of superparamagnetic iron oxide nanoparticles ${ }^{81}$.

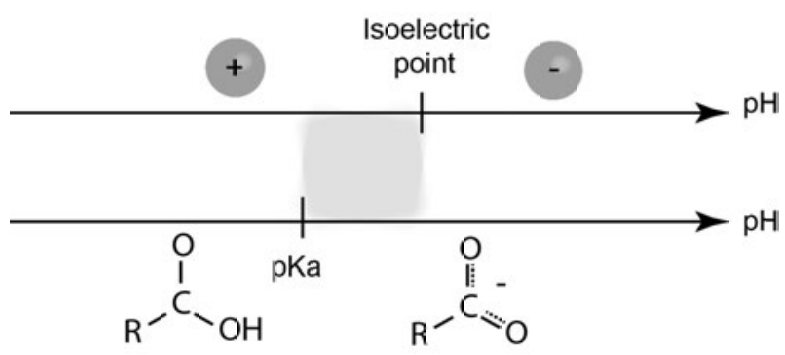

Figure 5.2 Ideal pH for efficient electrostatic interaction between particles and ligands. 


\subsection{Coupling chemistry}

In many cases PEGylation or other surface modifications are performed via chemical reactions between terminal functional groups on molecules present on the nanoparticle surface and/or free in solution. In Paper II the chemical modification of the $\mathrm{Gd}_{2} \mathrm{O}_{3}$ core using heterofunctional Mal-PEG-NHS capping molecules (Figure 5.3) comprised two common strategies as described below.

\subsubsection{EDC/NHS}

An amide bond can easily be formed when an amine group is joined with a carboxylic acid in the presence of the crosslinking agents 1-ethyl-3-(3dimethylaminopropyl) carbodiimide (EDC) and N-hydroxysuccinimide (NHS). The reaction is initiated by the activation of the carboxylic group and the creation of a reactive NHS ester. In the following reaction with an amine NHS is released. Unreacted NHS-esters are unstable and do easily hydrolyse ${ }^{82}$.

\subsubsection{Maleimide reactions}

Maleimide groups react specifically with sulfhydryl groups (-SH) forming stable thioeter bonds at neutral $\mathrm{pH}$. At alkaline $\mathrm{pH}(>8.5)$, the hydrolysis rate of the maleimide increases as so also the reaction with primary amines. In Paper II the maleimide terminated PEG molecule was attached to the nanoparticle surface via the linkage to sulfhydryl groups of MPTS.

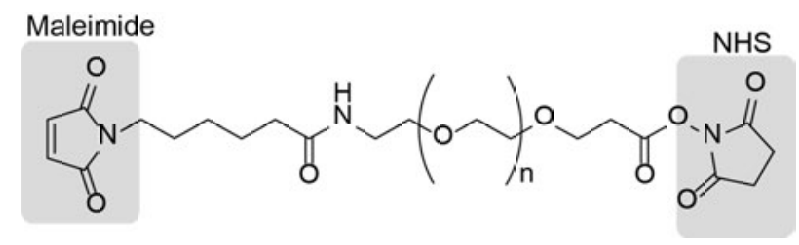

Figure 5.3 Molecular structure of Mal-PEG-NHS with the maleimide and NHS group highlighted. 


\subsection{Instrumentation to study surface capping of nanoparticles}

Successful organic surface modification of inorganic nanoparticles is preferentially studied by means of spectroscopic techniques. In spectroscopy in general the interaction between matter and electromagnetic waves is probed. Molecules and atoms scatter, absorb and emit light upon light irradiation and depending on the energy of the electromagnetic radiation several techniques get use of these phenomena. Upon absorption, a molecule is excited to a higher energy level. Depending on the energy range this higher energy level is reached by an electronic, vibrational or rotational transition. As electronic states are more energy separated as compared to the vibrational and rotational states, a more energetic electromagnetic radiation is needed to probe electron excitation. In Figure 5.4 the spectroscopic techniques used in this thesis work are presented together with the electromagnetic radiation in question and their relative energy order. Below is a more theoretical description of infrared spectroscopy, X-ray spectroscopy and near edge X-ray adsorption fine structure spectroscopy.

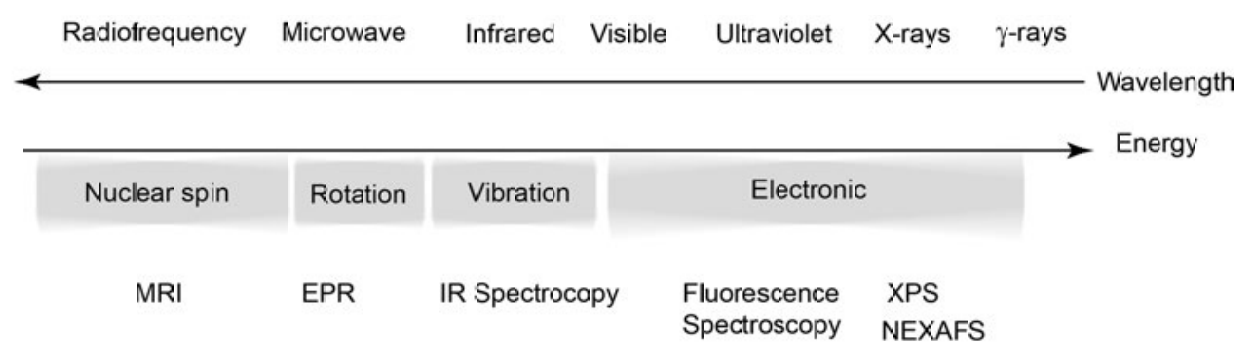

Figure 5.4 Spectroscopic methods used within the frame of this thesis and their correspondence to the energy and kind of electromagnetic radiation.

\subsubsection{Infrared Spectroscopy}

Infrared (IR) spectroscopy is one of the most common spectroscopic techniques for identifying chemical molecules. In this technique molecular vibrations are probed by irradiating the sample with IR light. The excitation to a higher molecular vibrational energy level is monitored by light absorption. IR spectroscopy is useful for identifying functional groups and backbone structure, as the exact energy of the absorbed light is 
characteristic for specific groups or bonds. The strength of the absorption is proportional to the concentration and quantitative analysis is thus achievable 83 .

Electromagnetic radiation is usually characterized by its wavelength $(\lambda)$. In IR spectroscopy the standard unit is wavenumber $\left(\mathrm{cm}^{-1}\right)$, which is related to the wavelength by

$$
\tilde{v}=1 / \lambda
$$

The wavenumber, as well as the frequency is proportional to the energy according to

$$
E=h v=h c \tilde{v}
$$

where $\mathrm{h}=6.626 \cdot 10^{-34} \mathrm{Js}$ is the Planck constant and $\mathrm{c}$ is the speed of light. A simplified description of the molecular vibration is focused on a two atom model in which two atoms are considered as point masses $m_{1}$ and $m_{2}$ which are held together by a spring with elastic force constant $k$. In this model the frequency $(v)$ of the vibration is:

$$
v=\frac{1}{2 \pi} \sqrt{\frac{k}{\mu}} \quad \text { where } \mu=\frac{m_{1} m_{2}}{m_{1}+m_{2}}
$$

The impact of the force constant can be illustrated by comparing the vibrational frequencies of alkyne (triple bond), alkene (double bond) and alkane (single bond), which are about 2000, 1600 and $1000 \mathrm{~cm}^{-1}$ respectively ${ }^{83}$. A pronounced mass effect is also present and exchanging hydrogen to deuterium in an organic molecule leads to a clear decrease in the vibrational frequency of the $\mathrm{C}-\mathrm{H}$ modes.

Infrared spectroscopy measurements are mainly performed within the energy range $400-4000 \mathrm{~cm}^{-1}$ (mid IR) but the vast majority of the vibrational bands appear in the so called finger print area in between 1500 and $650 \mathrm{~cm}^{-1}$. For large molecules a spectrum can have more than hundred absorption bands within this region and most often it is hard to assign them all. Instead the presence of a few intense peaks for instance indicating ester- , acid- or ether groups etc. assist in the interpretation. In Paper II and Paper $\mathbf{V}$ presence of $\mathrm{C}-\mathrm{O}-\mathrm{C}$ vibrations originating from the PEG molecules and $\mathrm{COOH} / \mathrm{COO}^{-}$vibrations were used in the verification of a successful surface capping of $\mathrm{Gd}_{2} \mathrm{O}_{3}$ nanoparticles. Metal oxides vibrational modes usually are present at low wavenumbers, below $800 \mathrm{~cm}^{-1}$, as a consequence of the large mass of the metal atom.

A major constraint in IR spectroscopy is the necessity for a dipole moment change which is associated with the vibrational excitation and molecular vibrations without a change in dipole moment are thus infrared inactive. As a consequence of this, only 
diatomic molecules with different atoms in the point mass model can be excited vibrationally. Multi-atomic molecules, on the other hand always have dipole changes associated with their vibration. The output in IR spectroscopy is based on the ratio of the intensity of the incident light $\left(I_{0}\right)$ and the outgoing light (I) which has passed the sample. The result is presented in a spectrum and expressed as Transmittance (T) or Absorbance $(A)$, where $T=I / I_{0}$ and $A=-\log \left(I / I_{0}\right)$, versus wavenumber $\left(\mathrm{cm}^{-1}\right)^{83}$. An example of an IR spectrum is shown in Figure 5.5.

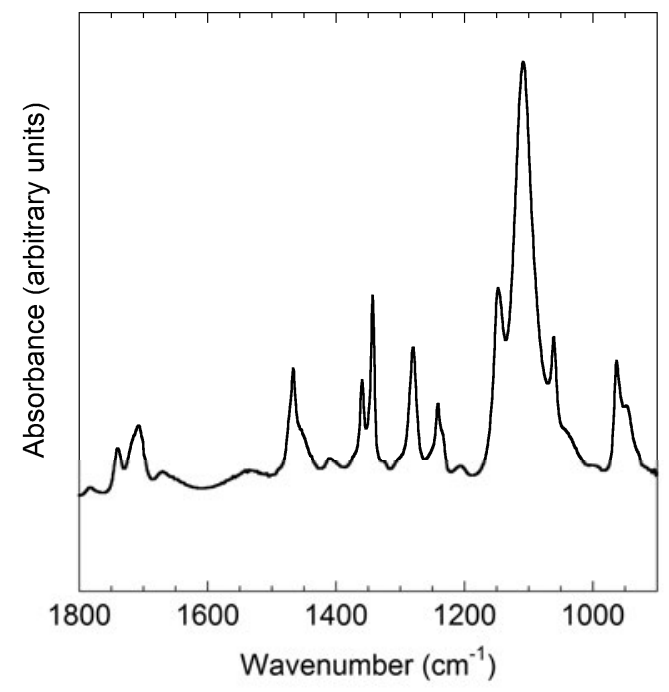

Figure 5.5. A transmission IR spectrum of Mal-PEG-NHS showing the peaks of the finger print area.

IR spectroscopy is powerful when studying coordination chemistry. In Paper IV the coordination of the carboxylate ion to gadolinium was theoretically discussed and also studied by means of experimental IR spectra. At least three modes of carboxylate metal ion coordination exist, i.e. the unidentate, bidentate and bridging coordination (Figure 5.6). Nakamoto, who summarizes a number of studies within the field, describes how the magnitude of the peak-to-peak wavenumber separation $(\Delta v)$ between the antisymmetric $v_{a s}\left(\mathrm{COO}^{-}\right)$and symmetric $v_{\mathrm{s}}\left(\mathrm{COO}^{-}\right)$vibrational modes since long has been used as an indicator of the particular mode according to ${ }^{84}$ :

$$
\Delta v \text { (bidentate) }<\Delta v \text { (bridging) }<\Delta v \text { (unidentate) }
$$

Nakamoto claims that for a bridging ligand $\Delta v$ is in the range $140-180 \mathrm{~cm}^{-1}$ whereas for unidentate and bidentate ligands $\Delta v$ is above respectively close to or below this range. 
In the case of a more ionic coordination $\Delta v$ is commonly very much lower than for unidentate coordination but close to the value for bridging coordination. Bidentate coordination of high asymmetry furthermore yields higher $\Delta v$ than symmetric ones and is sometimes approaching the value for unidentate mode. Interpretation is though very often complicated by the presence of several coordination modes, as also discussed in Paper IV.

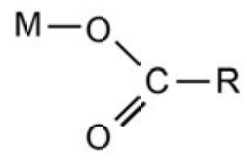

a)<smiles></smiles>

b)<smiles>[M]OC([R])O[M]</smiles>

c)

Figure 5.6 The carboxylate ion coordination to a metal can be a) unidentate, b) bidentate or c) bridging.

\subsubsection{X-ray Photoelectron Spectroscopy}

X-ray Photoelectron Spectroscopy (XPS) is a surface sensitive analytical technique useful for identification and quantification of the chemical composition in a sample. The technique is based upon the photoelectric effect, which refers to the ejection of electrons from the surface in response to incident light and can have a detection limit of surface impurities of $<1 \%$ of a monolayer ${ }^{85}$. For an electron to be emitted the energy of the incident light $(h v)$ must be greater than the binding energy of the electron $\left(E_{b}\right)$ plus the work function $(\phi)$. The difference between the two energies will turn into kinetic energy $\left(E_{k}\right)$ transporting the electron away from the atom. According to the energy conservation theory, no energy can be lost and the following equation can be set up:

$$
E=h v=E_{k}+E_{b}+\phi
$$

The work function is defined as the minimum energy required for an electron to move from the Fermi level to the vacuum level, as shown in the left part of Figure 5.7 which describes the photoelectron emission process. 

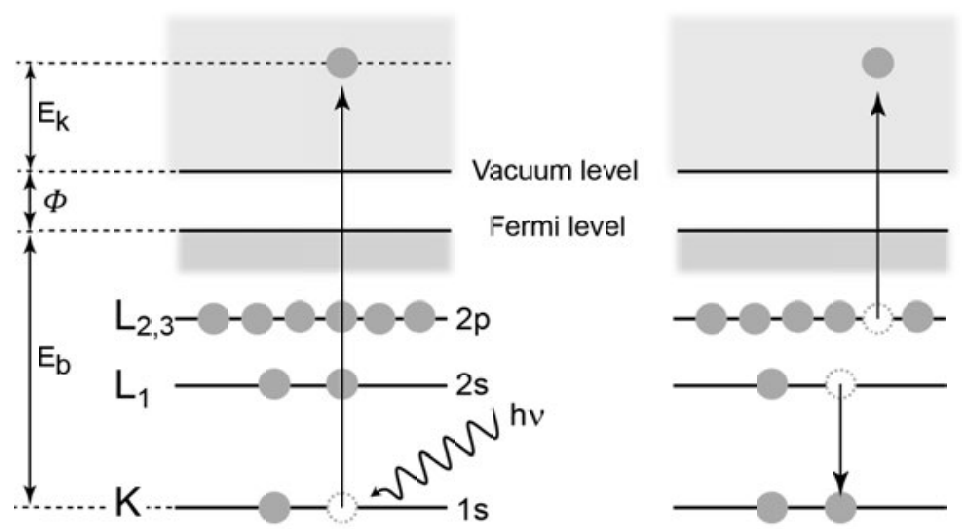

Figure 5.7 The photoelectron emission process (left) and the process of Auger decay (right).

Results from XPS measurements are presented in an XPS spectrum with the intensity (y) set versus the binding energy $(\mathrm{x})$, as shown in the $\mathrm{Gd}_{2} \mathrm{O}_{3}$ thin film overview spectrum in Figure 5.8. Excited core electrons which escape without loss of energy contribute to the characteristic XPS peaks of the spectrum. Electrons which suffer from energy loss through inelastic scattering processes contribute to the spectrum background; especially at higher binding energies. Furthermore, Auger peaks are often observed in the XPS spectra. These are obtained when the core hole created in the photoemission process is filled with an electron from a higher level. An Auger electron is ejected by using the energy collected from the internal transition, as described in the right part of Figure 5.7. Auger peaks are named with three letters referring to the energy levels involved in the Auger process. 


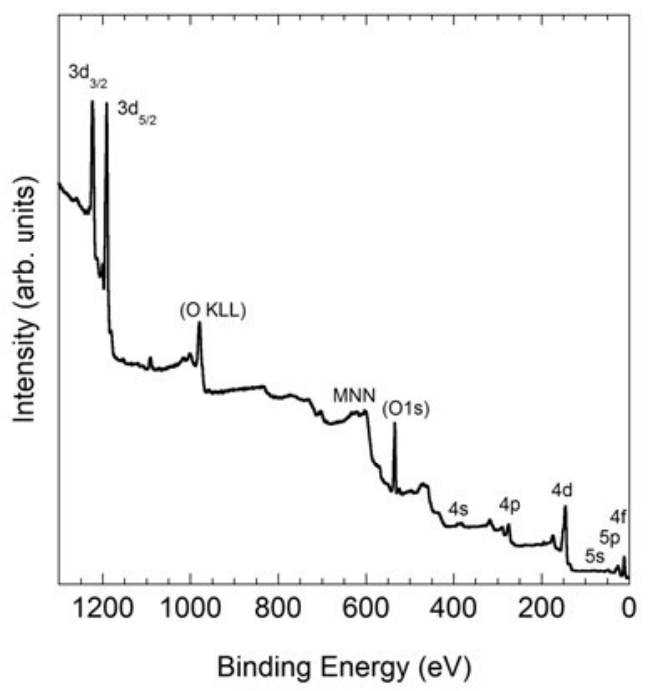

Figure 5.8 Example of an overview XPS spectrum of a $\mathrm{Gd}_{2} \mathrm{O}_{3}$ thin film with the most prominent peaks arising from the $3 \mathrm{~d}_{3 / 2}$ and $3 \mathrm{~d}_{5 / 2}$ level of $\mathrm{Gd}$.

Each photoemission peak in the XPS spectrum is derived from electrons of a specific electronic state. For electrons in orbitals with an angular momentum other than zero $l \neq$ 0 ), doublets are formed because of spin orbit coupling. The separate peaks in these doublets are named according to the total angular momentum of the electron $(j)$, i.e. the absolute sum of the angular momentum quantum number $(I)$ and the spin quantum number $\left(m_{s}\right)$. Hence $p$ orbitals are indexed as $p_{1 / 2}$ or $p_{3 / 2}$ and d-orbitals as $d_{3 / 2}$ or $d_{5 / 2}$. The peak to peak separation within these doublets depends on the power of the spin orbit coupling but the relative intensity is fixed and given by $(2 j+1)$, as it is dependent on the relative population of the states ${ }^{86}$.

Ejection of electrons from insolating specimen or from thick organic layers on conducting substrates in XPS causes electrostatic charging of the surface upon irradiation with X-rays. The built up positive charge reduces the speed of the electrons escaping the sample which in turn will have a lower kinetic energy as compared to the case when studying a conducting specimen. The affected kinetic energy will be observed as peak position shifts to higher binding energies in the spectrum. Shifting peaks back to their correct binding energy positions is part of the data processing in XPS and aligning is commonly done referring to the peak position of $\mathrm{Au} 4 \mathrm{f}_{7 / 2}$ at $84 \mathrm{eV}$ (if using a gold substrate) or C 1 s at $285 \mathrm{eV}$. 
Chemical information can be achieved in XPS as the nearest chemical environment of an atom affects the XPS binding energy peak position. Aliphatic carbons can be separated from for instance aromatic ones or carbons in acids or esters by studying the so called chemical shifts. This is usually done by curve fitting procedures in narrow scan spectra, ranging over a smaller binding energy range corresponding to the specific element. Curve fitting should be done using a single full width half maximum (FWHM) for all peaks within a specific core level. The exact value of the FWHM is dependent on the energy width of the incoming X-ray, the pass energy and the geometry factors of the analyzer etc, and is preferentially achieved by using a reference sample with a single line of the element peak in focus. The relative peak intensity of different core levels can be used for quantitative analysis in XPS. The intensity is not only dependent on the concentration of atoms, but also on the photoemission cross section $(\sigma)$, the inelastic mean free path $(\lambda)$ and the instrumental response for the particular kinetic energy. Therefore, the peak intensities of two core levels must be normalized with empirically determined atomic sensitivity factors $\left(\mathrm{S}_{i}\right)$ before relative amount of two particular atoms can be determined 86 . In this way an estimated relative concentration is achieved by

$$
\frac{C_{1}}{C_{2}}=\frac{I_{1} / S_{1}}{I_{2} / S_{2}}
$$

For peaks within the same binding energy range the inelastic mean free path of the electrons and the instrumental parameters are similar for different atoms and the sensitivity factor may be replaced by the photoemission cross section according to:

$$
\frac{C_{1}}{C_{2}}=\frac{I_{1} / \sigma_{1}}{I_{2} / \sigma_{2}}
$$

where $C_{i}$ is the atomic concentration of core level of element $i, I_{i}$ the peak area of the $i$ core level and $\sigma_{i}$ the photoemission cross section of the core level of atom $i^{85}$. It should be noted that these formulas are restricted to cases where the two elemental species are homogenously distributed throughout the sample depth.

The surface sensitivity of XPS is related to the inelastic mean free path (IMFP) of the electrons in consideration. This in turn is highly dependent on the kinetic energy of the electrons as shown in the relation empirically derived by Seah and Dench ${ }^{87}$ :

$$
\lambda=\frac{538}{E^{2}}+0.41 a^{3 / 2} E^{1 / 2}
$$


where $\lambda$ is the inelastic mean free path, $E$ is the kinetic energy of the electrons and $a$ is the mean atomic diameter of the element in nanometer. In Figure 5.9 a graphical representation of this formula is displayed showing that the surface sensitivity of the technique is greatest for electron energies of 30-100 eV. The graph was obtained using an arbitrary atomic diameter of $270 \mathrm{pm}$. The high surface sensitivity of XPS requires pure surfaces, i.e. that contamination is avoided. XPS measurements are therefore performed in ultrahigh vacuum $\left(10^{-8}\right.$ to $10^{-10}$ mbar or less). In that way electrons travelling to the detector are less likely to be scattered and the signal intensity increases ${ }^{86}$.

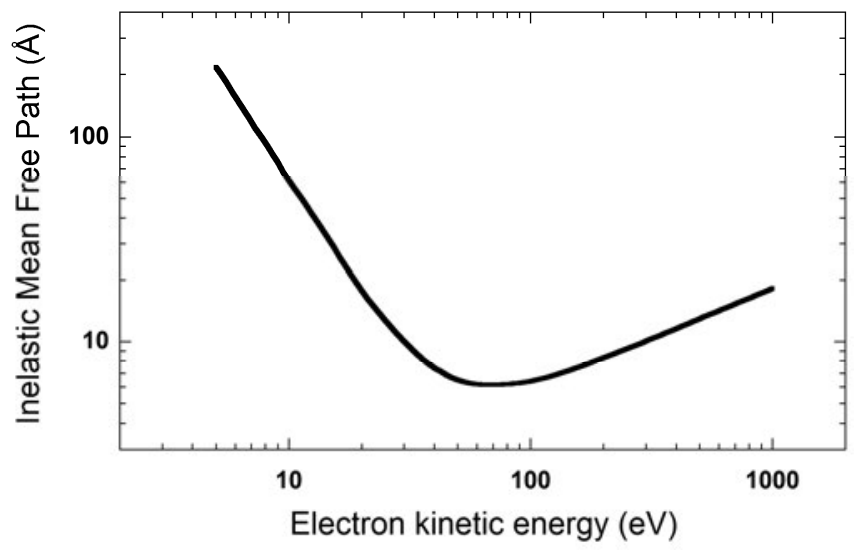

Figure 5.9 A graphical representation of the mean free path of electrons as a function of the kinetic energy as calculated from formula 5.7 with an atomic diameter of $270 \AA$.

\subsubsection{Near Edge X-ray Adsorption Fine Structure Spectroscopy}

In Near Edge X-ray Absorption Fine Spectroscopy (NEXAFS) X-ray absorption is studied in purpose to achieve information about the electronical and chemical structure and composition of a sample ${ }^{88}$. This is done by sweeping the incoming X-ray photon energy from a magnitude just a little lower than what is required for the absorption edge of the element of interest up to a 30-40 eV higher value. Within this range electrons are exited from core levels to unoccupied molecular final states and Rydberg states, as illustrated to the left in Figure 5.10. The lowest energy transitions in NEXAFS are $\pi^{*}$ and Rydberg $\left(\mathrm{R}^{*}\right)$ with the star denoting an unoccupied molecular orbital. These transitions occur at photon energies lower than the ionization potential, i.e. the final states are below the 
vacuum level. Transitions to $\pi^{*}$ orbitals are observed as sharp well defined peaks in spectra when studying molecules with double or triple bonds and the energy required for these transitions to occur is strongly dependent on the chemical environment. $\sigma^{*}$ transitions occur at energies higher than the ionization potential, i.e. the excited electrons are quasi bound. These resonances are broader because of the high probability of decay among continuum states.

Element specific information is achieved in NEXAFS because of the elemental dependency of the energies of the absorption edges. The extensive fine structure above the absorption edges also holds information about the bonding environment, as the energy levels of the empty states are affected by the local chemical surroundings.

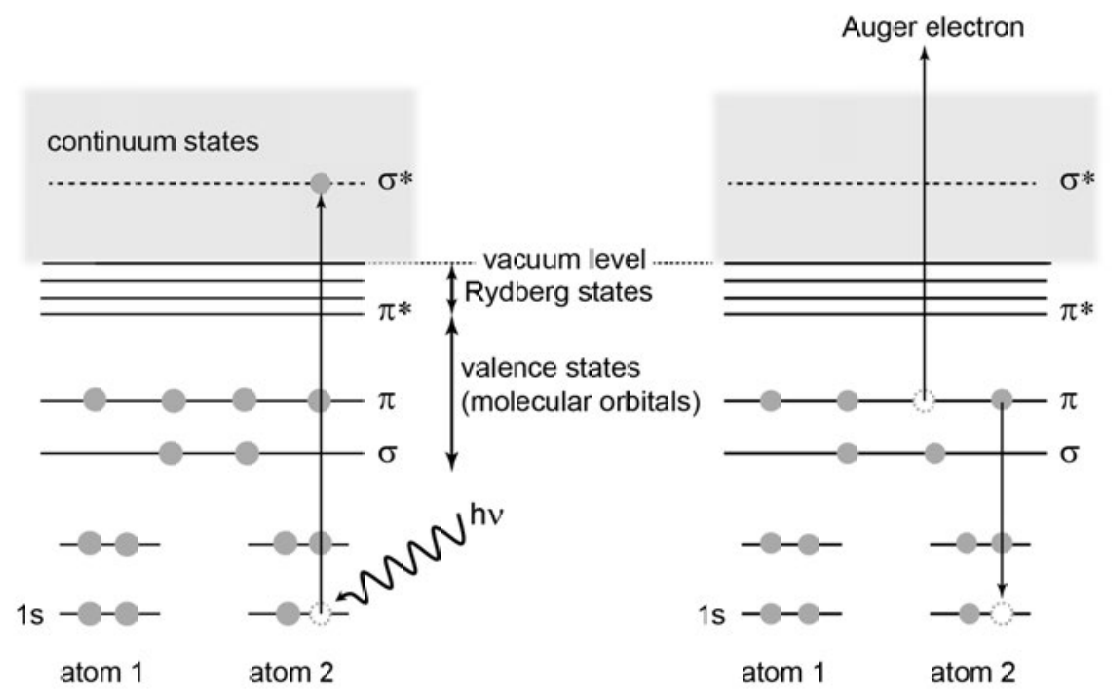

Figure 5.10 The K-shell excitation in a diatomic molecule (left) and the following Auger emission de-excitation (right).

In contrast to the detection principle in photoelectron spectroscopy, the detection principle in NEXAFS is based on secondary processes that occur after a core electron has been excited to an unoccupied molecular orbital. The core hole created is filled by an electron from a higher shell radiatively by emission of fluorescence or non-radiatively by emission of an Auger electron (right part of Figure 5.10). Detection can thus be performed by fluorescence or electron yield and these methods generate more or less 
identical spectra, besides from the different signal-to-noise and signal-to-background ratios. In this thesis partial electron yield (PEY) detection and total electron yield (TEY) detection have been used. In TEY detection, when electrons of all energies are recorded, the signal is dominated by low energy electrons $(\mathrm{E}<20 \mathrm{eV})$ and the total count-rate is very high. Detection is done for instance by simply measuring the sample current. In PEY detection a retardation voltage is applied to the detector cutting off the numerous low energy electrons. This latter alternative enhances the surface sensitivity of the detection.

\subsubsection{Synchrotron Radiation}

When sweeping the photon energy in NEXAFS measurements or optimizing the incident energy in XPS a synchrotron radiation facility is commonly used. The NEXAFS and XPS results presented in Paper IV were obtained at the D1011 station of the 90 meter long MAX II storage ring at MAX-lab synchrotron facility in Lund, Sweden. D1011 covers photon energies from 30 to $1600 \mathrm{eV}$. A synchrotron source is composed of a large closed storage ring in which electrons (or other charged particles) are circulating at a speed close to the speed of light. Synchrotron facilities utilize the electromagnetic radiation which is emitted from the high speed electrons tangentially to the circular path. Experimental stations, or beam lines, are thus located at positions of ring curvature. To avoid collisions in between electrons and gas molecules and to maintain a high electron speed the electron beam is travelling in high vacuum (typically $10^{-9}$ to $10^{-10} \mathrm{Torr}$ ) ${ }^{89}$. The high intensity and the broad spectrum (from IR to hard X-ray) of the emitted light make it useful for research within a wide range of fields in biology, chemistry, physics etc. and every beam line is optimized for a certain purpose by means of insertion devices. Various kinds of magnets, such as bending magnets, undulators and wigglers, are used to control the electron beam and to maintain a constant electron orbit. Monochromators are required to enable selection of the optimum light energy, a choice which is usually dependent on the specific experiment. Synchrotron radiation is highly linearly polarized and collimated, as compared to X-ray radiation produced in conventional X-ray sources. The intensity of the radiation is moreover high and these facts together result in opportunities for acquiring high resolution spectra in a short period of time ${ }^{90}$. 


\section{CHAPTER 6}

\section{Nanoparticles in biological systems}

Nanoparticles to be used in biological systems have to fulfill a wide range of requirements. Two central aspects are nanoparticle stability and biocompatibility. These two issues have been in focus during the thesis work and are shortly discussed below. Some examples in which the $\mathrm{Gd}_{2} \mathrm{O}_{3}$ nanoparticles synthesized within the frame of this thesis have been evaluated in cell studies are mentioned in the end of the chapter.

\subsection{Nanoparticle stability}

The colloidal stability of nanoparticle suspensions is dependent on the balance between the repulsive and the attractive forces present between the nanoparticles. Bare metal oxide nanoparticles are thermodynamic unstable in water, due to their high surface energy, and large attractive forces may cause the nanoparticles to agglomerate. In other cases though, bare nanoparticles tend to stabilize themselves by adsorbing surrounding molecules. Colloidal stability is commonly discussed in terms of electrostatic repulsion, steric stabilization and electrosteric stabilization ${ }^{91}$. In electrostatic stabilization, the nanoparticle surface charge attracts charges of opposite signs and an electrostatic double layer is formed around the particles, preventing nanoparticle agglomeration. Steric stabilization is achieved by adsorbing macromolecules on the nanoparticle surfaces. In many nanoparticle systems polymeric stabilizers, such as poly(vinyl alcohol) and poly(acrylic) acid, are used in purpose to achieve this kind of stabilization ${ }^{92}$. The colloidal stability depends on the nanoparticle binding strength as well as on the size and chemical composition of the adsorbent. By combining the concepts behind electrostatic and steric stabilization, electrosteric stabilization is achieved. Optimal nanoparticle stabilizers should then be both large and charged ${ }^{91}$. 
There are numerous ways to study the stability of nanoparticles and in many cases more than one method is needed to fully interpret the quality of a sample. Stability can generally relate to physical characters such as maintained size and shape, lack of degradation etc. in normal environment but also to the ability to resist degradation or aggregation at different temperatures, $\mathrm{pH}$ values, salt concentrations, buffers etc. These latter parameters vary considerably in different parts of a body and even inside a cell, and the demands on the stability of colloidal nanoparticle suspensions in purpose to use in biological systems are therefore very high.

Among the most commonly used methods to evaluate the colloidal nanoparticle stability are techniques based on the zeta potential, i.e. on the charge of the liquid layer surrounding the particles. The quantity of this charge partly determines the risk of agglomeration, as electrostatic repulsive forces between the particles prevent merging of them. Zeta potentials are measured in $\mathrm{mV}$ and they are, as well as the stability, highly affected by the $\mathrm{pH}$ of the system. Normally, particle suspensions showing zeta potentials with magnitudes higher than $+30 \mathrm{mV}$ or lower than $-30 \mathrm{mV}$ are considered to be electrostatically stable ${ }^{93}$.

\subsubsection{Stability and purification}

An important step in the synthesis of high quality nanoparticles is the purification. In this thesis purification has been performed either by dialysis or by centrifuge washing. The purpose of the purification has been to enable the removal of synthesis precursors or solvents and this step has often been used to transfer the particles to water phase. Excessive treatment of as-synthesized nanoparticles may lead to unstable nanoparticle system, as a consequence of the removal of surface bound molecules or changed charge conditions ${ }^{94}$. A sample dialyzed against a large volume of water is placed in a harsh environment and the purity, but also the nanoparticle stability is partly affected by the dialysis time. In addition, the estimated yield of the synthesis is dependent on the washing procedure, as is the free ion content. In centrifuge washing, the choice of washing solvent similarly is crucial in the process of removing unwanted species but still keeping the nanoparticles stable. Hence, purification of bare $\mathrm{Gd}_{2} \mathrm{O}_{3}$ nanoparticle samples has been a balance between stability and purity. This is a fact that enlightens the importance of further stabilizing surface modification. 


\subsubsection{Nanoparticle stability in this thesis}

The ultimate aim of the work performed in this thesis was to produce a contrast agent composed of $\mathrm{Gd}_{2} \mathrm{O}_{3}$ nanoparticles preferably having a long shelf time, i.e. possible to store for a long time. Stability issues as for instance to verify that no $\mathrm{Gd}^{3+}$ ions release from the particles have therefore often been in focus. In Paper II a dialysis study was performed confirming an increased stability by means of lower $\mathrm{Gd}^{3+}$ ion leakage for PEGylated $\mathrm{Gd}_{2} \mathrm{O}_{3}$ nanoparticles as compared to bare $\mathrm{Gd}_{2} \mathrm{O}_{3}$ nanoparticles. Visual inspection by the naked eye has in a first step confirmed the lack of major agglomeration. In the following, dynamic light scattering has been utilized to omit size effects, as was done in Paper II and Paper IV. Transmission electron microscopy was used in Paper IV to confirm that the crystal size, shape and structure of the core were maintained even after long storage. The colloidal stability of $\mathrm{Gd}_{2} \mathrm{O}_{3}$ nanoparticles, capped $\mathrm{Gd}_{2} \mathrm{O}_{3}$ nanoparticles and $\mathrm{Gd}$ decorated $\mathrm{ZnO}$ nanoparticles was furthermore studied by means of zeta potential in Paper IV, Paper V and Paper VI respectively.

In addition to the studies covered in the papers, electron paramagnetic resonance measurements were used in the stability control of newly dialyzed bare $\mathrm{Gd}_{2} \mathrm{O}_{3}$ nanoparticles synthesized within the polyol route. Since free $\mathrm{Gd}^{3+}$ ions cause a strong signal in EPR whereas polyol synthesized $\mathrm{Gd}_{2} \mathrm{O}_{3}$ nanoparticles do not, repeated EPR measurements were performed on the same sample during a time period of about 1 month to study ion leakage. The results presented in Figure 6.1 unexpectedly showed a high stability with no signal change during the first month for $\mathrm{Gd}_{2} \mathrm{O}_{3}$ nanoparticles in the static system, in contrast to the results presented in Paper II in which prolonged dialysis was shown to totally dissolve the $\mathrm{Gd}_{2} \mathrm{O}_{3}$ nanoparticles within 10 days. 


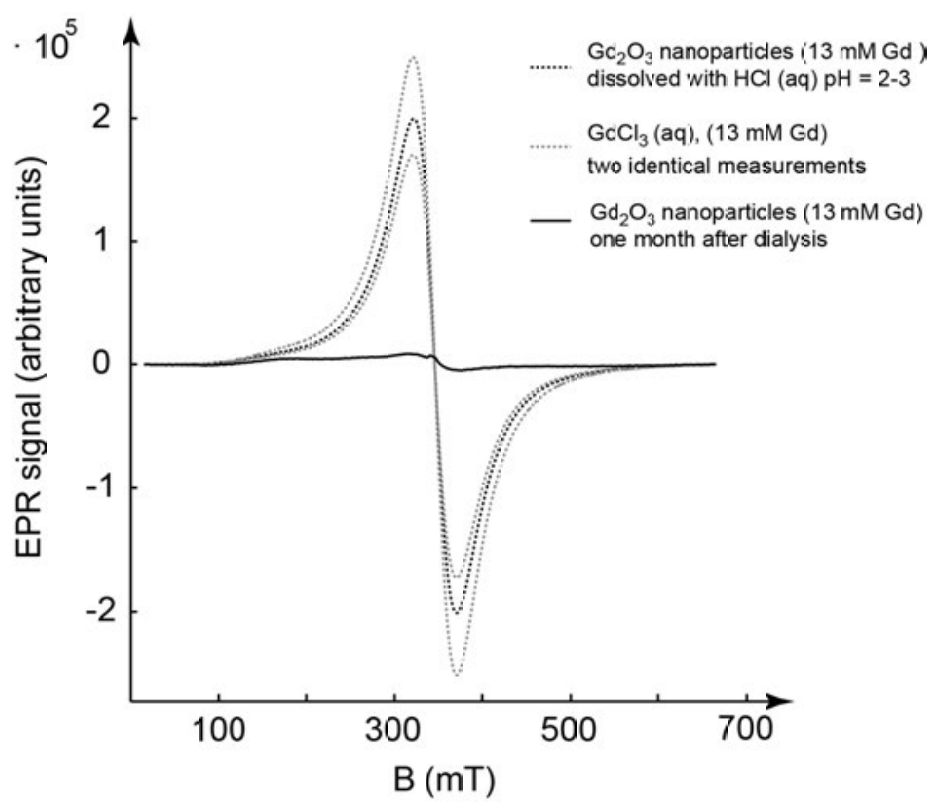

Figure 6.1 Results from electron paramagnetic resonance measurements on dialyzed $\mathrm{Gd}_{2} \mathrm{O}_{3}$ nanoparticles stored for one month, $\mathrm{Gd}_{2} \mathrm{O}_{3}$ nanoparticles dissolved into ionic form due to treatment with $\mathrm{HCl}$ and an aqueous solution of $\mathrm{GdCl}_{3}$.

\subsection{Biocompatibility and PEGylation}

Issues concerning both the stability, as described above, and the biocompatibility of the Gd based nanoparticle contrast agent are of main importance. Before introducing nanoparticulate agents into the human body, possible local or systemic toxic effects must be avoided and the particles must be made invisible for the immune system to avoid identification of the agent as foreign. The circulation time of the contrast agent in the body also has to be long enough to enable the collection of MR images however the agent should not accumulate in the body. The choice of surface coating is essential in order to achieve biocompatible nanoparticles. Commonly suggested coatings for magnetic metal oxide nanoparticles, and $\mathrm{Gd}_{2} \mathrm{O}_{3}$ in particular, are composed of citric acid $^{46 b}$, 95 , silanes ${ }^{96}$, dextrane ${ }^{97}$ and polymers such as poly acrylic acid ${ }^{98}$. The most frequently used strategy though is PEGylation of nanoparticles as discussed by for example Karakoti et $\mathrm{al}^{99}$ and Jokerst et al ${ }^{100}$. Polyethylene glycol (PEG) molecules are comprised of repeated units of $\left(\mathrm{CH}_{2} \mathrm{CH}_{2} \mathrm{O}\right)_{\mathrm{n}}$. These are commonly used in particle capping layer to decrease the non-specific interaction with opsonins, i.e. proteins which 
initiate the activation of the reticulo endothelial system (RES). In addition, PEGs increase the solubility and stability of nanoparticles. The anchoring to the nanoparticle surface is done passively or actively via functional groups attached to the PEG chain.

The average molecular weight of commonly used PEGs ranges from some hundreds up to several thousands of Daltons. Long chained PEGs are thought to offer higher flexibility minimizing the interaction time with proteins but they are also associated with greater challenges when high density coatings are preferred ${ }^{99}$. Protein repulsion is most efficiently achieved by using PEGs with molecular weights of at least 500-2000 Daltons, possibly as a consequence of changes in the PEG conformation at this length ${ }^{101}$. In Paper II a bifunctional 5000 D molecular weight PEG comprising two different functional groups was used to enable attachment to silanes on the nanoparticle surface and to the dye Rhodamine 123. Branched PEGs with several tails of repeated ethylene glycol units may be used in purpose to produce biocompatible nanoparticles, as in Paper V. In this case an in-house produced branched structure (Figure 6.2) was chosen to ensure numerous ethylene glycol units stabilizing the particles while still maintaining a small size nanoparticle, as discussed by Gillich et al ${ }^{102}$.

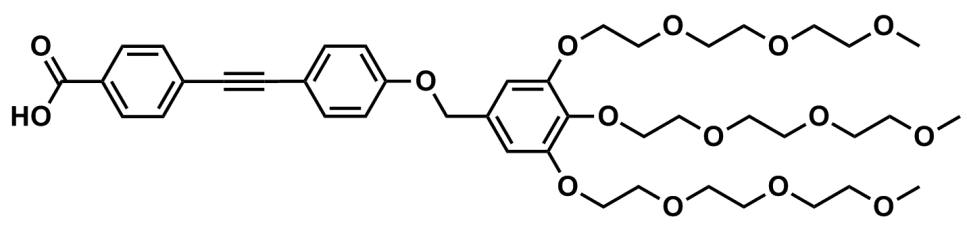

Figure 6.2 The molecular structure of the TEG used in the $\mathrm{Gd}_{2} \mathrm{O}_{3}$ nanoparticle surface capping in Paper V.

The biocompatibility of PEGylated nanoparticles depends on the charge of the terminal group of the PEG. This is studied for instance in a paper by Faure et al, in which $\mathrm{Gd}_{2} \mathrm{O}_{3}$ nanoparticles capped with PEG-NH2 (2000 D) were shown to accumulate in the liver and spleen of HEK- $\beta 3$-tumor bearing mice in contrast to the corresponding $\mathrm{COOH}$ and $\mathrm{CH}_{3}$ terminated PEGs, which were eliminated through the urine via the kidneys ${ }^{103}$. This difference in biodistribution is attributed to the positive charge of the nanoparticles carrying PEG- $\mathrm{NH}_{2}$ attracting negatively charged opsonins. A negative or neutral surface charge is also in general beneficial in purpose to ensure a longer circulation time and less uptake by phagocytic cells ${ }^{104}$. The biodistribution of inorganic nanoparticles after intravenous injection hence relies to a major part on surface coating but also on the 
nanoparticle size. To ensure elimination from the body through the kidneys, the metal containing nanoparticle size should not exceed $10 \mathrm{~nm}$ according to work done by for instance Skotland et $\mathrm{al}^{44}$. A small nanoparticle size is furthermore advantageous because of the somewhat longer circulation time enabling medical imaging to be performed. Nanoparticles larger than $30-50 \mathrm{~nm}$ are more easily recognized by the reticulo endothelial system (RES) and accumulate in the liver and spleen ${ }^{104}$.

\subsection{Cell studies with $\mathrm{Gd}_{2} \mathrm{O}_{3}$ nanoparticles}

Initial in vitro studies of the interaction between cells and $\mathrm{Gd}_{2} \mathrm{O}_{3}$ nanoparticles are included in Paper I, Paper II and Paper V. Microscopic methods were used to study the morphology of the cells upon nanoparticle exposure and/or the cell viability was monitored. In addition to these results a few other studies have been performed as described below.

\subsection{1 $\mathrm{Gd}_{2} \mathrm{O}_{3}$ and neutrophil granulocytes}

The potential toxicity of $\mathrm{Gd}_{2} \mathrm{O}_{3}$ nanoparticles have been evaluated in vitro with neutrophil granolucytes, i.e. cells commonly involved in the early phase of inflammation ${ }^{52}$. This was done by studying the production of reactive oxygen species (ROS) upon nanoparticle-cell interaction and the results are presented in a paper by Abrikossova et al ${ }^{52}$. Nanoparticle samples were composed of the as-synthesized $\mathrm{Gd}_{2} \mathrm{O}_{3}$ nanoparticles, dialyzed $\mathrm{Gd}_{2} \mathrm{O}_{3}$ nanoparticles and PEGylated and dialyzed $\mathrm{Gd}_{2} \mathrm{O}_{3}$ nanoparticles in focus in Paper II. The ROS production upon challenge with prey (IgG opsinized yeast particles) was monitored via luminol amplified chemiluminescence, and the intensity of the light was compared to that of control cells. Cells exposed to $\mathrm{Gd}_{2} \mathrm{O}_{3}$ nanoparticles were shown to have an inhibited response following challenge with prey. This inhibiting effect on the cells decreased with dialysis and PEGylation, and it was mainly attributed to the solvent diethylene glycol, used in the polyol synthesis. Morphological examination of cells exposed to nanoparticles, by means of fluorescence microscopy, showed that aggregation of neutrophils was induced upon nanoparticle exposure and the importance of PEGylation and dialysis was further verified (Figure 6.3). 


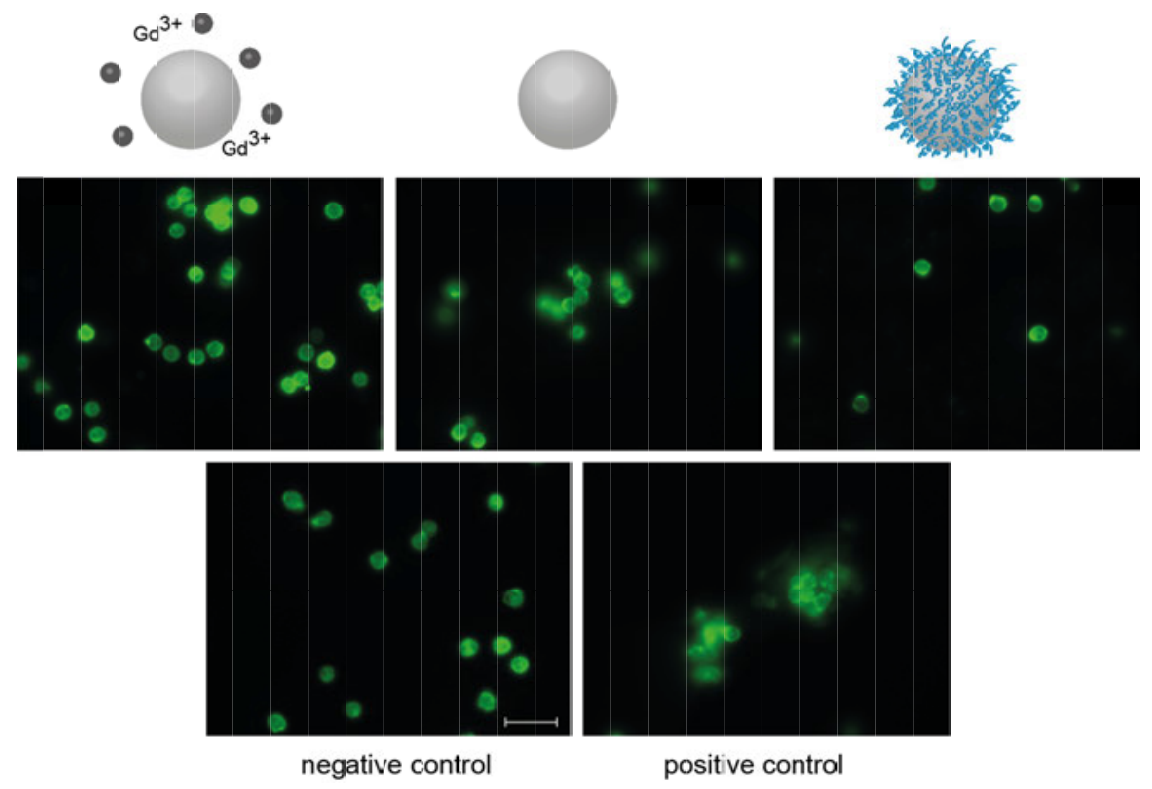

Figure 6.3 Fluorescence images of neutrophils stained for F-actin exposed to as-synthesized $\mathrm{Gd}_{2} \mathrm{O}_{3}$ nanoparticles, dialyzed $\mathrm{Gd}_{2} \mathrm{O}_{3}$ nanoparticles and PEGylated $\mathrm{Gd}_{2} \mathrm{O}_{3}$ nanoparticles with a $\mathrm{Gd}$ concentration of $0.9 \mathrm{mM}$. The scale bar indicates $20 \mu \mathrm{m}$. Reprinted with permission from ref ${ }^{52}$. (Copyright 2012 IOP Publishing, Ltd)

\subsection{2 $\mathrm{Gd}_{2} \mathrm{O}_{3}$ nanoparticle uptake in cells}

Intracellular $\mathrm{Gd}_{2} \mathrm{O}_{3}$ nanoparticle uptake in THP-1 cells was studied in Paper I. THP-1 is a monocytic cell line that is naturally phagocytic and later on this study was expanded to furthermore include hematopoietic progenitor $\mathrm{Ba} / \mathrm{F} 3$ cells ${ }^{105}$. The nanoparticle uptake was monitored with electron microscopy showing a higher degree of uptake in THP-1 (3-5 \%) as compared to $\mathrm{Ba} / \mathrm{F} 3$ (1-2 \%) upon the used incubation times. A representative set of electron microscopy images from this study is shown in Figure 6.4. In these images nanoparticles are observed near the cell membrane, on the cell membrane and in vacuoles of the cells. According to the scale bar the visible nanoparticles are partly aggregated, most likely as a consequence of the buffer medium affecting the nanoparticle dispersion.

Cell viability studies were performed and the results showed that the viability was only slightly affected upon $\mathrm{Gd}_{2} \mathrm{O}_{3}$ exposure ( $2 \mathrm{mM} \mathrm{Gd}$ ) for Ba/F3 cells as compared to control cells. No severe toxicological effects were thus noticed. A MRI study of washed cells showed that the water relaxation times were affected by the intracellular nanoparticles, indicating that $\mathrm{Gd}_{2} \mathrm{O}_{3}$ nanoparticles could function as an intracellular contrast agent. 


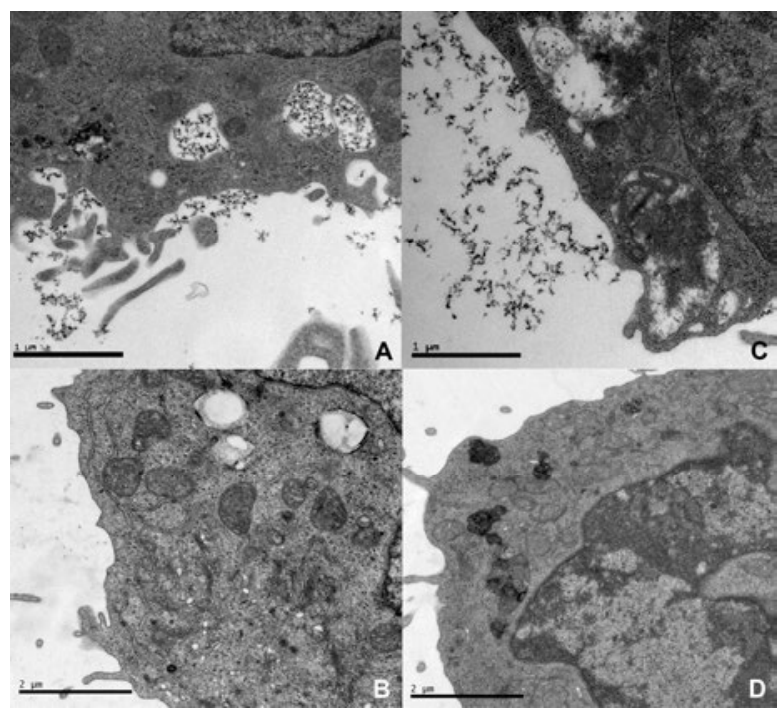

Figure 6.4 Electron microscopy images of THP-1 cells (A) and Ba/F3 cells (C) co-incubated with $\mathrm{Gd}_{2} \mathrm{O}_{3}$ nanoparticles and the corresponding control images of THP-1 cells (B) and Ba/F3 cells (D) not treated with nanoparticles. The scale bar indicates $1 \mu \mathrm{m}$ in $\mathrm{A}$ and $\mathrm{C}$ and $2 \mu \mathrm{m}$ in $\mathrm{B}$ and $\mathrm{D}$. Reprinted with permission from ref ${ }^{105}$. (Copyright 2011 Dove Medical Press Ltd)

Uptake of $\mathrm{Gd}_{2} \mathrm{O}_{3}$ nanoparticles in THP-1 cells has also been studied by Petoral et al ${ }^{106}$. In that work Tb doped nanoparticles capped with citric acids were used to enable the use of fluorescence microscopy in the evaluation, similar to the europium doped $\mathrm{Gd}_{2} \mathrm{O}_{3}$ nanoparticles in Paper V. In all cases nanoparticle uptake has been noted but the degree of uptake is dependent both on the cell type and capping molecules. 


\section{CHAPTER 7}

\section{Summary of papers}

\section{Paper I}

THP-1 cells were co-incubated with $\mathrm{GdCl}_{3}$ and $\mathrm{Gd}_{2} \mathrm{O}_{3}$ nanoparticles synthesized within the polyol route with diethylene glycol as a solvent. The as-synthesized nanoparticles were shown to be crystalline and with a core size of 2-5 $\mathrm{nm}$ by means of transmission electron microscopy. X-ray photoelectron spectroscopy studies supported the oxidation state of the $\mathrm{Gd}_{2} \mathrm{O}_{3}$ material. These studies also verified a reduced organic amount for dialyzed $\mathrm{Gd}_{2} \mathrm{O}_{3}$ nanoparticles as compared to as-synthesized nanoparticles. Uptake of $\mathrm{Gd}_{2} \mathrm{O}_{3}$ nanoparticles by the THP- 1 cells was noticed inducing signal enhancement in the magnetic resonance imaging measurement. The uptake increased with Gd concentration in the approximate range $0.5-2.5 \mathrm{mM} \mathrm{Gd}$. $\mathrm{Gd}_{2} \mathrm{O}_{3}$ nanoparticles were also suspended in cell medium and the relaxivities were monitored. No significant difference in $r_{1}$ was found between particles in cells and cell medium showing $r_{1}$ values of $4.1 \mathrm{~s}^{-1} \mathrm{mM}^{-1}$ and $3.6 \mathrm{~s}^{-1} \mathrm{mM}^{-1}$ respectively. $\mathrm{r}_{2}$ was slightly higher for $\mathrm{Gd}_{2} \mathrm{O}_{3}$ nanoparticles inside cells $(17.4$ $\left.\mathrm{s}^{-1} \mathrm{mM}^{-1}\right)$ as compared to in cell medium $\left(12.9 \mathrm{~s}^{-1} \mathrm{mM}^{-1}\right)$. The $\mathrm{r}_{2} / \mathrm{r}_{1}$ ratios were about 3-4 implying a rather strong $\mathrm{T}_{2}$ effect. No uptake of $\mathrm{GdCl}_{3}$ was observed. The viability of the cells was not significantly affected upon nanoparticle exposure for incubation time 2-192 hours.

\section{Paper II}

Crystalline $\mathrm{Gd}_{2} \mathrm{O}_{3}$ nanoparticles (3-5 nm) were synthesized within the polyol route with diethylene glycol as the solvent. Dialysis of the nanoparticles was followed by functionalization with the bifunctional Mal-PEG-NHS molecule (5000 D) via MPTS surface anchoring. The capped and dialyzed nanoparticles were studied with IR 
spectroscopy and X-ray photoelectron spectroscopy verifying the PEGylation. Vibrational modes associated with the mal group were present in the IR spectra whereas hydrolysis of the NHS group was noticed. A relative intensity decrease in the NHS N 1s peak as compared to the mal $\mathrm{N}$ 1s peak in the XPS spectrum of functionalized nanoparticles further supported the partly deactivation of the terminal NHS group. Extensive dialysis studies were performed on bare $\mathrm{Gd}_{2} \mathrm{O}_{3}$ nanoparticles and PEGylated $\mathrm{Gd}_{2} \mathrm{O}_{3}$ to monitor the ion leakage. These studies showed that bare $\mathrm{Gd}_{2} \mathrm{O}_{3}$ nanoparticles were totally dissolved upon 10 days of dialysis whereas stability was increased in PEGylated nanoparticles. PEGylation was also shown to increase the stability in the presence of $\mathrm{NaCl}(0.1 \mathrm{M})$, as studied by means of DLS. It was furthermore found that the dialysis time has a major impact on the relaxivity of the bare and functionalized nanoparticles. For bare nanoparticles relaxivity decreased with dialysis time whereas the opposite was true for PEGylated nanoparticles with the highest $r_{1}$ of $22.8 \mathrm{~s}^{-1} \mathrm{mM}^{-1}$. A microscopy study of neutrophil granulocytes co-incubated with bare and PEGylated $\mathrm{Gd}_{2} \mathrm{O}_{3}$ nanoparticles was performed showing that the degree of cell activation was more pronounced for bare $\mathrm{Gd}_{2} \mathrm{O}_{3}$ nanoparticles as compared to for PEGylated nanoparticles. The surface capping hence increases the cell compatibility of the nanoparticles. Finally the nanoparticle functionality was studied by the attachment of Rhodamine 123 to the NHS group of the PEG. This was done as a proof of concept showing that the material is prepared for being equipped with targeting molecules.

\section{Paper III}

The aim of this paper was to study how the electron spin relaxation time of crystalline $\mathrm{Gd}_{2} \mathrm{O}_{3}$ nanoparticles (5-7 nm) was affected upon dilution with diamagnetic $\mathrm{Y}_{2} \mathrm{O}_{3}$. This was done by comparing the signal line width for $\operatorname{Gd}_{\mathrm{x}} \mathrm{Y}_{(1-\mathrm{x})} \mathrm{O}_{3} \quad(0 \leq \mathrm{x} \leq 1)$ samples in spectra collected with electron paramagnetic resonance (EPR) spectroscopy. The nanoparticles were synthesized by the combustion method and characterized with X-ray diffraction, X-ray photoelectron spectroscopy, transmission electron microscopy, infrared spectroscopy and thermograviometry coupled with mass spectroscopy. The chemical characterization indicated in an incomplete synthesis reaction with some rare earth atoms being non-incorporated in the lattice and nitrogen and carbon containing species covering the nanoparticle surface. The magnetic behavior was studied by means of a SQUID magnetometer and the samples were shown to follow the Curie-Weiss law perfectly. The EPR line width was observed to decrease non-linearly upon higher amounts of yttrium in the sample, indicating that the electron spin relaxation time of $\mathrm{Gd}_{2} \mathrm{O}_{3}$ nanoparticles is affected upon yttrium dilution. 


\section{Paper IV}

In this paper a new method, previously used for the synthesis of $\mathrm{ZnO}$, was evaluated in the synthesis of crystalline $\mathrm{Gd}_{2} \mathrm{O}_{3}$ nanoparticles (4-5 nm). Among the advantages of using this method are the short reaction time and the room temperature used in the reaction. The nanomaterial was chemically characterized by means of X-ray photoelectron spectroscopy, near-edge X-ray absorption spectroscopy and infrared spectroscopy verifying a stabilizing carbonate- and acetate containing surface coating layer on the particles increasing the nanoparticle water dispersability. Theoretical calculations on different gadolinium acetate complexes within infrared spectroscopy and near-edge X-ray absorption spectroscopy were shown to be helpful in the interpretation of the experimental data. Measurements of the longitudinal and transverse relaxation times for these nanoparticles resulted in relaxivity values of 6.9 and $7.9 \mathrm{mM}^{-1} \mathrm{~s}^{-1}$ respectively.

\section{Paper V}

A dual-modal probe composed of $10 \%$ Eu(III) doped $\mathrm{Gd}_{2} \mathrm{O}_{3}$ nanoparticles capped with hydrophilic glycol-based conjugated carboxylates was produced via the precipitation synthesis route. The molecular capping layer was shown to sensitize the luminescence of the Eu(III) ions in the nanoparticles by functioning as an antennae harvesting energy. Results from transmission electron microscopy and dynamic light scattering verified a nanoparticle core size of about $4 \mathrm{~nm}$ and a hydrodynamic size of $13 \mathrm{~nm}$. X-ray photoelectron spectroscopy studies confirmed the presence of $\mathrm{Eu}$ and $\mathrm{Gd}$ in the nanoparticles and results from thermograviometic analyses indicated in a high ligand grafting density on the nanoparticles. Cell studies were performed with Hela cells and neutrophils to evaluate the potential application of the nanoparticles in vitro. Nanoparticle uptake was confirmed with both cell types and cell viability studies using Hela cells showed a viability of $90 \%$ upon $24 \mathrm{~h}$ of co-incubation with nanoparticles having a gadolinium concentration of $32 \mu \mathrm{M}$. The $r_{1}$ and $r_{2}$ relaxivities were 6.4 and 9.1 $\mathrm{mM}^{-1} \mathrm{~s}^{-1}$ respectively for capped $\mathrm{Gd}_{2} \mathrm{O}_{3}$ and 6.3 and $8.8 \mathrm{mM}^{-1} \mathrm{~s}^{-1}$ respectively for capped $\mathrm{Eu}(\mathrm{III})$ doped $\mathrm{Gd}_{2} \mathrm{O}_{3}$ nanoparticles.

\section{Paper VI}

The aim of the work presented in this paper was to produce a nanoparticle agent comprising both fluorescent and magnetic properties. This was done by synthesizing fluorescent $\mathrm{ZnO}$ nanoparticles which were covered with gadolinium acetate. Characterization by means of X-ray diffraction and transmission electron microscopy verified the hexagonal $\mathrm{ZnO}$ crystal structure and particles with core sizes in the range 4- 
$6 \mathrm{~nm}$. Results from X-ray photoelectron spectroscopy and elemental mapping verified the presence of Gd on the nanoparticle surface. The amount of surface bound Gd was shown to affect the water dispersability, the fluorescent properties and the MRrelaxivity. The fluorescence quantum yield was shown to increase with the gadolinium content in the studied $\mathrm{Gd} / \mathrm{Zn}$ ratio range studied (0.033-0.17). Infrared spectroscopy measurements showed that the relative acetate amount increased upon increased $\mathrm{Gd} / \mathrm{Zn}$ ratios and the specific acetate amount was hence suggested to play a major role for the quantum yield at different $\mathrm{Gd} / \mathrm{Zn}$ ratios. A high acetate amount was also proposed to increase the water dispersability. In terms of relaxivity, the maximum value of $r_{1}\left(19.9 \mathrm{mM}^{-1} \mathrm{~s}^{-1}\right)$ was reached for a Gd/Zn ratio of 0.04 .

\section{Paper VII}

The aim of this paper was to investigate if manganese oxide nanoparticles can be synthesized via the precipitation synthesis route used in Paper IV, V and VI, and also to evaluate the MR properties of the nanoparticle product. Transmission electron microscopy measurements verified that particles (3-4 $\mathrm{nm}$ ) were formed and the electron diffraction pattern indicated in a $\mathrm{MnO}$ crystal structure. X-ray photoelectron spectroscopy and infrared spectroscopy were used to further study the chemical composition of the samples and the Mn oxidation state. The nanoparticle surface was found to be covered with acetate groups and a minor amount of carbonate groups. $\mathrm{Mn}_{2} \mathrm{O}_{3}$ was suggested to co-exist with $\mathrm{MnO}$, especially at the nanoparticle surface, as judged from the Mn 2p XPS spectrum and the Mn-O vibrational mode in the IR spectrum. This statement was also supported by theoretical infrared spectroscopy calculations of the high spin $\mathrm{Mn}_{12} \mathrm{O}_{12}(\mathrm{OAc})_{16}\left(\mathrm{H}_{2} \mathrm{O}\right)_{4}$ nanoparticle. The MR properties of the manganese oxide nanoparticles were studied showing a $\mathrm{r}_{1}$ and $\mathrm{r}_{2}$ of 0.5 and $6 \mathrm{mMs}^{-1}$ respectively. 


\section{CHAPTER 8}

\section{Future perspectives}

This thesis work is all about using three different synthesis routes in the production of metal oxide nanoparticles. Nanoparticle surface modification is performed with organic molecules to increase the stability and biocompatibility of the nanoparticles and a major part of the work has been devoted to characterization of the material. The main application for the nanoparticles is as contrast enhancers in MRI but so far the nanoprobes are unspecific. MRI delivers images of very high resolution but the systemic distribution of today's Gd based contrast agents together with the inherent low sensitivity of the technique, as compared to techniques relying on radionucleides (PET/SPECT) or flourophores, hence make it desirable to increase the specificity of the contrast agents. When the nanoparticles are equipped with targeting properties by attaching molecules or peptide sequences to the capping layer, it is possible to direct them to certain cells or tissues. This is beneficial since it increases the local contrast and reduces the total dose of the agent. Whole antibodies could also be in question for this purpose in some cases but their use is restricted by their large size. Targeting of tumor cells with for example folate would of course be very valuable for early detection and diagnosis of cancer using MRI. Angiogenesis, i.e. the growth of new blood vessels from pre-existing vessels in the blood system, is furthermore a key point in affections such as cancer, inflammation and cardiovascular disease, and the precise monitoring of this would have a great impact on the healthcare. With these ideas, future contrast agents will be focused on Molecular Imaging, i.e. the observing of functional activity in the body by imaging biological processes at the molecular or cellular level.

Future contrast agents for MRI might likely as well be multi-modal, i.e. they will be able to be used in more than one imaging technique. When for example combining PET or SPECT with MRI it is possible to make use of the high anatomical resolution of the MRI 
and the high sensitivity when using radioactive nuclides. In a wider perspective, site directed nanoparticle probes which are sensitive to changes in the ambient conditions are also studied extensively. These probes are developed to map changes in parameters such as $\mathrm{pH}$ or temperature or to facilitate local contrast enhancement or even local medical treatment.

Targeting probes are today developed and studied in chemical, physical and medical perspective. The research includes synthesis, surface modification and characterization of the particles as well as investigations of their interaction with cells. In addition, the toxicity, biodistribution and excretion of metal oxide nanoparticles in animal in vivo studies are part of the evaluation of nanoparticle based probes. The research field is really multidisciplinary, and the design of promising targeting nanoparticles to be used for site directed medical imaging and/or treatment puts high demands on the research and fruitful collaborations in between different research fields are necessary. Regardless of project, the use of nanoparticles in biological systems, and in particular in humans, must be safe and well controlled. Development time will therefore be long and a lot of research is still to be done in purpose to produce an efficient Gd based nanoparticle contrast agent for human use. 


\section{References}

1. Caravan, P., Strategies for increasing the sensitivity of gadolinium based MRI contrast agents. Chemical Society Reviews 2006, 35 (6), 512-523.

2. Smart, L. E.; Moore, E. A., Solid State Chemistry: An Introduction. CRC Press Taylor \&Francis Group: United States, 2012.

3. Abrahams, E.; Keffer, F., Magnetism. In Solid-State Physics Source Book, Parker, S. P., Ed. McGrawHill Inc.: USA, 1988.

4. (a) Graham Jr., C. D., Magnetic Behavior of Gadolinium Near the Curie Point. Journal of Applied Physics 1965, 36 (3), 1135-1136; (b) Wolfson, R.; Pasachoff, J. M., Physics : with modern physics for scientists and engineers 2ed.; HarperCollins Collage Publishers: NY, USA, 1995.

5. Hughes, I. D.; Dane, M.; Ernst, A.; Hergert, W.; Luders, M.; Poulter, J.; Staunton, J. B.; Svane, A.; Szotek, Z.; Temmerman, W. M., Lanthanide contraction and magnetism in the heavy rare earth elements. Nature 2007, 446 (7136), 650-653.

6. Feynman, R., There's Plenty of Room at the Bottom: An Invitation to Enter a New Field of Physics. Engineering and Science 1960, 23, 22-26.

7. Taniguchi, N., On the Basic Concept of "Nano-Technology". Bulletin of the Japan Society of Precision Engineering 1974, 18-23.

8. Nanoscience and Nanotechnologies:opportunities and uncertainities; London, 2004.

9. Ramachandra Rao, C. N.; Kulkarni, G. U.; Thomas, P. J.; Edwards, P. P., Metal nanoparticles and their assemblies. Chemical Society Reviews 2000, 29 (1), 27-35.

10. Lin, K.-F.; Cheng, H.-M.; Hsu, H.-C.; Lin, L.-J.; Hsieh, W.-F., Band gap variation of size-controlled ZnO quantum dots synthesized by sol-gel method. Chemical Physics Letters 2005, 409 (4-6), 208211.

11. The Lanthanide Elements. In Chemistry of the Elements, 2nd ed.; Greenwood, N. N.; Earnshaw, A., Eds. Reed Educational and Professional Publishing Ltd: Oxford, 1997.

12. Caravan, P.; Ellison, J. J.; McMurry, T. J.; Lauffer, R. B., Gadolinium(III) Chelates as MRI Contrast Agents: Structure, Dynamics, and Applications. Chem. Rev. 1999, 99 (9), 2293-2352.

13. (a) Sharma, P.; Brown, S. C.; Walter, G.; Santra, S.; Scott, E.; Ichikawa, H.; Fukumori, Y.; Moudgil, B. M., Gd nanoparticulates: from magnetic resonance imaging to neutron capture therapy. Advanced Powder Technology 2007, 18 (6), 663-698; (b) Bridot, J.-L.; Dayde, D.; Riviere, C.; Mandon, C.; Billotey, C.; Lerondel, S.; Sabattier, R.; Cartron, G.; Le Pape, A.; Blondiaux, G.; Janier, M.; Perriat, P.; Roux, S.; Tillement, O., Hybrid gadolinium oxide nanoparticles combining imaging and therapy. Journal of Materials Chemistry 2009, 19 (16), 2328-2335.

14. Carnall, W. T.; Fields, P. R.; Rajnak, K., Electronic Energy Levels of the Trivalent Lanthanide Aquo Ions. IV. Eu ${ }^{3+}$. The Journal of Chemical Physics 1968, 49 (10), 4450-4455.

15. Dieke, G. H.; Crosswhite, H. M.; Crosswhite, H., Spectra and energy levels of rare earth ions in crystals. Interscience Publishers: 1968. 
16. Gallagher, P. K., Absorption and Fluorescence of Europium(III) in Aqueous Solutions. The Journal of Chemical Physics 1964, 41 (10), 3061-3069.

17. Gnanasammandhan, M. K.; Zhang, Y., Rare Earth Nanomaterials in Fluorescence Microscopy. In Rare Earth Nanotechnology, Tan, T. T. Y., Ed. Pan Stanford Publishing Pte. Ltd.: Singapore, 2012; pp 83-106.

18. Beatty, R., The Lanthanides. Marshall Cavendish Corporation: New York, USA, 2007.

19. Shannon, R., Revised effective ionic radii and systematic studies of interatomic distances in halides and chalcogenides. Acta Crystallographica Section A 1976, 32 (5), 751-767.

20. Janotti, A.; Walle, C. G. V. d., Fundamentals of zinc oxide as a semiconductor. Reports on Progress in Physics 2009, 72 (12), 126501.

21. Fosmire, G. J., Zinc toxicity. Am J Clin Nutr 1990, 51 (2), 225-7.

22. Saiki, A.; Ishizawa, N.; Mizutani, N.; Kato, M., Structural change of C-type rare earth oxides, ytterbium oxide and erbium oxide at high temperatures. Journal of the Ceramic Association of Japan $1985,93,649-654$.

23. Roux, S.; Bazzi, R.; Rivière, C.; Lux, F.; Perriat, P.; Tillement, O., Rare Earth Nanomaterials in Magnetic Resonance Imaging. In Rare Earth Nanotechnology, Tan, T. T. Y., Ed. Pan Stanford Publishing: Singapore, 2012; pp 107-160.

24. (a) Djerdj, I.; Arčon, D.; Jagličić, Z.; Niederberger, M., Nonaqueous Synthesis of Manganese Oxide Nanoparticles, Structural Characterization, and Magnetic Properties. The Journal of Physical Chemistry C 2007, 111 (9), 3614-3623; (b) Park, J.; Kang, E.; Bae, C. J.; Park, J.-G.; Noh, H.-J.; Kim, J.Y.; Park, J.-H.; Park, H. M.; Hyeon, T., Synthesis, Characterization, and Magnetic Properties of Uniform-sized MnO Nanospheres and Nanorods. The Journal of Physical Chemistry B 2004, 108 (36), 13594-13598.

25. Paton, M. G.; Maslen, E. N., A refinement of the crystal structure of yttria. Acta Crystallographica 1965, 19 (3), 307-310.

26. van Dijken, A.; Meulenkamp, E. A.; Vanmaekelbergh, D.; Meijerink, A., The Kinetics of the Radiative and Nonradiative Processes in Nanocrystalline $\mathrm{ZnO}$ Particles upon Photoexcitation. The Journal of Physical Chemistry B 2000, 104 (8), 1715-1723.

27. Vanheusden, K.; Warren, W. L.; Seager, C. H.; Tallant, D. R.; Voigt, J. A.; Gnade, B. E., Mechanisms behind green photoluminescence in ZnO phosphor powders. Journal of Applied Physics 1996, 79 (10), 7983-7990.

28. (a) Dosev, D.; Nichkova, M.; Liu, M.; Guo, B.; Liu, G. Y.; Hammock, B. D.; Kennedy, I. M., Application of luminescent Eu: $\mathrm{Gd}_{2} \mathrm{O}_{3}$ nanoparticles to the visualization of protein micropatterns. $J$ Biomed Opt 2005, 10 (6), 064006; (b) Nichkova, M.; Dosev, D.; Perron, R.; Gee, S.; Hammock, B.; Kennedy, I., Eu3+-doped $\mathrm{Gd}_{2} \mathrm{O}_{3}$ nanoparticles as reporters for optical detection and visualization of antibodies patterned by microcontact printing. Anal Bioanal Chem 2006, 384 (3), 631-637; (c) Goldys, E. M.; Drozdowicz-Tomsia, K.; Jinjun, S.; Dosev, D.; Kennedy, I. M.; Yatsunenko, S.; Godlewski, M., Optical Characterization of Eu-Doped and Undoped $\mathrm{Gd}_{2} \mathrm{O}_{3}$ Nanoparticles Synthesized by the Hydrogen Flame Pyrolysis Method. Journal of the American Chemical Society 2006, 128 (45), 1449814505.

29. Glomm, W. R.; Volden, S.; Sjöblom, J.; Lindgren, M., Photophysical Properties of Ruthenium(II) Tris(2,2'-Bipyridine) and Europium(III) Hexahydrate Salts Assembled into Sol-Gel Materials. Chemistry of Materials 2005, 17 (22), 5512-5520. 
30. Weishaupt, D.; Köchli, V. D.; Marincek, B., How does MRI work? . 2 ed.; Springer-Verlag: Leipzig, 2006.

31. Atkins, P.; De Paula, J., Atkins'Physical Chemistry. 8 ed.; Oxford University Press: Oxford, 2006.

32. Hornak, J. P., The Basics of MRI. Interactive Learning Software, Henietta, NY: 1996-2011.

33. Lauffer, R. B., Paramagnetic Metal Complexes as Water Proton Relaxation Agents for NMR Imaging: Theory and Design. Chemical Reviews 1987, 87 (5), 901-927.

34. Hsiao, J.-K.; Tsai, C.-P.; Chung, T.-H.; Hung, Y.; Yao, M.; Liu, H.-M.; Mou, C.-Y.; Yang, C.-S.; Chen, Y.-C.; Huang, D.-M., Mesoporous Silica Nanoparticles as a Delivery System of Gadolinium for Effective Human Stem Cell Tracking. Small 2008, 4 (9), 1445-1452.

35. Jin, T.; Yoshioka, Y.; Fujii, F.; Komai, Y.; Seki, J.; Seiyama, A., Gd ${ }^{3+}$-functionalized near-infrared quantum dots for in vivo dual modal (fluorescence/magnetic resonance) imaging. Chemical Communications 2008, 0 (44), 5764-5766.

36. Debouttière, P. J.; Roux, S.; Vocanson, F.; Billotey, C.; Beuf, O.; Favre-Réguillon, A.; Lin, Y.; PelletRostaing, S.; Lamartine, R.; Perriat, P.; Tillement, O., Design of Gold Nanoparticles for Magnetic Resonance Imaging. Advanced Functional Materials 2006, 16 (18), 2330-2339.

37. Hatakeyama, W.; Sanchez, T. J.; Rowe, M. D.; Serkova, N. J.; Liberatore, M. W.; Boyes, S. G., Synthesis of Gadolinium Nanoscale Metal-Organic Framework with Hydrotropes: Manipulation of Particle Size and Magnetic Resonance Imaging Capability. ACS Applied Materials \& Interfaces 2011, 3 (5), 1502-1510.

38. Zhang, G.; Zhang, R.; Wen, X.; Li, L.; Li, C., Micelles Based on Biodegradable Poly(l-glutamic acid)b-Polylactide with Paramagnetic Gd lons Chelated to the Shell Layer as a Potential Nanoscale MRI-Visible Delivery System. Biomacromolecules 2007, 9 (1), 36-42.

39. Kobayashi, H.; Brechbiel, M. W., Nano-sized MRI contrast agents with dendrimer cores. Advanced Drug Delivery Reviews 2005, 57 (15), 2271-2286.

40. Evanics, F.; Diamente, P. R.; van Veggel, F. C. J. M.; Stanisz, G. J.; Prosser, R. S., Water-Soluble $\mathrm{GdF}_{3}$ and $\mathrm{GdF}_{3} / \mathrm{LaF}_{3}$ NanoparticlesPhysical Characterization and NMR Relaxation Properties. Chemistry of Materials 2006, 18 (10), 2499-2505.

41. (a) Hifumi, H.; Yamaoka, S.; Tanimoto, A.; Citterio, D.; Suzuki, K., Gadolinium-Based Hybrid Nanoparticles as a Positive MR Contrast Agent. Journal of the American Chemical Society 2006, 128 (47), 15090-15091; (b) Dumont, M. F.; Baligand, C.; Li, Y.; Knowles, E. S.; Meisel, M. W.; Walter, G. A.; Talham, D. R., DNA Surface Modified Gadolinium Phosphate Nanoparticles as MRI Contrast Agents. Bioconjugate Chemistry 2012, 23 (5), 951-957.

42. Li, I. F.; Su, C.-H.; Sheu, H.-S.; Chiu, H.-C.; Lo, Y.-W.; Lin, W.-T.; Chen, J.-H.; Yeh, C.-S., $\mathrm{Gd}_{2} \mathrm{O}\left(\mathrm{CO}_{3}\right)_{2} \cdot \mathrm{H}_{2} \mathrm{O}$ Particles and the Corresponding $\mathrm{Gd}_{2} \mathrm{O}_{3}$ : Synthesis and Applications of Magnetic Resonance Contrast Agents and Template Particles for Hollow Spheres and Hybrid Composites. Advanced Functional Materials 2008, 18 (5), 766-776.

43. Hou, Y.; Qiao, R.; Fang, F.; Wang, X.; Dong, C.; Liu, K.; Liu, C.; Liu, Z.; Lei, H.; Wang, F.; Gao, M., $\mathrm{NaGdF}_{4}$ Nanoparticle-Based Molecular Probes for Magnetic Resonance Imaging of Intraperitoneal Tumor Xenografts in Vivo. ACS Nano 2012, 7 (1), 330-338.

44. Skotland, T.; Iversen, T.-G.; Sandvig, K., New metal-based nanoparticles for intravenous use: requirements for clinical success with focus on medical imaging. Nanomedicine: Nanotechnology, Biology and Medicine 2010, 6 (6), 730-737. 
45. (a) Bridot, J.-L.; Faure, A.-C.; Laurent, S.; Rivière, C.; Billotey, C.; Hiba, B.; Janier, M.; Josserand, V.; Coll, J.-L.; Vander Elst, L.; Muller, R.; Roux, S.; Perriat, P.; Tillement, O., Hybrid Gadolinium Oxide Nanoparticles: Multimodal Contrast Agents for in Vivo Imaging. Journal of the American Chemical Society 2007, 129 (16), 5076-5084; (b) Ahrén, M.; Selegård, L. a.; Klasson, A.; Söderlind, F.; Abrikossova, N.; Skoglund, C.; Bengtsson, T. r.; Engström, M.; Käll, P.-O.; Uvdal, K., Synthesis and Characterization of PEGylated $\mathrm{Gd}_{2} \mathrm{O}_{3}$ Nanoparticles for MRI Contrast Enhancement. Langmuir 2010, 26 (8), 5753-5762; (c) Azizian, G.; Riyahi-Alam, N.; Haghgoo, S.; Moghimi, H.; Zohdiaghdam, R.; Rafiei, B.; Gorji, E., Synthesis route and three different core-shell impacts on magnetic characterization of gadolinium oxide-based nanoparticles as new contrast agents for molecular magnetic resonance imaging. Nanoscale Res Lett 2012, 7 (1), 549.

46. (a) Park, J. Y.; Choi, E. S.; Baek, M. J.; Lee, G. H.; Woo, S.; Chang, Y., Water-Soluble Ultra Small Paramagnetic or Superparamagnetic Metal Oxide Nanoparticles for Molecular MR Imaging. European Journal of Inorganic Chemistry 2009, 2009 (17), 2477-2481; (b) Söderlind, F.; Pedersen, H.; Petoral Jr, R. M.; Käll, P.-O.; Uvdal, K., Synthesis and characterisation of $\mathrm{Gd}_{2} \mathrm{O}_{3}$ nanocrystals functionalised by organic acids. Journal of Colloid and Interface Science 2005, 288 (1), 140-148.

47. Louis, C.; Bazzi, R.; Marquette, C. A.; Bridot, J.-L.; Roux, S.; Ledoux, G.; Mercier, B.; Blum, L.; Perriat, P.; Tillement, O., Nanosized Hybrid Particles with Double Luminescence for Biological Labeling. Chemistry of Materials 2005, 17 (7), 1673-1682.

48. Yan, C.-H.; Zhang, C.; Sun, L.-D., Synthesis of Rare Earth Nanomaterials. In Rare Earth Nanotechnology, Tan, T. T. Y., Ed. Pan Stanford Publishing Pte. Ltd.: Singapore, 2012; pp 1-42.

49. Fievet, F.; Lagier, J. P.; Blin, B.; Beaudoin, B.; Figlarz, M., Homogeneous and heterogeneous nucleations in the polyol process for the preparation of micron and submicron size metal particles. Solid State lonics 1989, 32-33, Part 1 (0), 198-205.

50. Bazzi, R.; Flores-Gonzalez, M. A.; Louis, C.; Lebbou, K.; Dujardin, C.; Brenier, A.; Zhang, W.; Tillement, O.; Bernstein, E.; Perriat, P., Synthesis and luminescent properties of sub-5-nm lanthanide oxides nanoparticles. Journal of Luminescence 2003, 102-103 (0), 445-450.

51. Zhou, Z.; Wang, L.; Chi, X.; Bao, J.; Yang, L.; Zhao, W.; Chen, Z.; Wang, X.; Chen, X.; Gao, J., Engineered Iron-Oxide-Based Nanoparticles as Enhanced T1 Contrast Agents for Efficient Tumor Imaging. ACS Nano 2013.

52. Abrikossova, N.; Skoglund, C.; Ahrén, M.; Bengtsson, T.; Uvdal, K., Effects of gadolinium oxide nanoparticles on the oxidative burst from human neutrophil granulocytes. Nanotechnology 2012, 23 (27), 275101.

53. Zhang, W.-W.; Zhang, W.-P.; Xie, P.-B.; Yin, M.; Chen, H.-T.; Jing, L.; Zhang, Y.-S.; Lou, L.-R.; Xia, S.D., Optical properties of nanocrystalline Y2O3:Eu depending on its odd structure. Journal of Colloid and Interface Science 2003, 262 (2), 588-593.

54. (a) Rakshit, S.; Vasudevan, S., Trap-State Dynamics in Visible-Light-Emitting ZnO:MgO Nanocrystals. The Journal of Physical Chemistry C 2008, 112 (12), 4531-4537; (b) Schwartz, D. A.; Norberg, N. S.; Nguyen, Q. P.; Parker, J. M.; Gamelin, D. R., Magnetic Quantum Dots: Synthesis, Spectroscopy, and Magnetism of $\mathrm{Co}^{2+}$ - and $\mathrm{Ni}^{2+}$-Doped $\mathrm{ZnO}$ Nanocrystals. Journal of the American Chemical Society 2003, 125 (43), 13205-13218.

55. Ballem, M. A.; Söderlind, F.; Nordblad, P.; Käll, P.-O.; Odén, M., Growth of $\mathrm{Gd}_{2} \mathrm{O}_{3}$ nanoparticles inside mesoporous silica frameworks. Microporous and Mesoporous Materials 2013, 168 (0), 221224. 
56. Panda, A. B.; Glaspell, G.; El-Shall, M. S., Microwave Synthesis and Optical Properties of Uniform Nanorods and Nanoplates of Rare Earth Oxides. The Journal of Physical Chemistry C 2007, 111 (5), 1861-1864.

57. Batterman, B. W., X-ray Diffraction. In digital Encyclopedia of Applied Physics, WILEY-VCH Verlag GmbH \& Co KGaA: 2003.

58. Weller, M. T., Inorganic Materials Chemistry. Oxford University Press Inc: New York, United States, 1994.

59. Williams, D. B.; Barry, C. C., Transmission Electron Microscopy. Springer Science + Business Media, Inc.: New York, 1996.

60. Zou, X.; Hovmöller, S.; Oleynikov, P., Electron Crystallography: Electron Microscopy and Electron Diffraction. Oxford University Press Inc.: New York, 2011.

61. (a) Ross Hallett, F., Particle size analysis by dynamic light scattering. Food Research International 1994, 27 (2), 195-198; (b) Finsy, R., Particle sizing by quasi-elastic light scattering. Advances in Colloid and Interface Science 1994, 52 (0), 79-143.

62. Moosmüller, H.; Arnott, W. P., Particle Optics in the Rayleigh Regime. Journal of the Air \& Waste Management Association 2009, 59 (9), 1028-1031.

63. Alban, J. R., Principles and Applications of Fluorescence Spectroscopy. Blackwell Science: United Kingdom, 2007.

64. Kubin, R. F.; Fletcher, A. N., Fluorescence quantum yields of some rhodamine dyes. Journal of Luminescence 1982, 27 (4), 455-462.

65. Jang, J.; Weber, R. T. ELEXSYS E 500 user's manual; Bruker Instruments, Inc: USA, 2000.

66. (a) Zhang, L.; He, R.; Gu, H.-C., Oleic acid coating on the monodisperse magnetite nanoparticles. Applied Surface Science 2006, 253 (5), 2611-2617; (b) Mahajan, S. V.; Dickerson, J. H., Synthesis of monodisperse sub-3 nm RE $2 \mathrm{O}_{3}$ and $\mathrm{Gd}_{2} \mathrm{O}_{3}: \mathrm{RE}^{3+}$ nanocrystals. Nanotechnology 2007, 18 (32), 325605.

67. Anishur Rahman, A. T. M.; Vasilev, K.; Majewski, P., Ultra small $\mathrm{Gd}_{2} \mathrm{O}_{3}$ nanoparticles: Absorption and emission properties. Journal of Colloid and Interface Science 2011, 354 (2), 592-596.

68. Sperling, R. A.; Parak, W. J., Surface modification, functionalization and bioconjugation of colloidal inorganic nanoparticles. Philosophical Transactions A: Mathematical, Physical and Engineering Sciences 2010, 368, 1333-1383.

69. (a) Lattuada, M.; Hatton, T. A., Functionalization of Monodisperse Magnetic Nanoparticles. Langmuir 2006, 23 (4), 2158-2168; (b) Wu, W.; He, Q.; Jiang, C., Magnetic Iron Oxide Nanoparticles: Synthesis and Surface Functionalization Strategies. Nanoscale Res Lett 2008, 3 (11), 397-415.

70. Neouze, M.-A.; Schubert, U., Surface Modification and Functionalization of Metal and Metal Oxide Nanoparticles by Organic Ligands. Monatsh Chem 2008, 139 (3), 183-195.

71. Quinton, J. S.; Dastoor, P. C., Characterizing the bonding mechanisms at silane-metal interfaces: A model system. Journal of Materials Science Letters 1999, 18 (22), 1833-1835.

72. Yamaura, M.; Camilo, R. L.; Sampaio, L. C.; Macêdo, M. A.; Nakamura, M.; Toma, H. E., Preparation and characterization of (3-aminopropyl)triethoxysilane-coated magnetite nanoparticles. Journal of Magnetism and Magnetic Materials 2004, 279 (2-3), 210-217. 
73. Fortin, M.-A.; Jr, R. M. P.; Söderlind, F.; Klasson, A.; Engström, M.; Veres, T.; Käll, P.-O.; Uvdal, K., Polyethylene glycol-covered ultra-small $\mathrm{Gd}_{2} \mathrm{O}_{3}$ nanoparticles for positive contrast at $1.5 \mathrm{~T}$ magnetic resonance clinical scanning. Nanotechnology 2007, 18 (39), 395501.

74. Faucher, L.; Tremblay, M.; Lagueux, J.; Gossuin, Y.; Fortin, M.-A., Rapid Synthesis of PEGylated Ultrasmall Gadolinium Oxide Nanoparticles for Cell Labeling and Tracking with MRI. ACS Applied Materials \& Interfaces 2012, 4 (9), 4506-4515.

75. (a) Qi, L.; Sehgal, A.; Castaing, J.-C.; Chapel, J.-P.; Fresnais, J. r. m.; Berret, J.-F. o.; Cousin, F., Redispersible Hybrid Nanopowders: Cerium Oxide Nanoparticle Complexes with Phosphonated-PEG Oligomers. ACS Nano 2008, 2 (5), 879-888; (b) Traina, C. A.; Schwartz, J., Surface Modification of $\mathrm{Y}_{2} \mathrm{O}_{3}$ Nanoparticles. Langmuir 2007, 23 (18), 9158-9161; (c) Cinausero, N.; Azema, N.; Cochez, M.; Ferriol, M.; Essahli, M.; Ganachaud, F.; Lopez-Cuesta, J.-M., Influence of the surface modification of alumina nanoparticles on the thermal stability and fire reaction of PMMA composites. Polymers for Advanced Technologies 2008, 19 (6), 701-709; (d) Feichtenschlager, B.; Lomoschitz, C. J.; Kickelbick, G., Tuning the self-assembled monolayer formation on nanoparticle surfaces with different curvatures: Investigations on spherical silica particles and plane-crystal-shaped zirconia particles. Journal of Colloid and Interface Science 2011, 360 (1), 15-25.

76. Das, M.; Mishra, D.; Dhak, P.; Gupta, S.; Maiti, T. K.; Basak, A.; Pramanik, P., Biofunctionalized, Phosphonate-Grafted, Ultrasmall Iron Oxide Nanoparticles for Combined Targeted Cancer Therapy and Multimodal Imaging. Small 2009, 5 (24), 2883-2893.

77. Rehor, I.; Kubicek, V.; Kotek, J.; Hermann, P.; Lukes, I.; Szakova, J.; Vander Elst, L.; Muller, R. N.; Peters, J. A., ${ }^{1} \mathrm{H}$ NMR relaxivity of aqueous suspensions of titanium dioxide nanoparticles coated with a gadolinium(III) chelate of a DOTA-monoamide with a phenylphosphonate pendant arm. Journal of Materials Chemistry 2009, 19 (10), 1494-1500.

78. Cao, P.; Tong, L.; Hou, Y.; Zhao, G.; Guerin, G.; Winnik, M. A.; Nitz, M., Improving Lanthanide Nanocrystal Colloidal Stability in Competitive Aqueous Buffer Solutions using Multivalent PEGPhosphonate Ligands. Langmuir 2012, 28 (43), 15425-15425.

79. Guay-Bégin, A.-A.; Chevallier, P.; Faucher, L.; Turgeon, S.; Fortin, M.-A., Surface Modification of Gadolinium Oxide Thin Films and Nanoparticles using Poly(ethylene glycol)-Phosphate. Langmuir 2011, 28 (1), 774-782.

80. Hemmer, E.; Venkatachalam, N.; Hyodo, H.; Soga, K., The Role of pH in PEG-b-PAAc Modification of Gadolinium Oxide Nanostructures for Biomedical Applications. Advances in Materials Science and Engineering 2012, 2012, 15.

81. Basly, B.; Felder-Flesch, D.; Perriat, P.; Billotey, C.; Taleb, J.; Pourroy, G.; Begin-Colin, S., Dendronized iron oxide nanoparticles as contrast agents for MRI. Chemical Communications 2010, 46 (6), 985-987.

82. Fischer, M. E., Amine Coupling Through EDC/NHS: A Practical Approach. In Surface Plasmon Resonance, Mol, N. J.; Fischer, M. J. E., Eds. Humana Press: 2010; Vol. 627, pp 55-73.

83. Günzler, H.; Gremlich, H.-U., IR Spectroscopy. Wiley-VCH Verlag GmbH: Weinheim, Germany, 2002.

84. Nakamoto, K., Infrared and Raman Spectra of Inorganic and Coordination Compounds. 5th ed.; John Wiley Sonc, Inc.: United States, 1997; Vol. Part B.

85. Attard, G.; Barnes, C., Surfaces. Oxford University Press: Oxford, United States, 1998. 
86. Watts, J. F.; J, W., An Introduction to Surface Analysis by XPS and AES. John Wiley \&Sons Ltd: Chichester, England, 2003.

87. Seah, M. P., Quantification and measurement by Auger electron spectroscopy and X-ray photoelectron spectroscopy. Vacuum 1986, 36 (7-9), 399-407.

88. Stöhr, J., NEXAFS Spectroscopy. Springer: 1996.

89. Winick, H., Synchrotron Radiation sources: a primer. World Scientific Publishing Co Pte Ltd: Singapore, 1994.

90. Winick, H., Properties of Synchrotron Radiation. In Synchrotron Radiation Research, Winick, H.; Doniach, S., Eds. Springer US: 1980; pp 11-25.

91. Kraynov, A.; Muller, T. E., Concepts for the Stabilization of Metal Nanoparticles in lonic Liquids. In Applications of Ionic Liquids in Science and Technology, Handy, S., Ed. InTech Europe: Croatia, 2011.

92. Pachón, L. D.; Rothenberg, G., Transition-metal nanoparticles: synthesis, stability and the leaching issue. Applied Organometallic Chemistry 2008, 22 (6), 288-299.

93. Web site technical note : Zeta Potential An Introduction in 30 Minutes. Malvern Instruments: www.malvern.com, 2013.

94. Segets, D.; Marczak, R.; Schafer, S.; Paula, C.; Gnichwitz, J. F.; Hirsch, A.; Peukert, W., Experimental and theoretical studies of the colloidal stability of nanoparticles-a general interpretation based on stability maps. ACS Nano 2011, 5 (6), 4658-69.

95. Shi, Z.; Neoh, K. G.; Kang, E. T.; Shuter, B.; Wang, S.-C., Bifunctional Eu ${ }^{3+}$-doped $\mathrm{Gd}_{2} \mathrm{O}_{3}$ nanoparticles as a luminescent and T1 contrast agent for stem cell labeling. Contrast Media \& Molecular Imaging 2010, 5 (2), 105-111.

96. Jordan, A.; Scholz, R.; Wust, P.; Schirra, H.; Thomas, S.; Schmidt, H.; Felix, R., Endocytosis of dextran and silan-coated magnetite nanoparticles and the effect of intracellular hyperthermia on human mammary carcinoma cells in vitro. Journal of Magnetism and Magnetic Materials 1999, 194 (1-3), 185-196.

97. McDonald, M. A.; Watkin, K. L., Investigations into the Physicochemical Properties of Dextran Small Particulate Gadolinium Oxide Nanoparticles. Academic Radiology 2006, 13 (4), 421-427.

98. Hemmer, E.; Yamano, T.; Kishimoto, H.; Venkatachalam, N.; Hyodo, H.; Soga, K., Cytotoxic aspects of gadolinium oxide nanostructures for up-conversion and NIR bioimaging. Acta Biomaterialia 2013, 9 (1), 4734-4743.

99. Karakoti, A. S.; Das, S.; Thevuthasan, S.; Seal, S., PEGylated Inorganic Nanoparticles. Angewandte Chemie International Edition 2011, 50 (9), 1980-1994.

100. Jokerst, J. V.; Lobovkina, T.; Zare, R. N.; Gambhir, S. S., Nanoparticle PEGylation for imaging and therapy. Nanomedicine 2011, 6 (4), 715-28.

101. Ratner, B. D.; Hoffman, A. S., Nonfouling Surfaces. In Biomaterials Science: An Introduction to Materials in Medicine, 3rd ed.; Ratner, B. D.; Hoffamn, A. S.; Schoen, F. J.; Lemons, J., Eds. Elsevier: Oxford, UK, 2013; pp 241-247. 
102. Gillich, T.; Acikgöz, C.; Isa, L.; Schlüter, A. D.; Spencer, N. D.; Textor, M., PEG-Stabilized CoreShell Nanoparticles: Impact of Linear versus Dendritic Polymer Shell Architecture on Colloidal Properties and the Reversibility of Temperature-Induced Aggregation. ACS Nano 2012, 7 (1), 316-329.

103. Faure, A. C.; Dufort, S.; Josserand, V.; Perriat, P.; Coll, J. L.; Roux, S.; Tillement, O., Control of the in vivo biodistribution of hybrid nanoparticles with different poly(ethylene glycol) coatings. Small 2009, 5 (22), 2565-75.

104. Alexis, F.; Pridgen, E.; Molnar, L. K.; Farokhzad, O. C., Factors Affecting the Clearance and Biodistribution of Polymeric Nanoparticles. Molecular Pharmaceutics 2008, 5 (4), 505-515.

105. Hedlund, A.; Ahrén, M.; Gustafsson, H.; Abrikossova, N.; Warntjes, M.; Jönsson, J. I.; Uvdal, K.; Engström, M., $\mathrm{Gd}_{2} \mathrm{O}_{3}$ nanoparticles in hematopoietic cells for MRI contrast enhancement. International Journal of Nanomedicine 2011, 6, 3233-3240.

106. Petoral, R. M.; Söderlind, F.; Klasson, A.; Suska, A.; Fortin, M. A.; Abrikossova, N.; Selegård, L. a.; Käll, P.-O.; Engström, M.; Uvdal, K., Synthesis and Characterization of $\mathrm{Tb}^{3+}$-Doped $\mathrm{Gd}_{2} \mathrm{O}_{3}$ Nanocrystals: A Bifunctional Material with Combined Fluorescent Labeling and MRI Contrast Agent Properties. The Journal of Physical Chemistry C 2009, 113 (17), 6913-6920. 